\title{
Parathyroid hormone signaling in mature osteoblasts/osteocytes protects mice from age-related bone loss
}

\author{
Yuhei Uda ${ }^{1,}{ }^{*}$, Vaibhav Saini ${ }^{2,}{ }^{*}$, Christopher A. Petty ${ }^{1}$, Majed Alshehri ${ }^{1}$, Chao Shi ${ }^{1,3}$, Jordan M. \\ Spatz $^{2,4}$, Roberto Santos ${ }^{1}$, Carly M. Newell ${ }^{1}$, Tim Y. Huang ${ }^{1}$, Alejandro Kochen ${ }^{1}$, Ji W. Kim ${ }^{1}$, \\ Christodoulos K. Constantinou ${ }^{1}$, Hiroaki Saito ${ }^{5}$, Kathryn D. Held ${ }^{6}$, Eric Hesse ${ }^{5}$, Paola Divieti \\ Pajevic $^{1,2}$
}

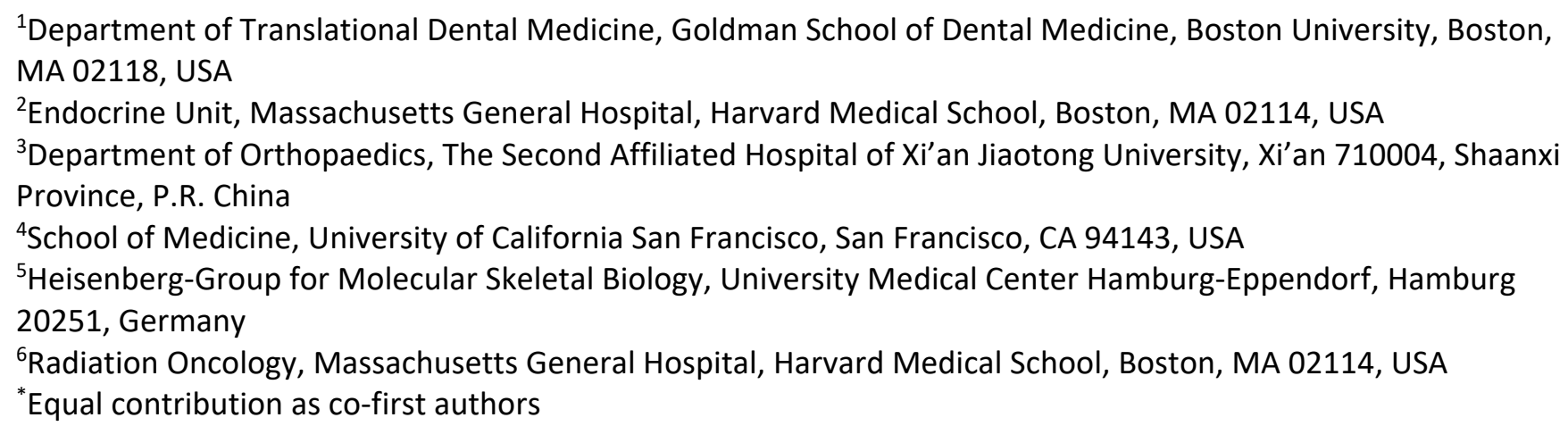

Correspondence to: Paola Divieti Pajevic; email: pdivieti@bu.edu

Keywords: osteocyte, oxidative stress, aging, osteoporosis, parathyroid hormone

Received: September 20, 2021 Accepted: November 30, $2021 \quad$ Published: December 30, 2021

Copyright: (C) 2021 Uda et al. This is an open access article distributed under the terms of the Creative Commons Attribution License (CC BY 3.0), which permits unrestricted use, distribution, and reproduction in any medium, provided the original author and source are credited.

\section{ABSTRACT}

Aging is accompanied by osteopenia, characterized by reduced bone formation and increased bone resorption. Osteocytes, the terminally differentiated osteoblasts, are regulators of bone homeostasis, and parathyroid hormone (PTH) receptor (PPR) signaling in mature osteoblasts/osteocytes is essential for PTH-driven anabolic and catabolic skeletal responses. However, the role of PPR signaling in those cells during aging has not been investigated. The aim of this study was to analyze the role of PTH signaling in mature osteoblasts/osteocytes during aging. Mice lacking PPR in osteocyte $\left(\mathrm{Dmp1}-\mathrm{PPR}^{\mathrm{KO}}\right)$ display an age-dependent osteopenia characterized by a significant decrease in osteoblast activity and increase in osteoclast number and activity. At the molecular level, the absence of PPR signaling in mature osteoblasts/osteocytes is associated with an increase in serum sclerostin and a significant increase in osteocytes expressing 4-hydroxy-2-nonenals, a marker of oxidative stress. In Dmp1-PPR ${ }^{\mathrm{KO}}$ mice there was an age-dependent increase in $\mathrm{p}^{16^{\operatorname{lnk4a}} / C d k n 2 a}$ expression, whereas it was unchanged in controls. In vitro studies demonstrated that PTH protects osteocytes from oxidative stressinduced cell death. In summary, we reported that PPR signaling in osteocytes is important for protecting the skeleton from age-induced bone loss by restraining osteoclast's activity and protecting osteocytes from oxidative stresses.

\section{INTRODUCTION}

Osteoporosis affects an estimated 200 million people worldwide and it becomes increasingly prevalent in the aging population $[1,2]$. It is well established that the first 34 amino acids of PTH and PTH-related peptide (PTHrP) are necessary and sufficient to fully activate the PTH/PTHrP receptor (PPR) and both PTH 
(teriparatide) and PTHrP (Abaloparatide) are approved anabolic agents to treat osteoporosis. PPR is coupled to G-proteins capable of activating multiple pathways, including those signaling through cyclic adenosine monophosphate (cAMP)/protein kinase A (PKA), phospholipase $\mathrm{C}$ (PLC)/protein kinase $\mathrm{C}$ (PKC), and non-PLC-dependent $\mathrm{PKC}$ and $\mathrm{Ca}_{\mathrm{i}}{ }^{++}$[3]. In the skeleton, PTH and PTHrP exert their anabolic and catabolic effects by binding and activating the PPR expressed on cells of the osteoblast lineage. This lineage comprises a variety of cells, from osteoprogenitors to mature osteoblasts and osteocytes; however, cellular targets of PTH actions are still not completely understood.

Osteocytes, the terminally differentiated osteoblasts deeply embedded in the bone mineral matrix, comprise $\sim 95 \%$ of all cells in the adult bone [4-6]. Recent literature supports direct and indirect interactions of osteocytes with nearby cells, including osteoblasts, osteoclasts, and endothelial cells and with distant organs, such as kidneys and muscles, through various secreted molecules, including receptor-activator of nuclear factor- $\mathrm{kB}$ ligand (RANKL), fibroblast growth factor 23 (FGF23) and sclerostin [7-13]. Sclerostin, a potent Wnt inhibitor, suppresses osteoblast function and proliferation, whereas RANKL is a master regulator of osteoclast differentiation and survival $[14,15]$. In addition, recent studies identified osteocytes as critical effectors in normal physiological processes, such as lactation, hematopoiesis, and bone modeling and remodeling $[8,10,15,16]$. Osteocytes may also play important roles in diseases such as hypophosphatemic rickets, osteopenia, sclerosteosis, Van Buchem disease, and osteopetrosis [17-19].

Mice with constitutively active PPR in osteocytes display increased trabecular bone mass, increased osteoblast number, and decreased Sost/sclerostin expression [20,21] whereas mice lacking RANKL in osteocytes have high bone mineral density and osteopetrosis $[14,15]$, demonstrating an important role for osteocytes in bone remodeling. We have previously generated mice with conditional knockout (KO) of the PPR predominantly in osteocytes by using the $10-\mathrm{Kb}$ dentin matrix protein 1 (Dmp1) promoter to drive Cre recombinase expression in PPR-floxed mice (Dmp1$\mathrm{PPR}^{\mathrm{KO}}$ ) [22]. At 3months of age, Dmp1-PPR ${ }^{\mathrm{KO}}$ mice show normal serum calcium, phosphate, and PTH, suggesting that under physiological conditions PPR signaling in osteocytes is not needed to maintain normal mineral homeostasis. These mice display a significant increase in trabecular and cortical bone, indicating that PPR on osteocytes is required for normal bone remodeling. When subjected to intermittent or continuous PTH administration, Dmp1-PPR ${ }^{\mathrm{KO}}$ mice generated blunted anabolic and catabolic skeletal responses, indicating that PPR signaling in osteocytes is necessary for full skeletal responses to the hormone [22].

To study the role of PPR signaling in osteocytes in agedependent osteopenia, we analyzed the skeletal phenotype of mice at 4 (adult) and 13 (middle-aged) months of age. As compared with controls, 4-month-old Dmp1-PPR ${ }^{\mathrm{KO}}$ animals showed increased trabecular bone and decreased osteoclast number and activity, whereas at 13 months these mutant mice had a significant decrease in trabecular bone associated with increased osteoclast number and activity. In vitro, PTH significantly protected osteocytic cells from hydrogen peroxide $\left(\mathrm{H}_{2} \mathrm{O}_{2}\right)$ induced cell death and reactive oxygen species (ROS) production. This effect was lost in cells lacking receptor expression. All together these data highlight an essential role of PPR signaling in osteocytes to protect against age-related bone loss and oxidative stresses.

\section{RESULTS}

\section{PPR ablation in mature osteoblasts/osteocytes induces severe osteopenia in 13-month-old male mice}

Mice lacking PPR in mature osteoblasts/osteocytes, namely Dmp1-PPR ${ }^{\mathrm{KO}}$, have increased bone mineral density and bone mass by three months of age and they are resistant to both the anabolic and catabolic effects of PTH [22]. To investigate whether PPR signaling in mature osteoblasts/osteocytes is needed to maintain skeletal homeostasis during age-dependent bone loss, we analyzed the skeletons of adult and middle-aged animals. Hematoxylin and eosin (H\&E) staining of the tibiae and von Kossa staining of the fifth lumbar (L5) vertebrae and the femora showed significant increase in trabecular bone volume over total tissue volume (BV/TV\%) at 4 months, as previously reported for young mice [22]. The increased bone mass was followed by a dramatic bone loss in Dmp1-PPR ${ }^{\mathrm{KO}}$ mice at 13 months, as compared to littermate controls (Figure 1A-1D, Table 1, Supplementary Figure 1A). Cortical thickness was similar between Dmp1-PPR ${ }^{\mathrm{KO}}$ and controls at both ages (Figure 1E). Micro-computed tomography $(\mu \mathrm{CT})$ analysis further confirmed the histological data (Figure 1F-1J, Table 2). At 4 months of age, in Dmp1-PPR ${ }^{\mathrm{KO}}$ mice there was a significant increase in $\mathrm{BV} / \mathrm{TV} \%$ in $\mathrm{L} 5$ and distal femur (Figure 1H-1I) and a significant increase in trabecular thickness (Figure 1H) in vertebral bones. In contrast, at 13 months of age, BV/TV\% in both sites (L5 and femurs) were significantly decreased in Dmp1-PPR ${ }^{\mathrm{KO}}$ mice compared to littermate controls (Figure 1H, 1I). The significant reduction in these trabecular parameters was still present in $\mathrm{KO}$ animals at 16 months of age 
(Supplementary Figure 1B). In Dmp1-PPR ${ }^{\mathrm{KO}}$ mice, bone volume of L5 and the distal femora decreased by $41 \%$ and $71 \%$, respectively, from 4 to 13 months, whereas in control animals this decrease was $12 \%$ and $42 \%$, respectively (Figure 1H, 1I). At 13 months of age, trabecular separation was also significantly increased in the L5 of Dmp1-PPR ${ }^{\mathrm{KO}}$ mice (Figure 1H) and trabecular number (Tb.N) was significantly decreased in the distal femora (Figure 1I) of Dmp1-PPR ${ }^{\mathrm{KO}}$ mice compared to controls. Taken together this data revealed a marked age-dependent trabecular bone loss in the absence of PPR signaling in mature osteoblasts/osteocytes.

Cortical area, as assessed by $\mu \mathrm{CT}$ analysis of the midshaft femur, was significantly increased at 4 months in Dmp1-PPR ${ }^{\mathrm{KO}}$ mice (Figure 1G, 1J, Table 2).
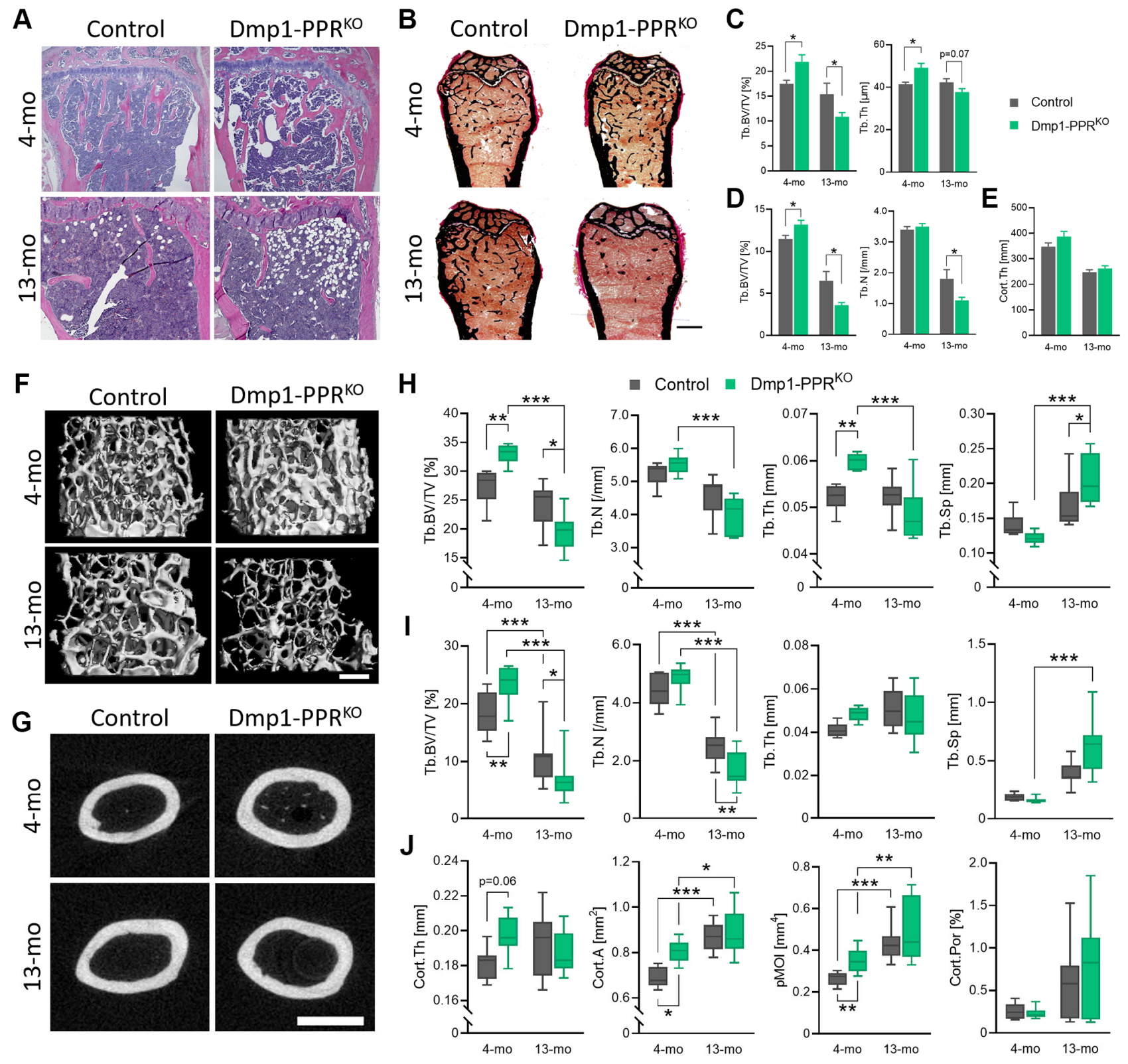

Figure 1. Age-dependent bone loss in Dmp1-PPR ${ }^{\mathrm{KO}}$ mice. Vertebrae and long bones of male control and KO animals were analyzed by (A) histology, (B-E) histomorphometry and (F-J) $\mu \mathrm{CT}$. (A) Representative H\&E of the proximal tibiae and (B) Von Kossa staining of the distal femora. Bar $=1.0 \mathrm{~mm}$. Histomorphometric analysis of (C) the $L 5$ and (D) trabecular and (E) cortical region in the distal and midshaft femora, respectively. $N=6-10$ per group. Data are presented as mean \pm SEM. Representative $\mu C T$ images of $(\mathbf{F})$ the distal and $(\mathbf{G})$ the midshaft femora. Bars $=(\mathbf{F}) 300 \mu \mathrm{m}$ and $(\mathbf{G}) 1.0 \mathrm{~mm}$. $\mu \mathrm{CT}$ analysis of $(\mathbf{H})$ the $\mathrm{L} 5$ and $(\mathbf{I})$ the distal femur (trabecular) and (J) the midshaft femur (cortical) are shown. Data are presented as box and whisker plot. $N=6-16$ per group. See Tables 1 and 2 for the full list of parameters. Analyses were performed in a blinded fashion. Unpaired Student's $t$ test (C-E) and Two-way ANOVA with Tukey's post hoc test or Mann-Whitney test $(\mathbf{H}-\mathrm{J})$ was performed. ${ }^{*} p<0.05,{ }^{* *} p<0.01,{ }^{* * *} p<0.001$. Abbreviations: Tb: Trabecular; Cort: cortical; BV: bone volume; TV: total tissue volume; Th: thickness; N: number; Sp: separation; A: area; pMOI: polar moment of inertia; Por: porosity. 
Table 1. Dynamic histomorphometric analysis of trabecular and cortical bone in 4- and 13-month-old Dmp1-PPR ${ }^{\mathrm{KO}}$ and control mice. Trabecular bone parameters measured in $\mathbf{L} 5$ vertebrae and distal femurs. Cortical bone parameters measured in midshaft of femurs. Values are expressed as mean $\pm \mathrm{SEM}$, two-tailed $t$ test assuming equal variance was performed to compare control vs. Dmp1-PPR ${ }^{\mathrm{KO}}$ male mice at 4 and 13 months of age. $p<0.05$ in bold and italics.

\begin{tabular}{|c|c|c|c|c|c|c|}
\hline \multirow{2}{*}{ Parameter } & \multicolumn{3}{|c|}{ 4-month-old } & \multicolumn{3}{|c|}{ 13-month-old } \\
\hline & Control & Dmp1-PPR ${ }^{\mathrm{KO}}$ & $p$ value & Control & Dmp1-PPR ${ }^{\mathrm{KO}}$ & $p$ value \\
\hline L5 vertebrae & $n=6$ & $n=10$ & & $n=8$ & $n=10$ & \\
\hline \multicolumn{7}{|l|}{ Structural } \\
\hline BV/TV (\%) & $17.5 \pm 0.7$ & $21.9 \pm 1.4$ & 0.04 & $15.4 \pm 2.2$ & $10.9 \pm 0.8$ & 0.04 \\
\hline Tb.N (/mm) & $4.23 \pm 0.12$ & $4.42 \pm 0.15$ & 0.40 & $3.56 \pm 0.38$ & $2.89 \pm 0.17$ & 0.09 \\
\hline Tb.Th $(\mu \mathrm{m})$ & $41.4 \pm 0.97$ & $49.2 \pm 2.04$ & 0.01 & $42.3 \pm 1.71$ & $37.7 \pm 1.62$ & 0.07 \\
\hline $\mathrm{Tb} . \mathrm{Sp}(\mu \mathrm{m})$ & $196.0 \pm 7.4$ & $179.3 \pm 8.9$ & 0.22 & $260.3 \pm 37.9$ & $321.4 \pm 23.8$ & 0.17 \\
\hline Distal femurs & $n=6$ & $n=7$ & & $n=8$ & $n=10$ & \\
\hline \multicolumn{7}{|l|}{ Structural } \\
\hline BV/TV (\%) & $11.5 \pm 0.4$ & $13.2 \pm 0.5$ & 0.02 & $6.5 \pm 1.1$ & $3.6 \pm 0.3$ & 0.04 \\
\hline Tb.N (/mm) & $3.4 \pm 0.1$ & $3.5 \pm 0.1$ & 0.83 & $1.8 \pm 0.3$ & $1.1 \pm 0.1$ & 0.04 \\
\hline Tb.Th $(\mu \mathrm{m})$ & $33.5 \pm 0.4$ & $38.2 \pm 1.6$ & 0.02 & $35.5 \pm 1.4$ & $34.6 \pm 2.0$ & 0.72 \\
\hline Tb.Sp $(\mu \mathrm{m})$ & $260.0 \pm 9.7$ & $252.7 \pm 6.4$ & 0.55 & $665.2 \pm 128.5$ & $959.8 \pm 65.3$ & 0.08 \\
\hline \multicolumn{7}{|l|}{ Dynamic } \\
\hline MS/BS (\%) & $33.5 \pm 0.8$ & $27.38 \pm 1.9$ & 0.04 & $21.8 \pm 1.5$ & $22.7 \pm 1.5$ & 0.07 \\
\hline $\operatorname{MAR}(\mu \mathrm{m} /$ day $)$ & $1.90 \pm 0.2$ & $1.72 \pm 0.1$ & 0.33 & $1.56 \pm 0.3$ & $0.95 \pm 0.1$ & 0.02 \\
\hline $\mathrm{BFR} / \mathrm{BS}$ & $231.5 \pm 13.8$ & $173.9 \pm 18.5$ & 0.06 & $130.8 \pm 27.7$ & $79.1 \pm 8.3$ & 0.71 \\
\hline BFR/BV (\%/year) & $1320.7 \pm 95.0$ & $840.1 \pm 67.9$ & $<0.01$ & $650.3 \pm 109.9$ & $478.4 \pm 55.8$ & 0.07 \\
\hline BFR/TV (\%/year) & $159.8 \pm 8.4$ & $116.2 \pm 13.1$ & 0.04 & $55.7 \pm 17.4$ & $16.1 \pm 1.6$ & 0.13 \\
\hline \multicolumn{7}{|l|}{ Formation } \\
\hline OV/BV (\%) & $0.35 \pm 0.11$ & $0.28 \pm 0.03$ & 0.45 & $0.51 \pm 0.08$ & $0.42 \pm 0.06$ & 0.42 \\
\hline OS/BS (\%) & $6.05 \pm 1.25$ & $5.09 \pm 0.34$ & 0.38 & $4.68 \pm 0.77$ & $3.32 \pm 0.37$ & 0.17 \\
\hline Ob.S/BS (\%) & $6.36 \pm 1.18$ & $5.14 \pm 0.37$ & 0.25 & $5.40 \pm 0.88$ & $3.78 \pm 0.48$ & 0.16 \\
\hline N.Ob/T.Ar & $41.29 \pm 6.54$ & $31.58 \pm 2.06$ & 0.11 & $14.26 \pm 3.86$ & $5.69 \pm 0.87$ & 0.08 \\
\hline N.Ob/B.Pm (/mm) & $6.04 \pm 0.58$ & $5.39 \pm 0.68$ & 0.52 & $3.83 \pm 0.71$ & $2.47 \pm 0.31$ & 0.13 \\
\hline \multicolumn{7}{|l|}{ Resorption } \\
\hline ES/BS (\%) & $1.81 \pm 0.30$ & $0.97 \pm 0.18$ & 0.04 & $0.50 \pm 0.13$ & $1.25 \pm 0.21$ & 0.01 \\
\hline Oc.S/BS (\%) & $1.62 \pm 0.27$ & $0.83 \pm 0.15$ & 0.01 & $0.45 \pm 0.11$ & $1.24 \pm 0.23$ & 0.01 \\
\hline N.Oc/B.Pm (/mm) & $0.57 \pm 0.09$ & $0.34 \pm 0.07$ & 0.05 & $0.25 \pm 0.07$ & $0.65 \pm 0.13$ & 0.03 \\
\hline \multicolumn{7}{|l|}{ Osteocyte } \\
\hline N.Ot/BV $\left(/ \mathrm{mm}^{2}\right)$ & $592.0 \pm 59.1$ & $590.9 \pm 39.2$ & 0.99 & $388.1 \pm 43.2$ & $300.0 \pm 47.1$ & 0.11 \\
\hline Midshaft femurs & $n=6$ & $n=10$ & & $n=8$ & $n=10$ & \\
\hline \multicolumn{7}{|l|}{ Structural } \\
\hline Cort.Th (mm) & $347.9 \pm 14.1$ & $386.9 \pm 20.2$ & 0.14 & $247.5 \pm 9.7$ & $262.0 \pm 10.4$ & 0.18 \\
\hline \multicolumn{7}{|l|}{ Dynamic } \\
\hline End.Cort MAR (mm/day) & $1.8 \pm 0.1$ & $1.8 \pm 0.2$ & 0.84 & $1.5 \pm 0.1$ & $1.2 \pm 0.1$ & 0.09 \\
\hline \multicolumn{7}{|l|}{ Osteocyte } \\
\hline Ot density $\left(/ \mathrm{mm}^{2}\right)$ & $470.7 \pm 26.8$ & $379.9 \pm 25.6$ & 0.03 & $445.3 \pm 21.0$ & $421.5 \pm 18.1$ & 0.23 \\
\hline
\end{tabular}


Table 2. $\mu \mathrm{CT}$ analysis of trabecular and cortical bone in 4- and 13-month-old Dmp1-PPR ${ }^{\mathrm{KO}}$ and control. Trabecular bone parameters measured in L5 vertebrae and distal femurs. Cortical bone parameters measured in midshaft of femurs. Values are presented as mean \pm SEM, two-tailed $t$ test assuming equal variance was performed to compare control vs. Dmp1-PPR ${ }^{\mathrm{KO}}$ male mice at 4 - and 13-months of age. $p<0.05$ in bold and italics.

\begin{tabular}{|c|c|c|c|c|c|c|}
\hline \multirow{2}{*}{ Parameter } & \multicolumn{3}{|c|}{ 4-month-old } & \multicolumn{3}{|c|}{ 13-month-old } \\
\hline & Control & Dmp1-PPR ${ }^{\mathrm{KO}}$ & $p$ value & Control & Dmp1-PPR ${ }^{\mathrm{KO}}$ & $p$ value \\
\hline L5 vertebrae & $n=6$ & $n=10$ & & $n=7$ & $n=11$ & \\
\hline BV/TV (\%) & $27.4 \pm 1.3$ & $33.0 \pm 0.5$ & $<0.001$ & $24.1 \pm 1.5$ & $19.4 \pm 0.9$ & 0.011 \\
\hline Tb.N (/mm) & $5.24 \pm 0.149$ & $5.52 \pm 0.087$ & 0.101 & $4.59 \pm 0.23$ & $4.01 \pm 0.16$ & 0.052 \\
\hline Tb.Th (mm) & $0.052 \pm 0.001$ & $0.060 \pm 0.001$ & $<0.001$ & $0.052 \pm 0.002$ & $0.049 \pm 0.002$ & 0.137 \\
\hline Tb.Sp (mm) & $0.14 \pm 0.007$ & $0.12 \pm 0.003$ & 0.015 & $0.17 \pm 0.014$ & $0.21 \pm 0.010$ & 0.053 \\
\hline Distal femurs & $n=7$ & $n=10$ & & $n=12$ & $n=15$ & \\
\hline BV/TV (\%) & $18.0 \pm 1.4$ & $23.6 \pm 1.0$ & 0.003 & $10.4 \pm 1.1$ & $6.8 \pm 0.7$ & 0.013 \\
\hline Tb.N (/mm) & $4.38 \pm 0.2$ & $4.87 \pm 0.1$ & 0.056 & $2.46 \pm 0.2$ & $1.69 \pm 0.2$ & 0.002 \\
\hline Tb.Th (mm) & $0.041 \pm 0.001$ & $0.048 \pm 0.001$ & $<0.001$ & $0.051 \pm 0.003$ & $0.047 \pm 0.003$ & 0.285 \\
\hline $\mathrm{Tb} . \mathrm{Sp}(\mathrm{mm})$ & $0.19 \pm 0.01$ & $0.16 \pm 0.01$ & 0.028 & $0.39 \pm 0.03$ & $0.62 \pm 0.06$ & 0.002 \\
\hline Midshaft femurs & $n=7$ & $n=10$ & & $n=12$ & $n=16$ & \\
\hline Cort.Th (mm) & $0.181 \pm 0.004$ & $0.197 \pm 0.003$ & 0.005 & $0.193 \pm 0.005$ & $0.187 \pm 0.003$ & 0.30 \\
\hline Cort.Dens (mmHA/ccm) & $1239.8 \pm 3.9$ & $1218.6 \pm 4.4$ & 0.004 & $1288.5 \pm 9.5$ & $1279.4 \pm 7.1$ & 0.44 \\
\hline Cort.A $\left(\mathrm{mm}^{2}\right)$ & $0.69 \pm 0.02$ & $0.81 \pm 0.02$ & $<0.001$ & $0.87 \pm 0.02$ & $0.89 \pm 0.02$ & 0.50 \\
\hline $\mathrm{MA}\left(\mathrm{mm}^{2}\right)$ & $0.77 \pm 0.03$ & $0.89 \pm 0.04$ & 0.040 & $0.98 \pm 0.10$ & $0.78 \pm 0.14$ & 0.27 \\
\hline Cort. Por (\%) & $0.26 \pm 0.03$ & $0.23 \pm 0.02$ & 0.48 & $0.56 \pm 0.12$ & $0.73 \pm 0.14$ & 0.37 \\
\hline $\mathrm{pMOI}\left(\mathrm{mm}^{4}\right)$ & $0.26 \pm 0.01$ & $0.35 \pm 0.02$ & 0.002 & $0.44 \pm 0.02$ & $0.49 \pm 0.04$ & 0.28 \\
\hline
\end{tabular}

Similarly, other cortical parameters, including polar moment of inertia, were also significantly increased in the mutant mice at 4 months of age, compared to controls whereas they were indistinguishable between the two genotypes at 13 months, indicating a differential temporal regulation of trabecular and cortical bone by PPR signaling in mature osteoblasts/osteocytes with age.

PPR deletion in mature osteoblasts/osteocytes increases osteoclast, but decreases osteoblast, activity in 13-month-old mice

To delineate the cellular mechanism of the age-related osteopenia in the Dmp1-PPR ${ }^{\mathrm{KO}}$ animals, we performed histomorphometric analysis on the L5 and the femora of adult and middle-aged mice. As shown in Figure $1 \mathrm{C}-1 \mathrm{E}$, histomorphometric analysis confirmed the decrease in trabecular $\mathrm{BV} / \mathrm{TV} \%$ and $\mathrm{Tb} . \mathrm{N}$ in male Dmp1-PPR ${ }^{\mathrm{KO}}$ mice at 13 months, both in axial and appendicular sites. Tartrate resistant acid phosphatase (TRAP) staining on the distal femora of these mice showed relatively fewer osteoclasts per bone perimeter at 4 months, but strikingly more TRAP-positive cells at 13 months in Dmpl-PPR ${ }^{\mathrm{KO}}$ animals as compared with controls (Figure 2A-2B). The significant increase in the number of TRAP-positive osteoclasts was also present in the proximal tibiae of 20-month-old Dmp1$\mathrm{PPR}^{\mathrm{KO}}$ female mice compared with control littermates (Supplementary Figure 2A). These findings were further supported by a significant reduction in osteoclast activity, such as erosion and osteoclast surface per bone surface, in 4-month-old Dmp1-PPR ${ }^{\mathrm{KO}}$ mice but a significant increase of all these parameters at 13 months of age (Figure 2B, Table 1). Bone formation rate (BFR) over bone volume (BFR/BV) was significantly decreased in Dmp1-PPR ${ }^{\mathrm{KO}}$ at 4 months and mineral apposition rate (MAR) was significantly reduced in 13-month-old Dmp1-PPR ${ }^{\mathrm{KO}}$ mice compared to controls (Figure 2C-2D, Table 1). These results indicate that, in the absence of PPR signaling in mature osteoblasts/osteocytes, there is an age-dependent increase in osteoclast numbers and activity and ageindependent decrease in osteoblast activity resulting in increased bone resorption and bone loss. 
Age-dependent changes in serum markers and skeletal genes in Dmp1-PPR ${ }^{\mathrm{KO}}$ mice

The main function of PTH is to maintain mineral homeostasis and it is still unclear whether mature osteoblasts/osteocytes directly contribute to mineral-ion homeostasis. To investigate if lack of PPR signaling in mature osteoblasts/osteocytes impaired mineral ions homeostasis, we measured serum levels of calcium, phosphate and PTH in adult and middle-aged mice. Biochemical analysis of male Dmp1-PPR ${ }^{\mathrm{KO}}$ and littermate control mice showed normal calcemia and phosphatemia at 4 and 13 months of age (Figure 3A), demonstrating that PPR in mature osteoblasts/osteocytes is not required to maintain mineral-ion homeostasis. In both control and Dmp1$\mathrm{PPR}^{\mathrm{KO}}$, with age, there was a significant decrease in serum calcium and an increase in serum PTH, similar to what has been observed in older adult mice. PTH levels were similar between Dmp1-PPR ${ }^{\mathrm{KO}}$ and controls at 4 months of age (Figure 3A), whereas they were significantly increased in Dmp1-PPR ${ }^{\mathrm{KO}}$ mice at 13 months of age (Figure 3A), indicating a possible resistance to $\mathrm{PTH}$. This increase in serum PTH in Dmp1-PPR ${ }^{\mathrm{KO}}$ was not observed in 13-month-old female mice (Supplementary Figure 3B), suggesting the sexdependent difference. Interestingly, phosphate serum levels significantly increased with age in Dmp1-PPR ${ }^{\mathrm{KO}}$ mice but not in controls (Figure 3A). Serum markers of bone formation, procollagen type $1 \mathrm{~N}$-terminal propeptide (P1NP), were significantly reduced in both male Dmp1-PPR ${ }^{\mathrm{KO}}$ and controls at 13 months whereas markers of bone resorption, $\mathrm{C}$-terminal telopeptide of type I collagen (CTX), were unchanged in both mice groups at both ages (Figure 3B), despite the significant increase in osteoclast numbers and activities present in Dmp1-PPR ${ }^{\mathrm{KO}}$ mice at 13 months of age, as shown in Table 1 and Figure 2B.

To investigate the molecular mechanism leading to the increased osteoclasts in 13-month-old Dmp1-PPR ${ }^{\mathrm{KO}}$ mice, we assessed the expression of PPR (encoded by Pth1r) and other osteocytic markers in bone marrowdeprived long bones of adult and middle-aged
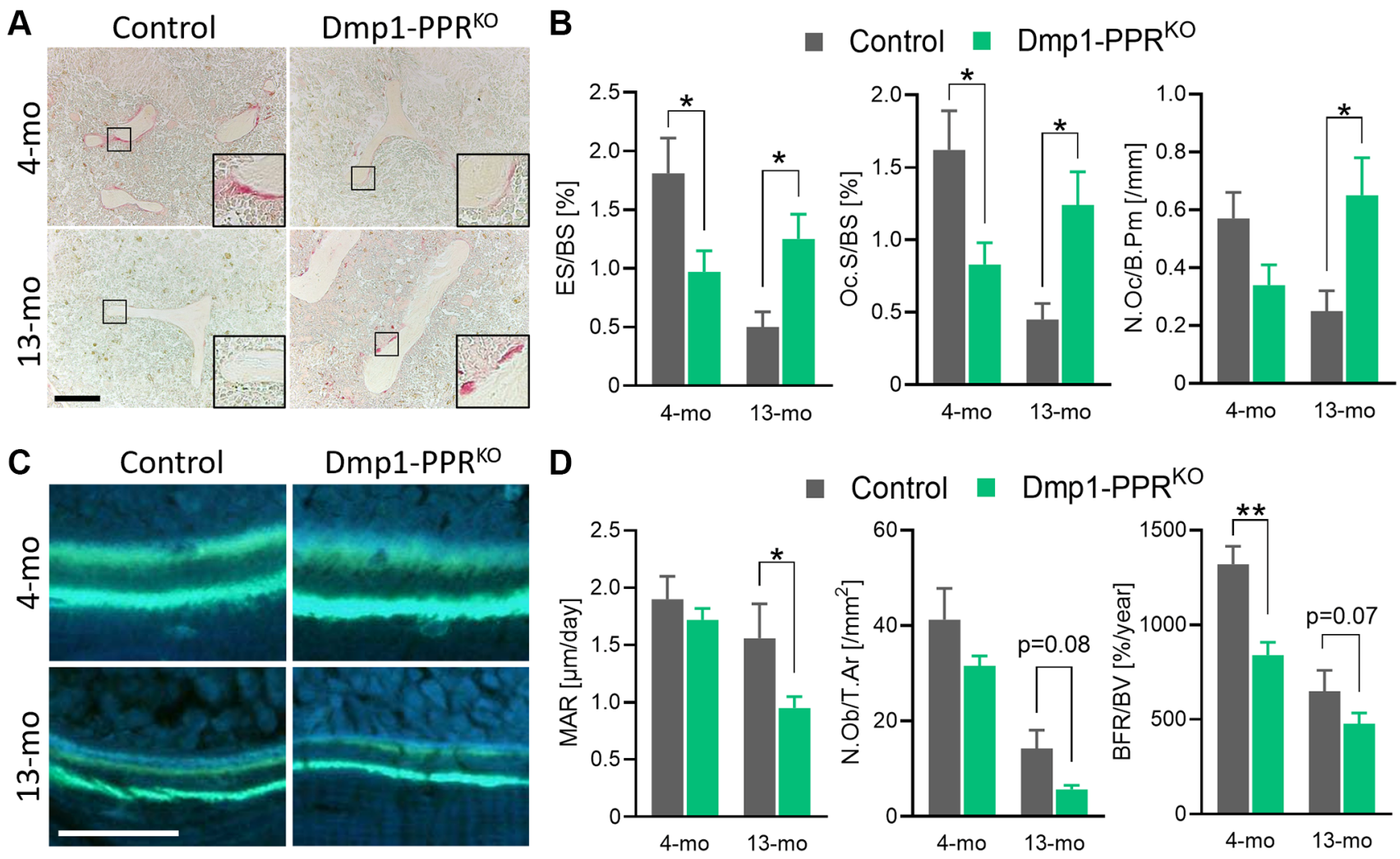

Figure 2. Histomorphometric analysis of trabecular bones of Dmp1-PPR ${ }^{\mathrm{KO}}$ mice. (A, B) Representative TRAP staining images and bone resorption parameters of the distal femora from male control and KO animals. The inset shows a closeup displaying the TRAP-positive osteoclasts on the trabecular bone surface. Bar $=200 \mu \mathrm{m}$. (C) Representative images of calcein double-staining on the distal femora of these mice. Bone formation within 7 days was visualized by double calcein labeling. Bar $=50 \mu m$. (D) Representative bone-formation parameters of the distal femora are shown. See Table 1 for the full list of resorption and formation parameters. $N=6-10$ per group. Analyses were performed in a blinded fashion. Unpaired Student's $t$ test was performed. ${ }^{*} p<0.05,{ }^{* *} p<0.01$. Data are presented as mean \pm SEM. Abbreviations: ES: Erosion surface; BS: bone surface; Oc.S: osteoclast surface; N.Oc: number of osteoclasts; B.Pm: bone perimeter; MAR: mineral apposition rate; N.Ob: number of osteoblasts; T.Ar: tissue area; BFR: bone formation rate; BV: bone volume. 
Dmp1-PPR ${ }^{\mathrm{KO}}$ and control mice. Receptor ablation in osteocytes was still present in both male and female 13month-old $\mathrm{KO}$ animals, as demonstrated by a significant decrease in PPR expression (Figure 3C, Supplementary Figure 4A). Although middle-aged male Dmp1-PPR ${ }^{\mathrm{KO}}$ mice showed a trend of increase (2.0-fold, $p=0.06)$ in Sost expression compared to controls, overall Sost expression was unaffected by genotypes (Figure 3C). Interestingly, serum sclerostin was significantly increased in the mutant mice as compared to controls, which can contribute to the suppression of bone formation present in these animals (Figure 3A). Other osteocytic genes, namely RANKL and osteoprotegerin $(\mathrm{OPG})$, were unchanged, suggesting that other factors might be driving the age-dependent increase in osteoclast numbers and activity present in middle-aged male Dmp1-PPR ${ }^{\mathrm{KO}}$ mice. In the female mice, OPG expression was significantly downregulated, while the

RANKL/OPG ratio was significantly increased, in KO mice at 13 months of age (Supplementary Figure 4A), demonstrating sex-dependent differences.

Tumor necrosis factor $\alpha$ (TNF $\alpha)$ promotes osteoclastogenesis independently of RANKL [23]; therefore, we performed immunofluorescence staining for $\mathrm{TNF} \alpha$ on the tibias of 13-month-old male mice and control littermates. In Dmp1-PPR ${ }^{\mathrm{KO}}$ mice, the number of TNF $\alpha$-expressing osteocytes was significantly decreased as compared to control littermates (Supplementary Figure 5), suggesting that other factors might drive osteoclastogenesis. In addition, we found a trend of increase (1.3-fold, $p=0.06)$ in M-CSF expression in the bone marrow of Dmp1-PPR ${ }^{\mathrm{KO}}$ mice at 13 months of age compared to control littermates Figure 4B), and this upregulation of M-CSF in KO mice was also observed in 16-month-old mice (1.5-fold, $p<0.001$,

A
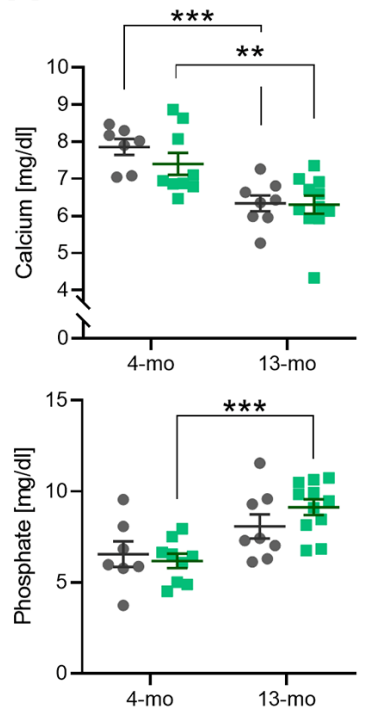

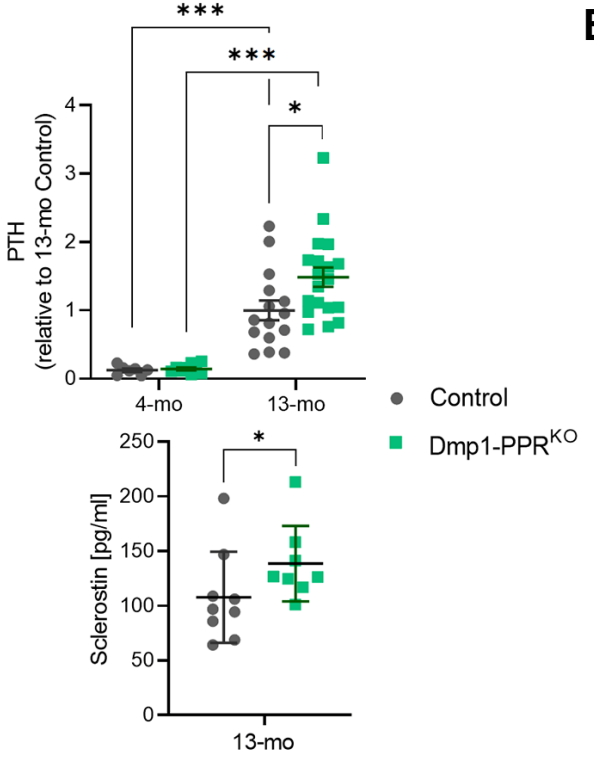

RANKL
B

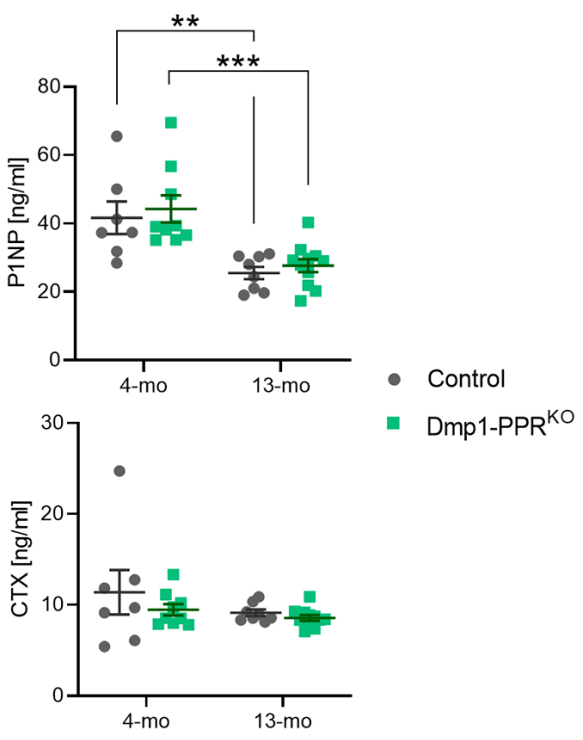

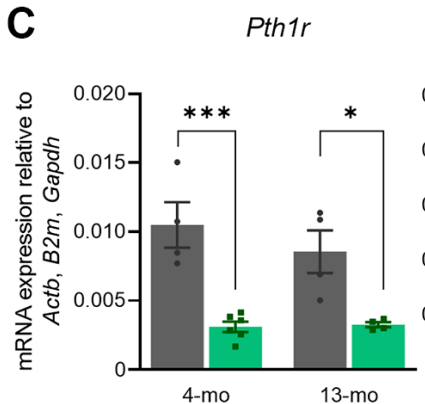
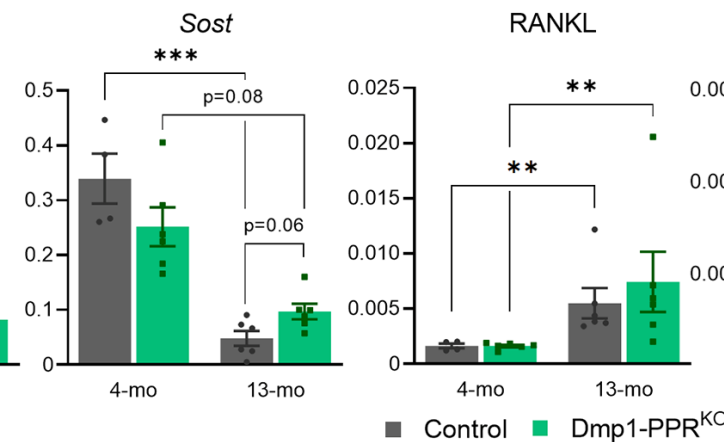

OPG

RANKL/OPG

Figure 3. Serum markers and skeletal gene expression in Dmp1-PPR ${ }^{\mathrm{KO}}$ mice. (A) Serum calcium, phosphate, PTH and sclerostin in male control and Dmp1-PPR ${ }^{K O}$ mice was measured by ELISA. PTH levels were normalized to 13-month-old control due to a high intra-assay variation (>9.8\%). (B) Serum levels of bone formation (P1NP) and resorption marker (CTX) were also measured by ELISA. $N=7-19$ per group. Data are presented as mean \pm SEM. (C) Gene expression in marrow-removed long bones of male mice was analyzed with qPCR. $N=$ 4-6 per group. Two-way ANOVA with Tukey's post hoc test, unpaired Welch's $t$ test, or Mann-Whitney test was performed. ${ }^{*} p<0.05,{ }^{* *} p<$ $0.01,{ }^{* * *} p<0.001$. Each gene expression was relative to 3 housekeeping genes (Actb, B2m, and Gapdh), which were selected by GeNorm. Expression data are presented as mean \pm SEM. 
data not shown). Sphingosine kinase (Sphk1) mediates $\mathrm{TNF} \alpha$-induced arthritis and osteoclastogenesis via $\mathrm{TNF} \alpha$ receptor activating factor 2 (TRAF2) [24]. We analyzed the expression of Sphk1 in the bone marrow of Dmp1-PPR ${ }^{\mathrm{KO}}$ mice and found that Sphk1 was significantly upregulated as compared to control littermates (Supplementary Figure 6B), suggesting a potential involvement of TNF $\alpha$-expressing osteocytes in the increase in M-CSF and Sphk1 expression in the bone marrow of Dmp1-PPR ${ }^{\mathrm{KO}}$ mice. Next we measured serum levels of cytokines, previously reported to be regulated by $\mathrm{PTH}$ or by aging, including $\mathrm{TNF} \alpha$, monocyte chemoattractant protein 1 (MCP-1/CCL2), and interleukin (IL)-6 and -10 in serum of 13-month-old male mice (Supplementary Figure 3A). While there was a trend of increase (2.2-fold, $p=0.06)$ in serum IL-10 in Dmp1-PPR ${ }^{\mathrm{KO}}$ compared to controls, serum concentration of other cytokines was unchanged.

\section{Serum from middle-aged Dmp1-PPR ${ }^{K O}$ male animals increases the number of osteoclasts in vitro}

To explore the molecular mechanism(s) driving the osteopenia and the increase in osteoclast numbers and

\section{A}

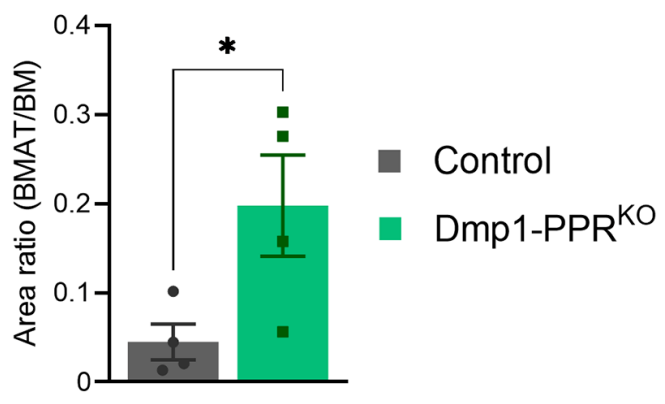

B

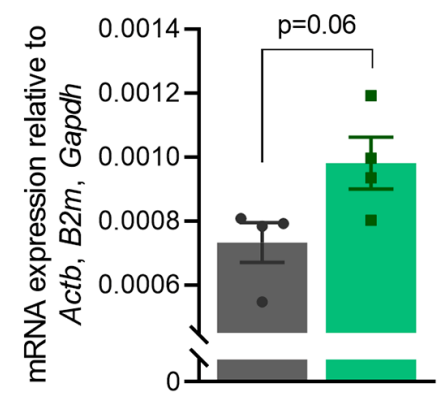

Control

- Dmp1-PPR ${ }^{\mathrm{KO}}$
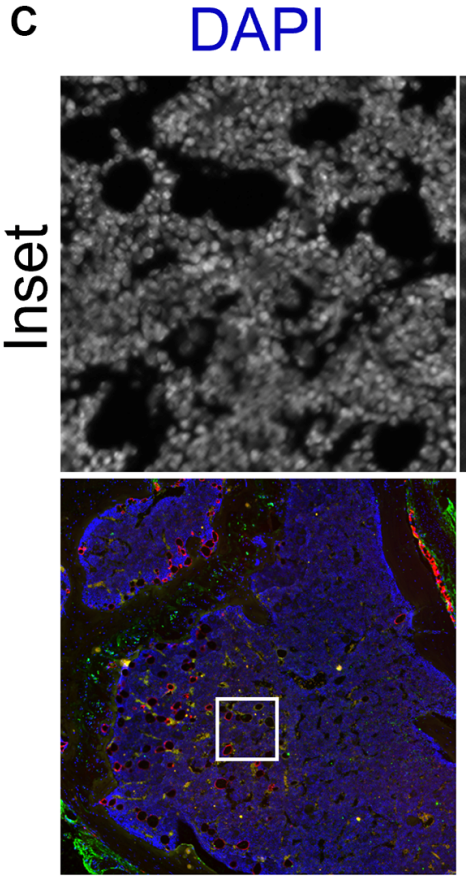

Perilipin-1
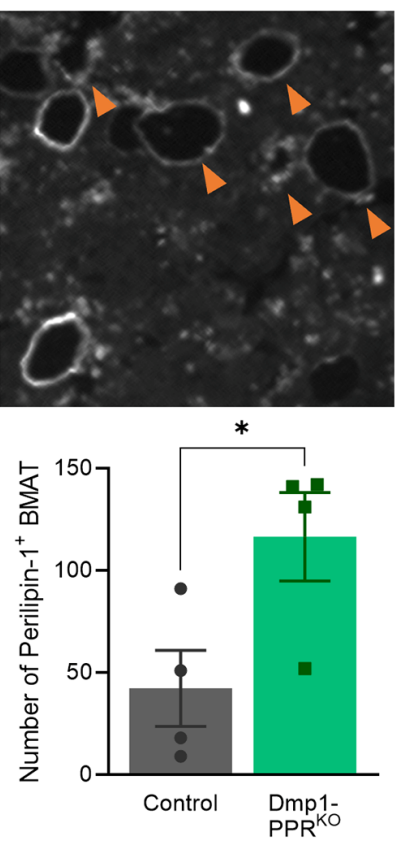

RANKL
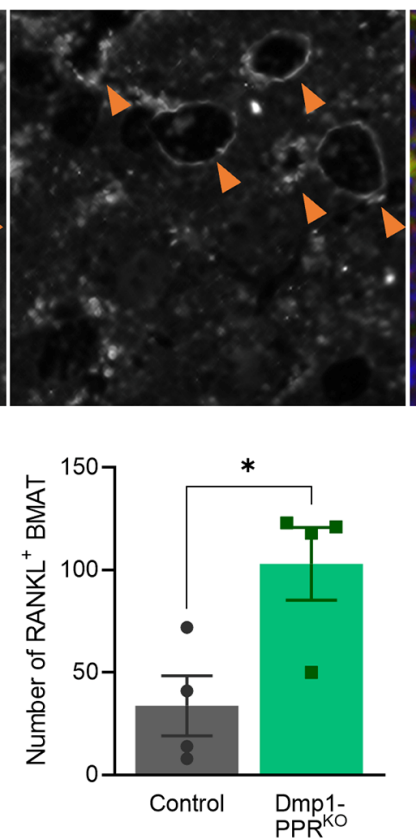

Merge
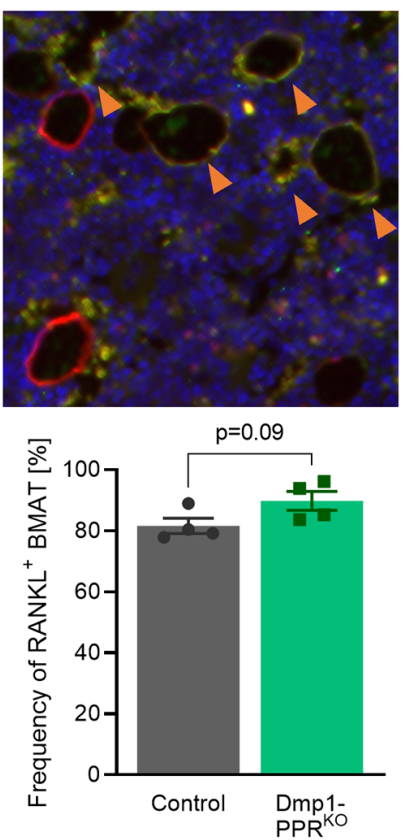

Figure 4. Increased bone marrow adipocytes in middle-aged Dmp1-PPR ${ }^{\text {KO }}$ mice. (A) The area of bone marrow adipose tissue (BMAT) over the total bone marrow (BM) space within 300- $\mu \mathrm{m}$ from the epiphyseal plate was analyzed on H\&E-stained tibiae sections of male control and Dmp1-PPR ${ }^{\mathrm{KO}}$ mice at 13 months of age. Representative images are shown in Figure $1 \mathrm{~A}$. $N=4$ per group. (B) Expression of $\mathrm{M}-\mathrm{CSF}$ in the BM isolated from the femora of middle-aged male animals (13 months old) was analyzed by qPCR. $N=4$ per group. (C) Immunofluorescence staining of perilipin-1, RANKL and DAPI was performed on the tibiae of middle-aged (13 months) male control and Dmp1-PPR ${ }^{K O}$ mice. Representative images of a tibia from Dmp1-PPR ${ }^{K O}$ mouse are shown. In the merged image, DAPI, perilipin-1 and RANKL staining is shown in blue, red, and green, respectively. The orange arrowheads indicate RANKL ${ }^{+}$BMAT (identified as perilipin- $1^{+}$). The number of BMAT (left) and the number (middle) and frequency (right) of RANKL ${ }^{+}$BMAT in the BM space were analyzed. $N=4$ per group. Unpaired student's $t$ test was performed. ${ }^{*} p<0.05$. Data are presented as mean \pm SEM. 
activity in middle-aged male Dmp1-PPR ${ }^{\mathrm{KO}}$ mice, we treated bone marrow mononuclear cells (BMMCs) isolated from wild type mice (3-4 months old) with serum obtained from 13-month-old male mice (Dmp1$\mathrm{PPR}^{\mathrm{KO}}$ and littermate controls) and analyzed osteoclastogenesis by TRAP staining and activity. BMMCs treated with serum from KO mice significantly increased the number of $\mathrm{TRAP}^{+}$osteoclasts compared to the control group (Figure 5A), whereas TRAP activity was similar between the two groups (Supplementary Figure 3C). These findings suggest that, in the absence of PTH signaling, osteocytes secrete factors that contribute, in part, to the increase in osteoclasts present in middle-aged Dmp1-PPR ${ }^{\mathrm{KO}}$ mice.

\section{Osteoprogenitors are decreased in middle-aged Dmp1-PPR ${ }^{\mathrm{KO}}$ animals}

Next we assessed if lack of PPR signaling in mature osteoblasts/osteocytes influenced the commitment or frequency of osteoprogenitor cells, and therefore their osteogenic potential. As shown in Figure 5B, colony forming unit osteoblasts (CFU-Ob) were significantly reduced in bone marrow of male Dmp1-PPR ${ }^{\mathrm{KO}}$ animals
A

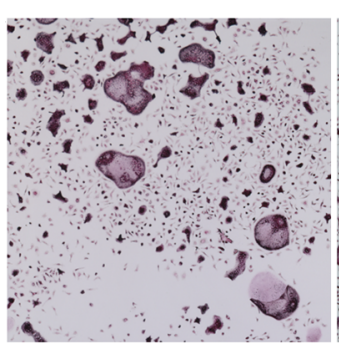

Control serum

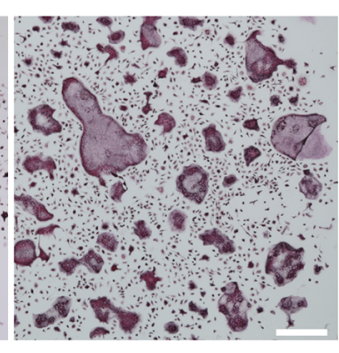

Dmp1-PPR ${ }^{\mathrm{KO}}$ serum
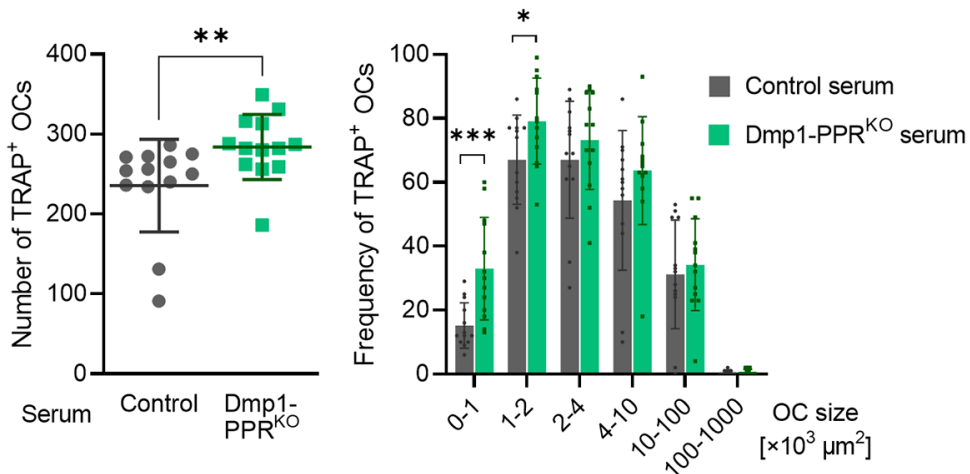

B
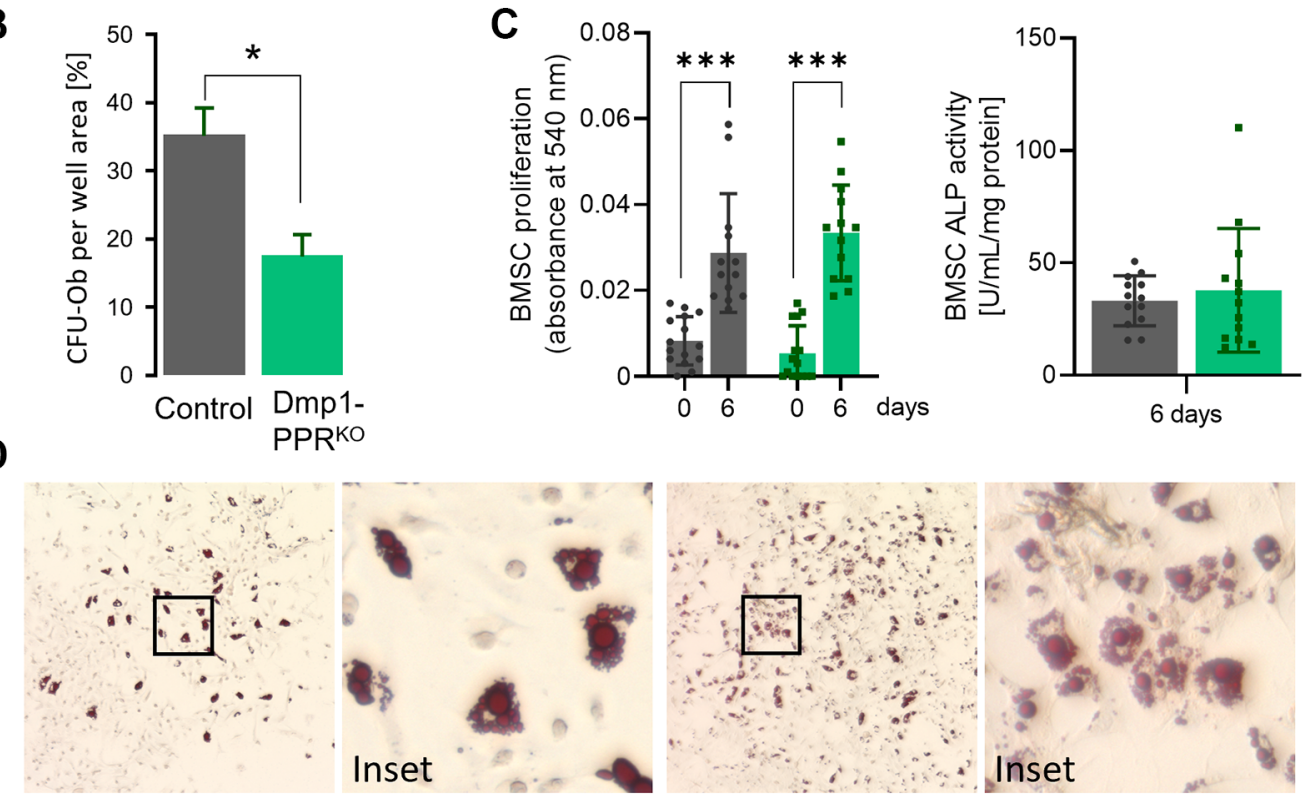

Control serum
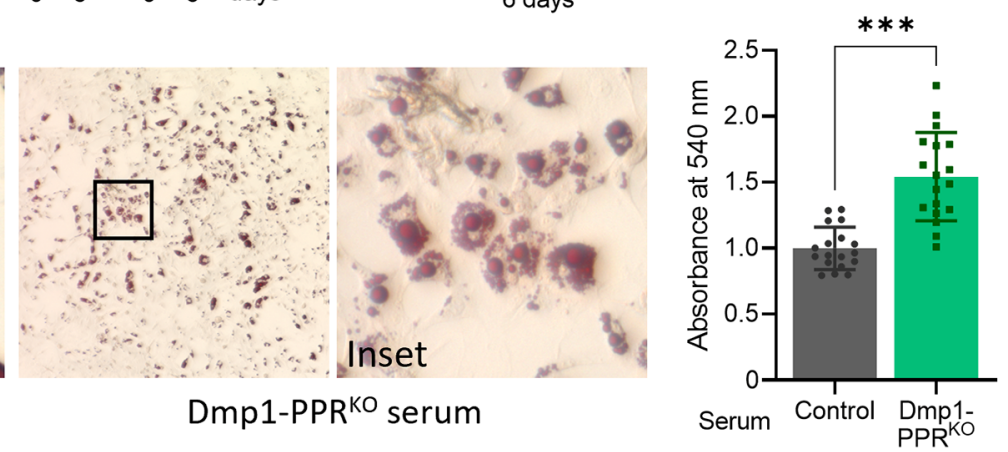

Figure 5. Serum from Dmp1-PPR ${ }^{\mathrm{KO}}$ mice increases osteoclastogenesis and adipogenesis. (A) Representative TRAP staining images of BMMCs isolated from 3-month-old male control mice under osteoclastic differentiation in the presence of serum from 13-month old male control and KO mice. The total number (middle) and size distribution (right) of TRAP' osteoclasts (OCs) per field were quantified. N $=13$ per group. Data are presented as mean \pm SEM. (B) CFU assay for osteoblasts was performed on BMSCs isolated from 13-month-old male control and Dmp1-PPR ${ }^{\mathrm{KO}}$ animals. Data are presented as mean \pm SEM. (C) Proliferation assay (left) and ALP activity assay (right) were performed on BMSCs isolated from 3-month-old male control mice under osteogenic differentiation in the presence of serum from male control and Dmp1-PPR ${ }^{\mathrm{KO}}$ mice at 13 months of age. ALP activity assay was performed on day 6 of the osteogenic differentiation. $N=13-15$ per group. (D) Representative Oil-red-O staining images of BMSCs isolated from 3-month-old male control mice under adipogenic differentiation in the presence of serum from male control and KO mice at 13 months of age. Quantification of lipid was performed by elution of Oil-red-O stain. $N=18$ per group. Mann-Whitney test (A) or paired or unpaired $t$ test (B-D) was performed. ${ }^{*} p<0.05,{ }^{* *} p<0.01$, ${ }^{* * *} p<0.001$. Data are presented as mean \pm SEM. 
compared to controls at 13 months, demonstrating a progressive reduction in osteoprogenitors. Similarly, middle-aged female $\mathrm{KO}$ animals showed a marked reduction in $\mathrm{CFU}-\mathrm{Ob}$ in the bone marrow (Supplementary Figure 3D).

\section{Serum from middle-aged Dmp1-PPR ${ }^{\mathrm{KO}}$ male animals promotes adipogenic differentiation of BMSCs in vitro}

Since circulating factors, including bone morphogenic proteins, are involved in osteolineage commitment of bone marrow stromal cells (BMSCs) [25], we examined the effect of serum from middle-aged mice on osteogenic differentiation of BMSCs. We treated BMSCs isolated from wild type mice (3-4 months old) with serum from 13-month-old male Dmp1-PPR ${ }^{\mathrm{KO}}$ mice and littermate controls. Treatment with serum from control and $\mathrm{KO}$ mice showed no difference in proliferation and alkaline phosphatase (ALP) activity of BMSCs (Figure 5C), while BMSCs treated with serum from $\mathrm{KO}$ mice significantly increased adipogenic differentiation, as assessed by oil-red-O staining (Figure 5D). These findings demonstrate that circulating factors promote lineage commitment of BMSCs. To investigate if the secreted factors are osteocyte-derived, we treated BMSCs with conditioned medium from ex vivo culture of osteocyte-enrichment bone explants (OEBEs) from 13-month-old control and Dmp1-PPR ${ }^{\mathrm{KO}}$ mice. Similarly, there was no difference in both BMSC proliferation and osteogenic differentiation between both treatment groups (Supplementary Figure 3E). These results indicate that factors secreted from osteocytes are not the major contributor to the reduced osteoprogenitors in Dmp1-PPR ${ }^{\mathrm{KO}}$ mice.

\section{Marrow adipocytes are the source of RANKL}

As demonstrated in Figure 5D, treatment with serum from 13-month-old Dmp1-PPR ${ }^{\mathrm{KO}}$ mice promoted adipogenic differentiation of BMSCs in vitro. To examine if there was any change in marrow adiposity in these mice, we performed histological analysis on bone marrow. In Dmp1-PPR ${ }^{\mathrm{KO}}$ male animals, at 13 months of age, there was a significant increase in marrow adiposity (Figures 1A, 4A). Since marrow adipocytes have been reported as a source of RANKL [26, 27], we analyzed RANKL expression in marrow adipocytes by immunofluorescence staining. Staining of RANKL along with an adipocyte marker, perilipin-1, revealed that the number of $\mathrm{RANKL}^{+}$marrow adipocytes was markedly increased in Dmp1-PPR ${ }^{\mathrm{KO}}$ compared to control male mice (Figure 4C). However, the ratio of $\mathrm{RANKL}^{+}$adipocytes over total adipocytes was unchanged between control and mutant animals, suggesting that the increase in the number, but not the frequency, of $\mathrm{RANKL}^{+}$adipocytes contributed to the increased osteoclast numbers in $\mathrm{KO}$ mice. It has also been reported that bone marrow adipocytes express $\mathrm{M}$ CSF [28]. Interestingly, we found that M-CSF expression was upregulated (1.3-fold, $p=0.06)$ in the bone marrow of male Dmp1-PPR ${ }^{\mathrm{KO}}$ mice as compared to controls (Figure 4B). This may indicate that the increased marrow adiposity also contributed to the upregulation of M-CSF in the middle-aged mutant mice. Expression of RANKL was unchanged in the bone marrow of 13-month-old male mice (Supplementary Figure 6A). Interestingly, the marrow adiposity was unchanged between female control and Dmp1-PPR ${ }^{\mathrm{KO}}$ at 20 months of age, suggesting sexual dimorphism (Supplementary Figure 2B).

\section{PPR signaling protects osteocytes from early onset of oxidative stress in vivo}

Aging is accompanied by an accumulation of oxidative stress due to an imbalance between pro-oxidants and antioxidants $[29,30]$. PTH protects osteoblasts from oxidative stress-induced cell death [31]; therefore we hypothesize that a similar effect was also present in osteocytes. To test the hypothesis, we analyzed the expression of 4-hydroxynonenal (4-HNE), a biomarker for oxidative stress-induced lipid peroxidation, in the L3/4 vertebrae of 4- and 13-month-old Dmp1-PPR ${ }^{\mathrm{KO}}$ and control littermates. As shown in Figure 6A, Dmp1$\mathrm{PPR}^{\mathrm{KO}}$ mice exhibited a significant increase in 4-HNEpositive osteocytes at 4 months of age, suggesting the protective effect of PPR signaling in osteocytes from early onset of oxidative stress.

Oxidative stress is one of the causes of cellular senescence and it has been previously shown that senescent osteocytes contribute to age-related bone loss [32]. We investigated if the age-dependent bone loss in Dmp1-PPR ${ }^{\mathrm{KO}}$ mice was driven by senescent osteocytes. The expression of the senescence marker $\mathrm{p} 16^{\mathrm{Ink} 4 \mathrm{a}}$ was significantly increased in Dmp1-PPR ${ }^{\mathrm{KO}}$ mice at 13 months of age compared to 4 months, whereas it was unchanged in controls (Figure 6B). Other markers of cellular senescence were unchanged (Supplementary Figure 4C).

\section{PTH protects osteocytes from oxidative stress- induced cell death and intracellular ROS accumulation in vitro}

To study the effects of PTH in oxidative stress, we used an in vitro model in which PPR expression was knocked-out by CRISPR/Cas9 technique. In the absence of PPR expression in Ocy454-12H cells [33] (12H $\mathrm{PPR}^{\mathrm{KO}}$ ) (Supplementary Figure $7 \mathrm{~A}-7 \mathrm{C}$ ), there was a significant decrease in the basal RANKL and 

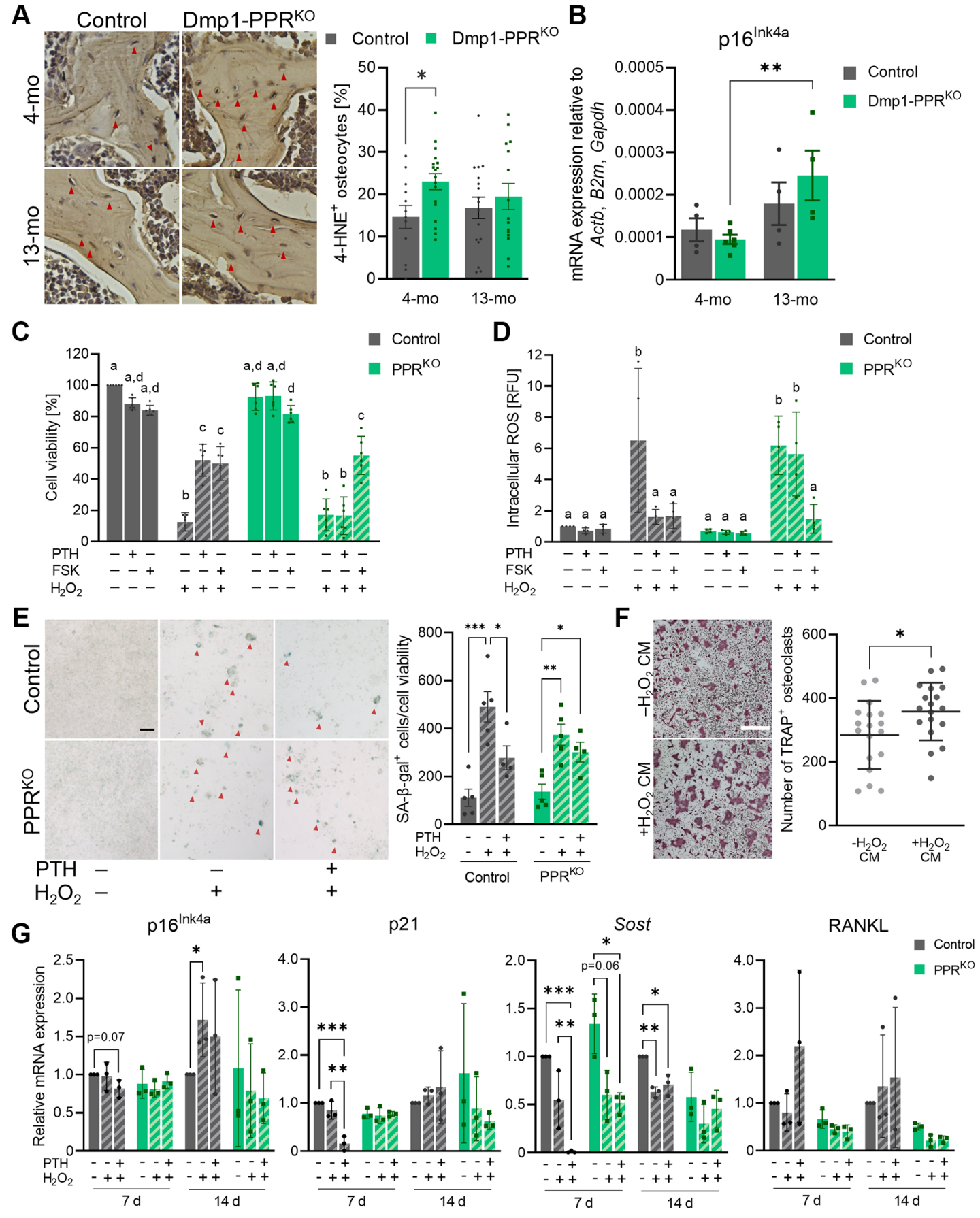

Figure 6. PTH protects osteocytes from oxidative stress-induced cell death and senescence. (A) Representative images of immunohistochemistry for 4-HNE on the L3/4 vertebrae from male animals are shown. The frequency of 4-HNE ${ }^{+}$osteocytes per image field was analyzed. Mean \pm SEM is shown. (B) Expression of p16 $6^{\text {Inka }}$ in the tibiae of male control and Dmp1-PPR ${ }^{\mathrm{KO}}$ mice was analyzed by qPCR. $N$ = 4-6 per group. Mean \pm SEM is shown. (C-E) Control and $12 \mathrm{H}-\mathrm{PPR}^{\mathrm{KO}}$ osteocytic cell line was pretreated with either $10 \mathrm{nM} \mathrm{hPTH}(1-34)$ or $10 \mu \mathrm{M}$ forskolin (FSK) for 18-22 hrs prior to $\mathrm{H}_{2} \mathrm{O}_{2}$ exposure. (C) After $\mathrm{H}_{2} \mathrm{O}_{2}$ exposure ( $1 \mathrm{mM}$, overnight), cell viability was measured by resazurin-based assays. (D) After $\mathrm{H}_{2} \mathrm{O}_{2}$ exposure $(1 \mathrm{mM}, 4 \mathrm{~h}$ ) intracellular ROS levels were measured using a fluorescent probe (DCFDA). Data are presented as relative fluorescence unit (RFU). (E) After continuous exposure to $\mathrm{H}_{2} \mathrm{O}_{2}(150 \mu \mathrm{M}, 14 \mathrm{~d})$, cells were stained for SA $\beta$ gal. Representative SA $\beta$-gal staining images and the quantification of SA $\beta$-gal ${ }^{+}$cells (red arrowheads) are shown. Bar $=100 \mu \mathrm{m}$. $(\mathbf{F}$ ) Representative TRAP staining images are shown of BMMCs isolated from 3-4-month-old male control mice under osteoclastic differentiation in the presence of conditioned medium from $\mathrm{H}_{2} \mathrm{O}_{2}$-treated control osteocytic cell line $\left(-\mathrm{H}_{2} \mathrm{O}_{2}\right.$ or $+\mathrm{H}_{2} \mathrm{O}_{2}, 150 \mu \mathrm{M}$ for 7 days). Bar $=400 \mu \mathrm{m} . N=18$ per group. (G) After continuous exposure to $\mathrm{H}_{2} \mathrm{O}_{2}$ (100 or $150 \mu \mathrm{M}, 7$ or $14 \mathrm{~d}$ ), cells were harvested for RNA isolation. mRNA expression of p16 ${ }^{\ln 4 a}$, p21, Sost, and RANKL were analyzed by qPCR. $N=3$ per group. Kruskal-Wallis test with Dunn's post hoc test, two-way ANOVA with Tukey's post hoc test, one-way ANOVA with Sidak's post hoc test or Mann-Whitney test were performed. ${ }^{*} p<0.05$, ${ }^{* *} p<0.01,{ }^{* * *} p<0.001$. Same letter indicates n.s. Data are presented as mean \pm SD. 
RANKL/OPG expression (Supplementary Figure 7C), which is similar to the phenotype present in 3-monthold Dmp1-PPR ${ }^{\mathrm{KO}}$ animals [22], whereas Sost expression was unchanged compared to control cells. $12 \mathrm{H}-\mathrm{PPR}^{\mathrm{KO}}$ cells were treated with $\mathrm{hPTH}(1-34)$ or forskolin for 18$22 \mathrm{hrs}$ and then exposed to a high dose of $\mathrm{H}_{2} \mathrm{O}_{2}(1 \mathrm{mM})$. As shown in Figure $6 \mathrm{C}-6 \mathrm{D}$, PTH treatment significantly suppressed oxidative stress-induced cell death and intracellular accumulation of ROS in control cells, whereas this effect was lost in $12 \mathrm{H}-\mathrm{PPR}^{\mathrm{KO}}$ cells, demonstrating that PTH protects osteocytes from oxidative stress-induced cell death.

\section{PTH protects osteocytes from oxidative stress}

ROS accumulation promotes oxidative stress and cellular senescence, therefore we evaluated the effects of PTH during oxidative stress. Control and $12 \mathrm{H}-\mathrm{PPR}^{\mathrm{KO}}$ cells were pretreated with $\mathrm{hPTH}(1-34)$ prior to 7 and 14 days of continuous exposure to a low dose of $\mathrm{H}_{2} \mathrm{O}_{2}(150$ $\mu \mathrm{M})$. In the non-pretreated groups, $\mathrm{H}_{2} \mathrm{O}_{2}$ exposure markedly increased the number of senescenceassociated $\beta$-galactosidase-positive (SA $\beta$-gal ${ }^{+}$) cells in both control and $12 \mathrm{H}-\mathrm{PPR}^{\mathrm{KO}}$ cells, while PTHpretreatment significantly reduced the number of SA $\beta$ $\mathrm{gal}^{+}$cells in control, but not in $12 \mathrm{H}-\mathrm{PPR}^{\mathrm{KO}}$ cells (Figure 6E, Supplementary Figure 8A). Gene expression in these cells after 7 and 14 days of $\mathrm{H}_{2} \mathrm{O}_{2}(100-200 \mu \mathrm{M})$ exposure (Figure 6G) demonstrated that PTH had a long-lasting effect on Sost and RANKL expression. Importantly, pretreatment of control, but not $12 \mathrm{H}-$ $\mathrm{PPR}^{\mathrm{KO}}$, cells with $\mathrm{PTH}$ significantly suppressed $\mathrm{p} 21$ expression at day 7 , demonstrating a potential molecular mechanism by which PTH protects osteocytes from oxidative stress-induced senescence. Expression of $\mathrm{p} 16^{\text {Ink4a }}$ was significantly upregulated in control cells exposed to $\mathrm{H}_{2} \mathrm{O}_{2}$ alone (-PTH) at day 14 (Figure 6G).

Next we assessed whether factors secreted by osteocytes under oxidative stress promote osteoclastogenesis. Conditioned medium (CM) from cells treated with $\mathrm{H}_{2} \mathrm{O}_{2}\left(+\mathrm{H}_{2} \mathrm{O}_{2} \mathrm{CM}, 7\right.$ days) (both without PTH pretreatment) was used to treat BMMCs. The BMMCs treated with $+\mathrm{H}_{2} \mathrm{O}_{2} \mathrm{CM}$ increased osteoclast numbers compared to $\mathrm{CM}$ control $\left(-\mathrm{H}_{2} \mathrm{O}_{2}\right.$ $\mathrm{CM}$ ) (Figure $6 \mathrm{~F}$ ), demonstrating that, under oxidative stress, osteocytes secrete osteoclastogenic factors, which might contribute to the increased osteoclasts in Dmp1-PPR ${ }^{\mathrm{KO}}$ mice. Treatment with $\mathrm{H}_{2} \mathrm{O}_{2}$ medium alone did not increase osteoclast numbers compared to CM control (data not shown).

Interestingly, when $12 \mathrm{H}-\mathrm{PPR}^{\mathrm{KO}}$ cells were pre-treated with PTH and then exposed to $\gamma$-irradiation (5 Gy) or busulfan (50 $\mu \mathrm{M}, 7$ days), an alkylating agent [34], PTH had no effect (Supplementary Figure 8B).
Taken together these results demonstrate that, in the absence of PPR signaling in mature osteoblasts/osteocytes, there is an age-dependent trabecular bone loss associated with increased bone resorption driven by a significant increase in osteoclast numbers and activity and impaired bone formation. Mechanistically, PPR signaling in mature osteoblasts/osteocytes regulates osteoblast formation through serum sclerostin and osteoclastogenesis via secreted factors other than RANKL and OPG. At the molecular level, PPR signaling protects, in vitro, osteocytes from oxidative stress-induced cell death through a cAMP-mediated mechanism. Further studies will be needed to elucidate the downstream effectors.

\section{DISCUSSION}

Over the last two decades, the actions of PTH have expanded to include important effects on skeletal homeostasis and hematopoiesis. In particular, the amino-terminal fragment of PTH and PTHrP were approved by FDA as therapeutic agents capable of restoring bone mass and increasing the number of hematopoietic stem cells $[1,35,36]$. It has been shown that the anabolic effects of PTH in bone comprise the recruitment of osteoblast progenitors, the suppression of osteoblasts and osteocytes apoptosis, the suppression of Sost/sclerostin expression and the activation of bone lining cells. Although the cellular targets of these actions are still not completely understood, the use of genetically manipulated animals has shed light on some of the hormonal actions. Using transgenic mice in which the PTH receptor is ablated predominantly in mature osteoblasts and osteocytes, we have demonstrated that receptor expression in these cells was required for bone modeling and remodeling and for a full anabolic and catabolic response to PTH administration [22].

Here we report that, with aging, Dmp1-PPR ${ }^{\mathrm{KO}}$ mice develop a significant osteopenia characterized by reduced trabecular bone, whereas the cortical compartment is relatively unaffected. The bone loss is driven by an increase in the number of osteoclasts, their surface area and activity and a concomitant reduction in osteoblast activity (Figure 7). In contrast, at 4 months of age, and as previously reported for 3-month-old animals [22], Dmp1-PPR ${ }^{\mathrm{KO}}$ mice have increased trabecular bone associated with reduced osteoclast and osteoblast functions. These findings demonstrate that PPR signaling in osteocytes exerts different effects on trabecular and cortical bone and that these effects are age dependent and shift, with age, from maintenance of bone homeostasis to prevention of bone loss. Interestingly, recent transcriptomic profiles of skeletal tissue in male and female mice over their lifespan 
identified Pthlr as one of the genes highly dependent on both gender and age [37]. We identify a notably sexdependent difference in our study (8.67-fold-increase of RANKL in male vs. female at 13-month-old, $p<0.001$ ) that can be explained in light on the Pthlr differential expression (1.72-fold-increase in male vs. female at 13month-old, $p=0.07)$.

Considering the classical role of PTH in calcium homeostasis, we investigated whether PPR signaling in mature osteoblasts/osteocytes is required in maintaining mineral ion homeostasis. There was a significant agerelated decrease in serum calcium and increase in serum PTH in both genotypes. Notably, 13-month-old Dmp1$\mathrm{PPR}^{\mathrm{KO}}$ male mice had a higher serum PTH level than littermate controls, whereas no difference was found between female Dmp1-PPR ${ }^{\mathrm{KO}}$ mice and controls. The significant increase in serum $\mathrm{PTH}$ in Dmp1-PPR ${ }^{\mathrm{KO}}$

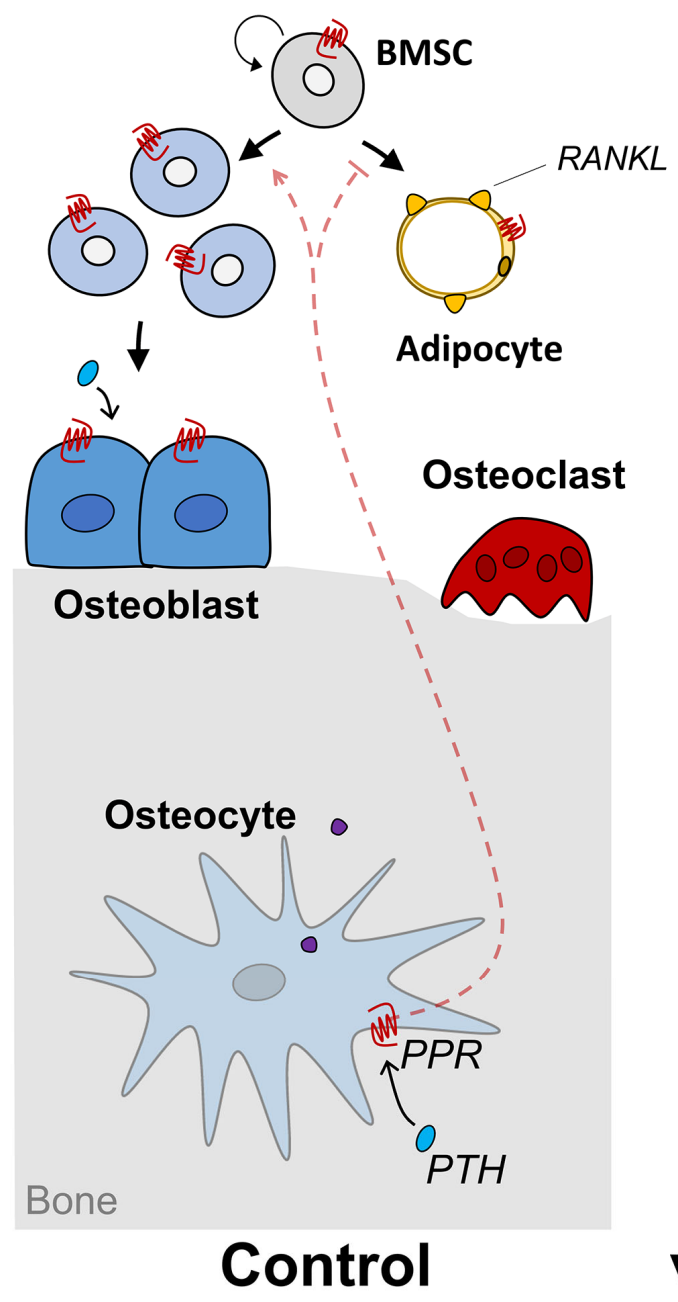

males could be due to an age-dependent resistance to PTH. Elevated serum PTH levels might be indicative of a secondary hyperparathyroidism-like state, which may contribute to the accelerated bone loss in Dmp1-PPR ${ }^{\mathrm{KO}}$ mice. Despite the elevated serum PTH, osteoblasts were not increased, most likely due to the concomitant increase in serum sclerostin. In addition, in the Dmp1$\mathrm{PPR}^{\mathrm{KO}}$ mice, there is an age-dependent exhaustion of osteoprogenitor cells, as supported by a reduction in CFU-Ob. Phosphate levels were also increased in male Dmp1-PPR ${ }^{\mathrm{KO}}$ mice with age, whereas were unchanged in the control mice. Since PTH increases FGF23 in osteocytes [38], Dmp1-PPR ${ }^{\mathrm{KO}}$ mice might have a lower FGF23 secretion than control littermates, which can lead to reduced phosphate excretion in the kidneys.

To delineate the molecular mechanisms by which Dmp1-PPR ${ }^{\mathrm{KO}}$ animals display severe bone loss with

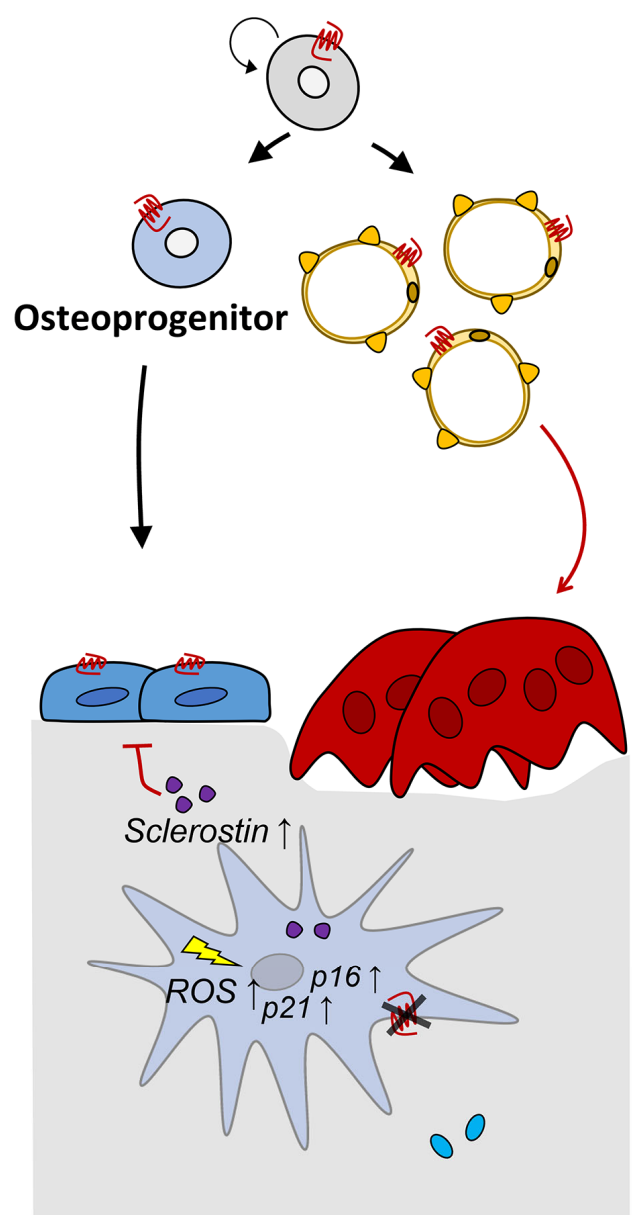

Dmp1-PPR ${ }^{K O}$

Figure 7. Graphical summary. 13-month-old Dmp1-PPR ${ }^{\mathrm{KO}}$ mice showed trabecular bone loss driven by increased osteoclast number and activity and reduced osteoblast function. Mechanistically, the lack of PPR signaling in mature osteoblasts/osteocytes decreases osteoprogenitors and increases serum sclerostin, RANKL-expressing marrow adipocytes and early onset of 4-HNE+ osteocytes and p16 Ink4a upregulation in KO mice. Circulating factor(s) from these mutant mice increases, directly or indirectly, osteoclastogenic and adipogenic differentiation of BMMCs and BMSCs, respectively. Furthermore, in vitro data showed that PPR signaling induces long-lasting suppression of p21 and protects osteocytes from oxidative stress-induced intracellular ROS accumulation, cell death and senescence. 
age, we analyzed the expression of osteocytic markers. Despite the important role of osteocytes in regulation of both osteoblasts and osteoclasts, expression of Sost, RANKL, and OPG was similar between middle-aged male Dmp1-PPR ${ }^{\mathrm{KO}}$ and littermate controls. Contrarily, in 13-month-old Dmp1-PPR ${ }^{\mathrm{KO}}$ females, OPG and RANKL/OPG expression were significantly suppressed and increased, respectively, as compared to littermate controls. In male mice, Sost and RANKL expression at 4 months of age was unchanged between genotypes, whereas we previously reported an increase and decrease in Sost and RANKL expression, respectively, in $\mathrm{KO}$ animals at 3 months of age [22]. At the moment we do not have any explanation for this age-dependent difference and further studies will be needed.

RANKL, OPG, and RANKL/OPG expression were unchanged in the long bones of male mice, suggesting that additional cytokines might be involved in the increase in osteoclast numbers and activity. Serum $\mathrm{TNF} \alpha$ levels were unchanged between control and mutant mice at 13 months of age, and $\mathrm{TNF} \alpha$ expression in osteocytes, as assessed by immunofluorescence, was decreased in long bones of mutant mice compared to controls, indicating that additional factors might be involved. Bone marrow adipocytes are responsive to PTH and are a local source of RANKL; therefore we investigated if increased osteoclast activity in Dmp1-PPR ${ }^{\mathrm{KO}}$ mice was dependent on these cells. Indeed, we found that, with aging, there was a significant increase in RANKL+ adipocyte in the bone marrow of mutant mice, as compared to controls. Treatment of BMMCs with serum of Dmp1-PPR ${ }^{\mathrm{KO}}$ mice induced a significant increase in osteoclasts as compared to controls, demonstrating the presence of osteoclastogenic factors in the serum of mutant mice. We previously identified osteocyte-derived molecules that modulate osteoclast numbers and activities, such as Nrp1, Sema3a, and Sema3d [39]. RNA-sequencing of osteocytes [40] demonstrated that PTH significantly increased the expression of Nrp1 (2.52-fold increase, $p<0.001$ ) in these cells, suggesting a possible mechanism of action.

Serum CTX is often used as a marker of bone resorption and, despite the severe bone loss and the significant increase in osteoclasts, we did not detect any significant changes in serum CTX in Dmp1-PPR ${ }^{\mathrm{KO}}$ mice, compared to controls. It has been reported that systemic CTX levels vary according to circadian rhythm and that food intake reduces the levels of CTX in humans [41, 42]. Moreover, CTX measurements can be affected by lipids and proteins present in the serum after food intake. Since mice were not starved before serum collection, it is possible that the levels of CTX measured were not accurate.
PTH reduces the rate of both osteoblast and osteocyte apoptosis, which releases factors capable of promoting osteoclastogenesis [43-45]. We investigated whether the osteopenia present in the Dmp1-PPR ${ }^{\mathrm{KO}}$ animals at 13 months old was due to increased osteocyte apoptosis. Terminal deoxynucleotidyl transferase deoxyuridine triphosphate nick-end labeling (TUNEL) assay showed no difference in osteocyte apoptosis in both controls and Dmp1-PPR ${ }^{\mathrm{KO}}$ mice, both in males and females (Supplementary Figure 2C, 2D), suggesting that mechanisms other than osteocyte apoptosis are responsible for the osteopenia.

We demonstrated that 13-month-old Dmp1-PPR ${ }^{\mathrm{KO}}$ mice have reduced $\mathrm{CFU}-\mathrm{Ob}$ and increased marrow adiposity compared to controls, suggesting that the stem cell population might be depleted. Similarly, we observed the reduced expression of PPR in bone marrow cells in Dmp1-PPR ${ }^{\mathrm{KO}}$ male mice, but not in females (Supplementary Figure 6A, 6C). Treatment of BMSCs with serum from Dmp1-PPR ${ }^{\mathrm{KO}}$ mice induced adipogenic differentiation but had no effect on osteoblastic differentiation. It has been reported that ceruloplasmin ( $\mathrm{Cp}$ ), a multicopper ferroxidase (also known as an adipokine), increases adipogenic differentiation of MC3T3 cells [46]. Cp is also the one of the osteocyte-secreted proteins that we identified previously [39] and PTH has been reported to reduce mRNA expression of $\mathrm{Cp}$ in osteocytes [40], indicating the possible involvement of $\mathrm{Cp}$ in the increase in marrow adiposity in $\mathrm{KO}$ mice. We also observed a trend of increase in Sost expression in long bone of 13month-old Dmp1-PPR ${ }^{\mathrm{KO}}$ male mice compared to controls and a significant increase in serum sclerostin. We can speculate that sclerostin may contribute to the reduction in osteoblast proliferation, possibly in favor of marrow adipocytes, by suppressing the $\mathrm{Wnt} / \beta$-catenin signaling pathway. Indeed, it has also been reported that sclerostin reduces proliferation and differentiation of BMSC, in part by suppressing bone morphogenetic protein activity and by increasing bone marrow adipose tissue (BMAT) [19, 47]. Further studies will be needed to identify the molecular mechanism(s) by which osteocytes affect the BMSCs.

Aging is characterized by reduced skeletal mass and increased oxidative stress and recent studies identified senescence and senescent osteocytes as important players in age-dependent bone loss $[32,48]$. The aging process comprises not only cellular dysfunction and genomic instability but also stem cell exhaustion. Several studies have demonstrated that the decline in bone formation that occurs with age, both in humans and animal models, is invariably associated with reduced proliferation and differentiation of mesenchymal stem cells. Here we report that the 
absence of PPR expression in mature osteoblasts/osteocytes in mice induces a significant increase in the number of $4-\mathrm{HNE}^{+}$osteocytes in 4month-old mutant mice compared to control littermates and a marked increase in $\mathrm{p} 16^{\text {Ink4a }}$ expression at 13 months of age. These findings suggest that PTH protects osteocytes from early onset of oxidative-stress. Further studies are needed to unveil the underlying molecular mechanism.

Our in vitro study showed PTH protects osteocytes from oxidative stress-induced cell death and intracellular accumulation of ROS in a cyclic AMP-dependent manner. These results suggest that signaling through PPR, which is expressed on these cells and some mature osteoblasts, is needed to protect osteocytes from oxidative stress and possibly cellular senescence. One mechanism by which Dmp1-PPR ${ }^{\mathrm{KO}}$ animals become severely osteopenic is by increased production of ROS, due to reduced activities of antioxidants during aging [29]. Indeed, the role of ROS and PTH in osteoblastic cells has been documented by the work of Jilka et al. [45], demonstrating that intermittent PTH administration reduces intracellular $\operatorname{ROS}$ and $\mathrm{p} 66^{\text {shc }}$ phosphorylation.

Autophagy has also recently been shown to play an important role in aging and senescence. To investigate a possible relationship between PPR signaling in osteocytes and autophagy, we analyzed expression of transcripts known to regulate autophagy, such as Sirt-1, FOXO-1 and Beclin-1. However, we found no changes in expression of these genes in our mutant mice (Supplementary Figure 4B).

It has been previously reported that, similar to $\mathrm{PTH}$, PTHrP protects osteoblastic cells from oxidative stress. Ardura et al. reported that PTHrP counteracts the proapoptotic actions of ROS by modulating mitogenactivated protein kinases (MAPK) phosphatase 1 (MAPK1) and promoting dephosphorylation of MAPK [49]. Mice with the "knock-in" (KI) of the 1-84 fragment of PTHrP, which lacks both the nuclear localization sequence (NLS) and the C-terminus, display early senescence and defective osteoblast functions. In these animals, ROS levels are increased and antioxidant enzymes are downregulated, demonstrating a role for PTHrP in prevention of oxidative stress [50-52]. Since PTH and PTHrP both bind to and activate the PPR, it is plausible to hypothesize that they might exert similar effects. Additional studies will be needed to analyze PTH and PTHrP responses. Interestingly, PTHrP mRNA expression in long bone of control and Dmp1-PPR ${ }^{\mathrm{KO}}$ mice was similar, therefore we can speculate that this effect was not dependent on PTHrP.
In summary, we have reported, for the first time, that PPR signaling in mature osteoblasts/osteocytes is needed to protect the skeleton from age-dependent bone loss. In Dmp1-PPR ${ }^{\mathrm{KO}}$ mice, there is a striking agedependent trabecular bone loss driven by increased osteoclast number and activity and reduced osteoblast function. Mechanistically, we demonstrated that lack of PPR signaling decreases osteoprogenitors while increasing serum sclerostin, RANKL-expressing marrow adipocytes and $4-\mathrm{HNE}^{+}$osteocytes. Moreover, there was an age-dependent upregulation of $\mathrm{p} 16^{\mathrm{Ink} 4 \mathrm{a}}$ in $\mathrm{KO}$ mice. We also found that circulating factor(s) from these mutant mice increases, directly or indirectly, osteoclastogenic and adipogenic differentiation of BMMCs and BMSCs, respectively. Furthermore, in vitro data showed that PPR signaling induces longlasting suppression of Sost and p21 and protects osteocytes from oxidative stress-induced intracellular ROS accumulation, cell death and possibly senescence (Figure 7).

\section{MATERIALS AND METHODS}

\section{Mice}

Dmp1-PPR ${ }^{\mathrm{KO}}$ (Dmp1-Cre ${ }^{+} ; \mathrm{PPR}^{\mathrm{fl} / \mathrm{fl})}$ mice under the C57BL/6 genetic background were generated as described previously [22]. Littermates homozygous for floxed PPR gene, but lacking Cre-recombinase expression, were used as control (Dmp1-Cre ${ }^{-} ; \mathrm{PPR}^{\mathrm{fl} / \mathrm{fl}}$ ). Details are provided in Supplementary Methods. Institutional Animal Care and Use Committee and the Subcommittee on Research Animal Care at Massachusetts General Hospital and Boston University Medical Center approved all animal protocols.

\section{Cell lines}

Ocy454-12H (or 12H) cells, a derivative of the conditionally immortalized osteocytic cell line Ocy454, were used for all the in vitro experiments [33, 53, 54]. CRISPR/Cas9 genome editing technique was used to knockout PPR expression in these cells $(12 \mathrm{H}-$ $\left.\mathrm{PPR}^{\mathrm{KO}}\right)$. Both control and $12 \mathrm{H}-\mathrm{PPR}^{\mathrm{KO}}$ cells were routinely maintained at $33^{\circ} \mathrm{C}$ (permissive temperature) with $5 \% \quad \mathrm{CO}_{2}$ and cultured in growth medium $(\alpha$ minimum essential medium (Gibco, Thermo Fisher Scientific) containing $10 \%$ heat-inactivated fetal bovine serum (Gibco) and 1\% antibiotic-antimycotic (Gibco)). Upon proliferation, cells were transferred to $37^{\circ} \mathrm{C}$ with $5 \% \quad \mathrm{CO}_{2}$ to be fully differentiated into mature osteocytes and incubated for the number of days required for each experiment. Fresh growth medium was added every 3-4 days. Details are provided in Supplementary Methods. 


\section{Immunofluorescent staining}

Immunofluorescent staining for RANKL and perilipin-1 was performed on paraffin sections of the left tibiae from middle-aged (13 months old) male mice. See Supplementary Methods for details. The following antibodies were used: anti-mouse perilipin-1 (\#9349, Cell Signaling Technology, Danvers, MA, USA) (1:100), anti-mouse RANKL (\#sc-7628, Santa Cruz Biotechnology, Dallas, TX, USA) (1:50), Alexa flour 546 donkey anti-rabbit IgG (\#A10040, Invitrogen, Carlsbad, CA, USA) (1:100) and Alexa flour 488 donkey anti-goat IgG (\#A11055, Invitrogen) (1:100).

\section{Senescence-associated $\beta$-gal staining}

Cells were plated at a density of $1.0 \times 10^{5}$ cells $/ \mathrm{ml}$ in growth medium on a 6 - or 12 -well plate $\left(\right.$ Biolite $^{\mathrm{TM}}$ ) under $37^{\circ} \mathrm{C}$ with $5 \% \mathrm{CO}_{2}$ followed by treatment, on the next day, with $10 \mathrm{nM} \mathrm{hPTH}(1-34)$ for 18-22 hrs. Cells were then exposed to oxidative stress by adding an equal volume of $300 \mu \mathrm{M} \mathrm{H} \mathrm{H}_{2} \mathrm{O}_{2}$ medium (final concentration: $150 \mu \mathrm{M}$ ) on top of the well and cultured for an additional 7 or 14 days. Medium was replaced once on day 7. On day 7 and 14, conditioned medium was collected and the cells were either harvested for RNA isolation or fixed with $4 \%$ paraformaldehyde (Acros Organics, Fair Lawn, NJ, USA) in PBS for 15 min at room temperature for SA $\beta$-gal staining. Cells were then washed with PBS and incubated with SA $\beta$ gal staining solution (pH 6.0) overnight at $37^{\circ} \mathrm{C}$ without $\mathrm{CO}_{2}$ injection. The SA $\beta$-gal staining solution was prepared by following the protocol from Chen et al. [55]. Cell viability was measured using PrestoBlue cell viability reagent (Invitrogen) as per manufacturer's instruction. Bright field images were acquired under the microscope with a $4 \mathrm{X}$ objective (Keyence). The number of SA $\beta$-gal positive osteocytes was counted in a blinded fashion using ImageJ.

\section{Oxidative stress-induced cell death and reactive oxygen species accumulation}

Cells were plated at a density of $2.6 \times 10^{4} \mathrm{cells} / \mathrm{cm}^{2}$ in growth medium on a 24-well plate and grown for 3 days at $33^{\circ} \mathrm{C}$. The growth medium was replaced and the cells were cultured for an additional 2 days under $37^{\circ} \mathrm{C}$ and treated with either $10 \mathrm{nM} \mathrm{hPTH}(1-34)$ or $10 \mu \mathrm{M}$ forskolin for 18-22 hrs followed by an exposure to 1 $\mathrm{mM} \mathrm{H}_{2} \mathrm{O}_{2}$ for $4 \mathrm{hrs}$ or overnight. Cell viability was measured using PrestoBlue cell viability reagent as per manufacturer's instruction. Intracellular levels of ROS were determined upon cell staining with $14 \mu \mathrm{M}$ of $2^{\prime}$, 7'-dichlorofluorescin diacetate (DCFDA) (Sigma) for $30 \mathrm{~min}$ at $37^{\circ} \mathrm{C}$ with $5 \% \mathrm{CO}_{2}$. The cells were then trypsinized and transferred into wells of a 96-well plate and fluorescence (485 nm excitation and $535 \mathrm{~nm}$ emission) was measured using a spectrophotometer (TriStar LB941, Berthold Technologies, Oak Ridge, TN, USA). The fluorescent intensity was normalized with cell viability.

\section{Statistics}

Normal distribution and heteroscedasticity of the data was tested using D'Agostino-Pearson or AndersonDarling test and Spearman's test, respectively. Equality of variance between two datasets was analyzed with the F test. Parametrical statistics were used for the data that follow normal distribution and/or equal variance. Otherwise, non-parametrical statistics were used. Statistical significance was defined as $p$ values less than 0.05 (two-tailed). Statistical test used for each analysis is described in the legends of each figure. All statistical analysis was performed on GraphPad Prism (GraphPad Software, San Diego, CA, USA).

\section{AUTHOR CONTRIBUTIONS}

PDP, YU and VS designed and performed the research. JMS, CS and CAP generated Ocy454, Ocy454-12H and Ocy454-12H-PPR ${ }^{\mathrm{KO}}$ osteocytic cell line, respectively. CS conducted analysis of osteoprogenitors in vitro. CAP, MA and RS performed characterization of Ocy454-12H-PPR ${ }^{\mathrm{KO}}$ cells and in vitro senescence experiments. $\mathrm{CMN}, \mathrm{TYH}, \mathrm{AK}, \mathrm{JWK}$ and $\mathrm{CKC}$ conducted image analysis and real-time qPCR analysis on in vitro samples. JWK analyzed IHC staining for $\mathrm{TNF} \alpha$ and 4-HNE on vertebrae. HS, KDH and EH performed the micro-CT analysis. YU, VS and PDP wrote the manuscript.

\section{ACKNOWLEDGMENTS}

The authors would like to thank Katharina Jähn, Saman F. Khaled, Cordula Erdmann, Jenna L. Garr, Vladimir Zoubine, Rahul Sompuram, Margaret M. Kobelski, Keertik S. Fulzele, Xiaolong Liu, Christopher G. Dedic, Forest Lai and William Doyle for their technical help.

\section{CONFLICTS OF INTEREST}

The authors declare no conflicts of interest related to this study.

\section{FUNDING}

Research reported in this publication was supported by the National Institute of Diabetes and Digestive and Kidney Diseases and the National Institute of Arthritis, Musculoskeletal and Skin Disease, both part of the National Institutes of Health (DK079161, AR060221 
and AR059655) to PDP; by the Center for Skeletal Research Core (P30 AR066261) to PDP; by an Interim Support Grant from the Executive Committee of Research (ECOR), MGH to PDP; by the Deutsche Forschungsgemeinschaft grant HE 5208/2-1 to EH; and by a postdoctoral fellowship of the Japanese Society for the promotion of Science to HS.

\section{REFERENCES}

1. Finkelstein JS, Klibanski A, Schaefer EH, Hornstein MD, Schiff I, Neer RM. Parathyroid hormone for the prevention of bone loss induced by estrogen deficiency. N Engl J Med. 1994; 331:1618-23. https://doi.org/10.1056/NEJM199412153312404 PMID:

2. Riancho JA, Hernández JL. Pharmacogenomics of osteoporosis: a pathway approach. Pharmacogenomics. 2012; 13:815-29.

https://doi.org/10.2217/pgs.12.50 PMID:22594513

3. Jüppner $H$, Abou-Samra $A B$, Freeman $M$, Kong $X F$, Schipani E, Richards J, Kolakowski LF Jr, Hock J, Potts JT Jr, Kronenberg HM, Segre GV. A G protein-linked receptor for parathyroid hormone and parathyroid hormone-related peptide. Science. 1991; 254:1024-6. https://doi.org/10.1126/science.1658941 PMID:1658941

4. Knothe Tate ML, Adamson JR, Tami AE, Bauer TW. The osteocyte. Int J Biochem Cell Biol. 2004; 36:1-8. https://doi.org/10.1016/s1357-2725(03)00241-3 PMID:14592527

5. Noble BS. The osteocyte lineage. Arch Biochem Biophys. 2008; 473:106-11.

https://doi.org/10.1016/j.abb.2008.04.009 PMID:18424256

6. Bonewald LF. The amazing osteocyte. J Bone Miner Res. 2011; 26:229-38.

https://doi.org/10.1002/jbmr.320 PMID:21254230

7. Agholme F, Isaksson H, Li X, Ke HZ, Aspenberg P. Antisclerostin antibody and mechanical loading appear to influence metaphyseal bone independently in rats. Acta Orthop. 2011; 82:628-32.

https://doi.org/10.3109/17453674.2011.625539 PMID:22103277

8. Asada N, Katayama $Y$, Sato M, Minagawa K, Wakahashi K, Kawano H, Kawano Y, Sada A, Ikeda K, Matsui T, Tanimoto M. Matrix-embedded osteocytes regulate mobilization of hematopoietic stem/progenitor cells. Cell Stem Cell. 2013; 12:737-47. https://doi.org/10.1016/i.stem.2013.05.001 PMID:23746979
9. Divieti P. Regulation of Bone Resorption and Mineral Homeostasis by Osteocytes. IBMS BoneKey. 2009; 6:63-70. https://doi.org/10.1138/20090363

10. Fulzele K, Krause DS, Panaroni C, Saini V, Barry KJ, Liu $\mathrm{X}$, Lotinun S, Baron R, Bonewald L, Feng JQ, Chen M, Weinstein LS, Wu JY, et al. Myelopoiesis is regulated by osteocytes through Gs $\alpha$-dependent signaling. Blood. 2013; 121:930-9. https://doi.org/10.1182/blood-2012-06-437160 PMID:23160461

11. Liu S, Zhou J, Tang W, Jiang X, Rowe DW, Quarles LD. Pathogenic role of Fgf23 in Hyp mice. Am J Physiol Endocrinol Metab. 2006; 291:E38-49. https://doi.org/10.1152/ajpendo.00008.2006 PMID:16449303

12. Manolagas SC. Choreography from the Tomb: An Emerging Role of Dying Osteocytes in the Purposeful, and Perhaps Not So Purposeful, Targeting of Bone Remodeling. International Bone and Mineral Society Knowledge Environment. 2006; 3:5-14. https://doi.org/10.1138/20060193

13. Tatsumi S, Ishii K, Amizuka N, Li M, Kobayashi T, Kohno K, Ito M, Takeshita S, Ikeda K. Targeted ablation of osteocytes induces osteoporosis with defective mechanotransduction. Cell Metab. 2007; 5:464-75.

https://doi.org/10.1016/j.cmet.2007.05.001 PMID: $\underline{17550781}$

14. Nakashima $T$, Hayashi $M$, Fukunaga $T$, Kurata $K$, OhHora M, Feng JQ, Bonewald LF, Kodama T, Wutz A, Wagner EF, Penninger JM, Takayanagi $\mathrm{H}$. Evidence for osteocyte regulation of bone homeostasis through RANKL expression. Nat Med. 2011; 17:1231-4.

https://doi.org/10.1038/nm.2452 PMID:21909105

15. Xiong J, Onal M, Jilka RL, Weinstein RS, Manolagas SC, O'Brien CA. Matrix-embedded cells control osteoclast formation. Nat Med. 2011; 17:1235-41. https://doi.org/10.1038/nm.2448 PMID:21909103

16. Qing H, Ardeshirpour L, Pajevic PD, Dusevich V, Jähn K, Kato S, Wysolmerski J, Bonewald LF. Demonstration of osteocytic perilacunar/canalicular remodeling in mice during lactation. J Bone Miner Res. 2012; 27:1018-29. https://doi.org/10.1002/jbmr.1567 PMID:22308018

17. Hamersma H, Gardner J, Beighton P. The natural history of sclerosteosis. Clin Genet. 2003; 63:192-7. https://doi.org/10.1034/j.1399-0004.2003.00036.x PMID: 12694228 
18. Keller $\mathrm{H}$, Kneissel M. SOST is a target gene for PTH in bone. Bone. 2005; 37:148-58.

https://doi.org/10.1016/j.bone.2005.03.018 PMID: 15946907

19. Winkler DG, Sutherland MK, Geoghegan JC, Yu C, Hayes T, Skonier JE, Shpektor D, Jonas M, Kovacevich BR, Staehling-Hampton K, Appleby M, Brunkow ME, Latham JA. Osteocyte control of bone formation via sclerostin, a novel BMP antagonist. EMBO J. 2003; 22:6267-76.

https://doi.org/10.1093/emboj/cdg599

PMID: 14633986

20. O'Brien CA, Plotkin LI, Galli C, Goellner JJ, Gortazar $A R$, Allen MR, Robling AG, Bouxsein M, Schipani $E$, Turner $\mathrm{CH}$, Jilka RL, Weinstein RS, Manolagas SC, Bellido T. Control of bone mass and remodeling by PTH receptor signaling in osteocytes. PLoS One. 2008; 3:e2942.

https://doi.org/10.1371/journal.pone.0002942 PMID: 18698360

21. Delgado-Calle J, Tu X, Pacheco-Costa R, McAndrews K, Edwards R, Pellegrini GG, Kuhlenschmidt K, Olivos N, Robling A, Peacock M, Plotkin LI, Bellido T. Control of Bone Anabolism in Response to Mechanical Loading and PTH by Distinct Mechanisms Downstream of the PTH Receptor. J Bone Miner Res. 2017; 32:522-35.

https://doi.org/10.1002/jbmr.3011

PMID:27704638

22. Saini V, Marengi DA, Barry KJ, Fulzele KS, Heiden E, Liu X, Dedic C, Maeda A, Lotinun S, Baron R, Pajevic PD. Parathyroid hormone (PTH)/PTH-related peptide type 1 receptor (PPR) signaling in osteocytes regulates anabolic and catabolic skeletal responses to PTH. J Biol Chem. 2013; 288:20122-34.

https://doi.org/10.1074/ibc.M112.441360

PMID:23729679

23. Marahleh A, Kitaura H, Ohori F, Kishikawa A, Ogawa $S$, Shen WR, Qi J, Noguchi T, Nara Y, Mizoguchi I. TNF- $\alpha$ Directly Enhances Osteocyte RANKL Expression and Promotes Osteoclast Formation. Front Immunol. 2019; 10:2925.

https://doi.org/10.3389/fimmu.2019.02925 PMID: $\underline{31921183}$

24. Baker DA, Barth J, Chang R, Obeid LM, Gilkeson GS. Genetic sphingosine kinase 1 deficiency significantly decreases synovial inflammation and joint erosions in murine TNF-alpha-induced arthritis. J Immunol. 2010; 185:2570-9.

https://doi.org/10.4049/jimmunol.1000644

PMID:20644167

25. Xiao YT, Xiang LX, Shao JZ. Bone morphogenetic protein. Biochem Biophys Res Commun. 2007; 362:550-3. https://doi.org/10.1016/j.bbrc.2007.08.045 PMID: 17719560

26. Takeshita S, Fumoto T, Naoe Y, Ikeda K. Age-related marrow adipogenesis is linked to increased expression of RANKL. J Biol Chem. 2014; 289:16699-710.

https://doi.org/10.1074/jbc.M114.547919 PMID:24753250

27. Fan $Y$, Hanai JI, Le PT, Bi R, Maridas D, DeMambro V, Figueroa CA, Kir S, Zhou X, Mannstadt M, Baron R, Bronson RT, Horowitz MC, et al. Parathyroid Hormone Directs Bone Marrow Mesenchymal Cell Fate. Cell Metab. 2017; 25:661-72. https://doi.org/10.1016/j.cmet.2017.01.001 PMID:28162969

28. Sulston RJ, Cawthorn WP. Bone marrow adipose tissue as an endocrine organ: close to the bone? Horm Mol Biol Clin Investig. 2016; 28:21-38. https://doi.org/10.1515/hmbci-2016-0012 PMID:27149203

29. Gruber R, Koch H, Doll BA, Tegtmeier F, Einhorn TA, Hollinger JO. Fracture healing in the elderly patient. Exp Gerontol. 2006; 41:1080-93. https://doi.org/10.1016/j.exger.2006.09.008 PMID: 17092679

30. Kitase $Y$, Vallejo JA, Gutheil W, Vemula $H$, Jähn K, Yi J, Zhou J, Brotto M, Bonewald LF. $\beta$-aminoisobutyric Acid, I-BAIBA, Is a Muscle-Derived Osteocyte Survival Factor. Cell Rep. 2018; 22:1531-44.

https://doi.org/10.1016/j.celrep.2018.01.041 PMID:29425508

31. Schnoke M, Midura SB, Midura RJ. Parathyroid hormone suppresses osteoblast apoptosis by augmenting DNA repair. Bone. 2009; 45:590-602.

https://doi.org/10.1016/i.bone.2009.05.006 PMID: 19450716

32. Farr JN, Xu M, Weivoda MM, Monroe DG, Fraser DG, Onken JL, Negley BA, Sfeir JG, Ogrodnik MB, Hachfeld CM, LeBrasseur NK, Drake MT, Pignolo RJ, et al. Targeting cellular senescence prevents age-related bone loss in mice. Nat Med. 2017; 23:1072-9.

https://doi.org/10.1038/nm.4385

PMID:28825716

33. Shi C, Uda Y, Dedic C, Azab E, Sun N, Hussein Al, Petty CA, Fulzele K, Mitterberger-Vogt MC, Zwerschke W, Pereira R, Wang K, Pajevic PD. Carbonic anhydrase III protects osteocytes from oxidative stress. FASEB J. 2018; 32:440-52.

https://doi.org/10.1096/fj.201700485RR PMID:28928248

34. Probin V, Wang Y, Zhou D. Busulfan-induced senescence is dependent on ROS production 
upstream of the MAPK pathway. Free Radic Biol Med. 2007; 42:1858-65.

https://doi.org/10.1016/j.freeradbiomed.2007.03.020 PMID:17512465

35. Calvi LM, Adams GB, Weibrecht KW, Weber JM, Olson DP, Knight MC, Martin RP, Schipani E, Divieti P, Bringhurst FR, Milner LA, Kronenberg HM, Scadden DT. Osteoblastic cells regulate the haematopoietic stem cell niche. Nature. 2003; 425:841-6.

https://doi.org/10.1038/nature02040

PMID: 14574413

36. Adams GB, Martin RP, Alley IR, Chabner KT, Cohen KS, Calvi LM, Kronenberg HM, Scadden DT. Therapeutic targeting of a stem cell niche. Nat Biotechnol. 2007; 25:238-43.

https://doi.org/10.1038/nbt1281 PMID: 17237769

37. Lu D, Demissie S, Horowitz NB, Gower AC, Lenburg ME, Alekseyev YO, Hussein Al, Bragdon B, Liu Y, Daukss D, Page JM, Webster MZ, Schlezinger JJ, et al. Temporal and Quantitative Transcriptomic Differences Define Sexual Dimorphism in Murine Postnatal Bone Aging. JBMR Plus. 2021. [Epub ahead of print]. https://doi.org/10.1002/ibm4.10579

38. Silver J, Naveh-Many T. FGF-23 and secondary hyperparathyroidism in chronic kidney disease. Nat Rev Nephrol. 2013; 9:641-9.

https://doi.org/10.1038/nrneph.2013.147 PMID:23877588

39. Azab E, Chandler KB, Uda $Y$, Sun N, Hussein A, Shuwaikan R, Lu V, Costello CE, McComb ME, Divieti Pajevic P. Osteocytes control myeloid cell proliferation and differentiation through Gs $\alpha$ dependent and -independent mechanisms. FASEB J. 2020; 34:10191-211.

https://doi.org/10.1096/fj.202000366R

PMID: $\underline{32557809}$

40. Wein MN, Liang $Y$, Goransson $O$, Sundberg TB, Wang J, Williams EA, O'Meara MJ, Govea N, Beqo B, Nishimori S, Nagano K, Brooks DJ, Martins JS, et al. SIKs control osteocyte responses to parathyroid hormone. Nat Commun. 2016; 7:13176.

https://doi.org/10.1038/ncomms13176 PMID:27759007

41. Qvist P, Christgau S, Pedersen BJ, Schlemmer A, Christiansen $C$. Circadian variation in the serum concentration of C-terminal telopeptide of type I collagen (serum CTx): effects of gender, age, menopausal status, posture, daylight, serum cortisol, and fasting. Bone. 2002; 31:57-61.

https://doi.org/10.1016/s8756-3282(02)00791-3

PMID:12110413
42. Kuo TR, Chen $\mathrm{CH}$. Bone biomarker for the clinical assessment of osteoporosis: recent developments and future perspectives. Biomark Res. 2017; 5:18.

https://doi.org/10.1186/s40364-017-0097-4 PMID:28529755

43. Jilka RL, Weinstein RS, Bellido $T$, Roberson P, Parfitt AM, Manolagas SC. Increased bone formation by prevention of osteoblast apoptosis with parathyroid hormone. J Clin Invest. 1999; 104:439-46.

https://doi.org/10.1172/JCl6610

PMID:10449436

44. Jilka RL, Weinstein RS, Bellido T, Parfitt AM, Manolagas SC. Osteoblast programmed cell death (apoptosis): modulation by growth factors and cytokines. J Bone Miner Res. 1998; 13:793-802. https://doi.org/10.1359/ibmr.1998.13.5.793 PMID: 9610743

45. Jilka RL, Almeida M, Ambrogini E, Han L, Roberson PK, Weinstein RS, Manolagas SC. Decreased oxidative stress and greater bone anabolism in the aged, when compared to the young, murine skeleton with parathyroid hormone administration. Aging Cell. 2010; 9:851-67.

https://doi.org/10.1111/j.1474-9726.2010.00616.x PMID:20698835

46. Challa TD, Straub LG, Balaz M, Kiehlmann E, Donze O, Rudofsky G, Ukropec J, Ukropcova B, Wolfrum C. Regulation of De Novo Adipocyte Differentiation Through Cross Talk Between Adipocytes and Preadipocytes. Diabetes. 2015; 64:4075-87.

https://doi.org/10.2337/db14-1932

PMID:26340931

47. Holdsworth G, Roberts SJ, Ke HZ. Novel actions of sclerostin on bone. J Mol Endocrinol. 2019; 62:R167-85.

https://doi.org/10.1530/JME-18-0176

PMID:30532996

48. Kim HN, Xiong J, MacLeod RS, Iyer S, Fujiwara $Y$, Cawley KM, Han L, He Y, Thostenson JD, Ferreira E, Jilka RL, Zhou D, Almeida M, O'Brien CA. Osteocyte RANKL is required for cortical bone loss with age and is induced by senescence. JCl Insight. 2020; 5:e138815.

https://doi.org/10.1172/jci.insight.138815

PMID: $\underline{32870816}$

49. Ardura JA, Portal-Núñez S, Castelbón-Calvo I, Martínez de Toda I, De la Fuente M, Esbrit P. Parathyroid Hormone-Related Protein Protects Osteoblastic Cells From Oxidative Stress by Activation of MKP1 Phosphatase. J Cell Physiol. 2017; 232:785-96.

https://doi.org/10.1002/icp.25473

PMID:27357344 
50. Miao D, Su H, He B, Gao J, Xia Q, Zhu M, Gu Z, Goltzman D, Karaplis AC. Severe growth retardation and early lethality in mice lacking the nuclear localization sequence and C-terminus of PTHrelated protein. Proc Natl Acad Sci U S A. 2008; 105:20309-14.

https://doi.org/10.1073/pnas.0805690105

PMID:19091948

51. Zhu M, Zhang J, Dong Z, Zhang Y, Wang R, Karaplis A, Goltzman D, Miao D. The p27 Pathway Modulates the Regulation of Skeletal Growth and Osteoblastic Bone Formation by Parathyroid Hormone-Related Peptide. J Bone Miner Res. 2015; 30:1969-79. https://doi.org/10.1002/jbmr.2544 PMID:25917430

52. Zhang $Y$, Chen G, Gu Z, Sun H, Karaplis A, Goltzman D, Miao D. DNA damage checkpoint pathway modulates the regulation of skeletal growth and osteoblastic bone formation by parathyroid hormone-related peptide. Int J Biol Sci. 2018; 14:508-17.

https://doi.org/10.7150/ijbs.23318

PMID:29805302
53. Spatz JM, Wein MN, Gooi JH, Qu Y, Garr JL, Liu S, Barry KJ, Uda Y, Lai F, Dedic C, Balcells-Camps M, Kronenberg HM, Babij P, Pajevic PD. The Wnt Inhibitor Sclerostin Is Up-regulated by Mechanical Unloading in Osteocytes in Vitro. J Biol Chem. 2015; 290:16744-58.

https://doi.org/10.1074/jbc.M114.628313

PMID:25953900

54. Wein MN, Spatz J, Nishimori S, Doench J, Root D, Babij P, Nagano K, Baron R, Brooks D, Bouxsein M, Pajevic PD, Kronenberg HM. HDAC5 controls MEF2Cdriven sclerostin expression in osteocytes. J Bone Miner Res. 2015; 30:400-11.

https://doi.org/10.1002/jbmr.2381

PMID:25271055

55. Chen JH, Ozanne SE, Hales CN. Methods of cellular senescence induction using oxidative stress. Methods Mol Biol. 2007; 371:179-89.

https://doi.org/10.1007/978-1-59745-361-5 14

PMID: $\underline{17634582}$ 


\section{SUPPLEMENTARY MATERIALS}

\section{Supplementary Methods}

\section{Mice}

Mice were maintained under standard laboratory conditions on a 12:12 hr light;dark cycle. Water and standard chow (\#2918, Teklad global 15\% protein, Envigo, Indianapolis, IN, USA, or \#5V75, LabDiet PicoLab crude $20 \%$ protein, PMI Nutrition International, St. Louis, MO, USA) was provided ad libitum. Mice were housed in ventilated cages at 4-5 animals per cage. Male (4 and 13-16 months old) and female (13-20 months old) mice were used for this study.

All mice were euthanized by cervical dislocation following isoflurane (Henry Schein, Melville, NY, USA) anesthesia. Femora and tibiae from both sides and vertebrae were dissected and cleaned of soft tissue. Left femora were used for $\mu \mathrm{CT}$ analysis and subsequently used for either histomorphometric analysis (described below). Right femora were used for histological analysis (described below). The L5 vertebrae were used for $\mu \mathrm{CT}$ analysis and subsequently used for histomorphometric analysis. The third and fourth lumbar (L3 and L4) vertebrae were used for histological analysis (described below). The right femora and/or tibiae were used for RNA isolation and gene expression analysis (described below).

\section{Cell lines}

CRISPR/Cas9 genome editing technique was used to knockout PPR expression in Ocy454-12H (or 12H) cells. Briefly, three independent single-guided RNAs (sgRNAs) were designed using both sgRNA Design Tool (Zhang Lab, MIT, http://crispr.mit.edu/) and sgRNA Designer Ver.1 (Genetic Perturbation Platform Web Portal, Broad Institute). Each sgRNA was cloned into a pSpCas9(BB)-2A-GFP (PX458) plasmid (\#48138) (a gift from Dr. Feng Zhang [1], Addgene, Watertown, MA, USA). The plasmid was then transfected into Ocy454-12H cells with FuGENE HD (Promega, Madison, WI, USA) following the manufacturer's protocol. Two days after transfection, enhanced green fluorescent protein expressing cells $\left(12 \mathrm{H}-\mathrm{PPR}^{\mathrm{KO}}\right)$ were sorted using fluorescence-activated cell sorting technique (MoFlo Astrios, Beckman Coulter, Brea, CA, USA). Successful knockout of the PPR gene (Pthlr) and the loss of PPR signaling in $12 \mathrm{H}-\mathrm{PPR}^{\mathrm{KO}}$ cells was confirmed by quantitative real time polymerase chain reaction (PCR) (StepOne Plus, Applied Biosystems, Foster City, CA, USA) and direct cAMP radioimmunoassay (RIA) (MGH Center for Skeletal
Research Cores, Boston, MA, USA), as described below, along with DNA sequencing (Eton Bioscience, Charlestown, MA, USA) (Supplementary Figure 7). An empty PX458 plasmid (without any sgRNA insertion) was used to generate control cells $\left(12 \mathrm{H}-\mathrm{PPR}^{\text {Cont }}\right)$. Both control and $12 \mathrm{H}-\mathrm{PPR}^{\mathrm{KO}}$ cells were routinely maintained at $33^{\circ} \mathrm{C}$ (permissive temperature) with $5 \% \mathrm{CO}_{2}$ and cultured in growth medium ( $\alpha$ minimum essential medium ( $\alpha \mathrm{MEM})$ (Gibco, Thermo Fisher Scientific) containing 10\% heat-inactivated fetal bovine serum (FBS) (Gibco) and $1 \%$ antibiotic-antimycotic (Gibco)). Upon proliferation, cells were transferred to $37^{\circ} \mathrm{C}$ with $5 \%$ $\mathrm{CO}_{2}$ to be fully differentiated into mature osteocytes and incubated for the number of days required for each experiment. Fresh growth medium was added every three-four days.

Human PTH 1-34 (hPTH(1-34)) peptide (MGH Peptide Core Facility) was dissolved in $0.1 \%$ trifluoroacetic acid at $1 \mathrm{mM}$, aliquoted, stored at $-80^{\circ} \mathrm{C}$, and subsequently diluted to the appropriate concentration in growth medium. For the relevant experiments, cells were treated with hPTH(1-34) or forskolin (Sigma-Aldrich, St. Louis, MO, USA) for 4 or 18-22 hrs and the total RNA was isolated using RNeasy Plus Mini Kit (Qiagen, Valencia, CA, USA).

\section{Colony forming unit assay}

Upon sacrifice, BMSCs were isolated from long bones (tibiae and/or femora) of 13-month-old control and Dmp1-PPR ${ }^{\mathrm{KO}}$ animals (both male and female) by either a brief centrifugation or flushing out bones using a $25 \mathrm{G}$ needle (BD, Franklin Lakes, NJ, USA) with $\alpha \mathrm{MEM}$ containing $0.1 \%$ bovine serum albumin (BSA) (Sigma) and $25 \mathrm{mM}$ HEPES buffer (Fisher Scientific, Hampton, $\mathrm{NH}$, USA). Cells were hemolyzed with red blood cell lysing buffer (Sigma) and plated on either 6- or 24-well plates Biolite $^{\mathrm{TM}}$, Thermo Fisher Scientific, or Primaria $^{\mathrm{TM}}$, Corning, Corning, NY, USA) at 1.0-2.0 $\times$ $10^{6}$ cells/well under growth medium. Cells were cultured at $37^{\circ} \mathrm{C}$ with $5 \% \mathrm{CO}_{2}$ for 2 days and nonadherent cells were removed by replacing the growth medium with osteogenic differentiation medium (growth medium supplemented with $10 \mathrm{mM} \quad \beta$ glycerophosphate (Calbiochem, Millipore, Burlington, MA, USA), and $50 \mu \mathrm{g} / \mathrm{ml}$ of ascorbic acid (Sigma)). The differentiation medium was replaced every 2-3 days. After 6-12 days in culture, cells were fixed with $10 \%$ phosphate-buffered formalin (Fisher Scientific) and stained for alkaline phosphatase (ALP) by incubating with $0.1 \mathrm{mg} / \mathrm{ml}$ naphthol AS-MX phosphate (\#N5000, Sigma) and $0.6 \mathrm{mg} / \mathrm{ml}$ Fast Blue BB salt 
(\#151112, MP Biomedicals, Santa Ana, CA, USA) dissolved in $0.1 \mathrm{M}$ Tris buffer $(\mathrm{pH}$ 8.5) (Fisher Scientific). CFU-Ob assay was performed by quantifying the number or the area of colonies that are positive for ALP as previously reported [2, 3]. Cells were subsequently stained with $0.05 \%$ crystal violet (CV) for the fibroblasts CFU (CFU-F) assay and the total area of $\mathrm{CV}$-positive colonies was quantified using Image J (NIH, Rockville, MD, USA).

\section{Histology}

The left tibiae and/or the L3 and L4 vertebrae were dissected from adult (4 months old) and middle-aged male (13-16 months old) or female (13-20 months old) mice and were fixed in $10 \%$ phosphate-buffered formalin $(\mathrm{pH}$ 6.9-7.2) for at least 24 and $48 \mathrm{hrs,}$ respectively. The bones were further decalcified in $20 \%$ ethylenediaminetetraacetic acid (EDTA) (Fisher Scientific or Alfa Aesar, Haverhill, MA, USA), processed, embedded in paraffin, and sectioned as described previously (12). Following deparaffinization, sections were stained with hematoxylin (Thermo Fisher Scientific) and eosin (Fisher Scientific) or used for immunofluorescent staining, TUNEL assay, or TRAP staining (each described below).

\section{Immunofluorescent staining}

Immunofluorescent staining for TNF $\alpha$, RANKL and perilipin-1 was performed on paraffin sections of the left tibiae from middle-aged (13 months old) male mice. Antigen was retrieved by Tris-EDTA buffer $(10 \mathrm{mM}$ Tris, $1 \mathrm{mM}$ EDTA, $0.05 \%$ Tween 20, $\mathrm{pH} 9.0$ ) in a boiling water bath at $95^{\circ} \mathrm{C}$ for $12 \mathrm{~min}$ for $\mathrm{TNF} \alpha$ or overnight incubation at $60^{\circ} \mathrm{C}$ in sodium citrate buffer $(10 \mathrm{mM}$ sodium citrate (Fisher Scientific), $0.05 \%$ Tween 20 (Sigma), $\mathrm{pH}$ 6.0) for RANKL and perilipin-1. Slides were permeabilized with $0.1 \%$ Triton X-100 (Sigma) in phosphate buffered saline (PBS) at room temperature for 10 min (for RANKL and perilipin-1) and then blocked with TNB blocking buffer (20 mM Tris, $150 \mathrm{mM} \mathrm{NaCl}$ (Fisher Scientific), $0.5 \%$ tyramide signal amplification (TSA) blocking reagent (\#FP1020, PerkinElmer, Waltham, MA, USA)) for $30 \mathrm{~min}(\mathrm{TNF} \alpha)$ or $2 \mathrm{hrs}$ (RANKL and perilipin-1) at room temperature, followed by overnight incubation at $4{ }^{\circ} \mathrm{C}$ with anti-TNF $\alpha$ antibody (\#ab6671, Abcam, Cambridge, United Kingdom) or antimouse perilipin-1 (\#9349, Cell Signaling Technology, Danvers, MA, USA) (1:100) and anti-mouse RANKL (\#sc-7628, Santa Cruz Biotechnology, Dallas, TX, USA) (1:50) in TNB blocking buffer. For RANKL and perilipin-1, after washing, slides were further incubated with Alexa flour 546 donkey anti-rabbit IgG (\#A10040, Invitrogen, Carlsbad, CA, USA) (1:100) and Alexa flour 488 donkey anti-goat IgG (\#A11055, Invitrogen) (1:100) in TNB blocking buffer for $1 \mathrm{hr}$ at room temperature. For TNF $\alpha$, after washing, slides were incubated with biotin-SP (long spacer)-conjugated AffiniPure goat antirabbit (\#111-065-144, Jackson ImmunoResearch Laboratories, West Grove, PA, USA) for $30 \mathrm{~min}$ at room temperature. Subsequently, slides were washed and incubated for $30 \mathrm{~min}$ at room temperature with streptavidin-conjugated horseradish peroxidase (\#438323, Zymed Laboratories, San Francisco, CA, USA) and tyramide following the manufacturer's protocol (TSA Biotin Kit, PerkinElmer). After washing, slides were incubated with streptavidin-conjugated Texas Red (\#43-4317, Zymed Laboratories) for $30 \mathrm{~min}$ at room temperature. To reduce background, slides were incubated with TrueVIEW autofluorescence quenching solution (Vector Laboratories, Burlingame, CA, USA) for $2 \mathrm{~min}$ at room temperature for all immunofluorescent staining. Cell nuclei were counterstained with $5 \mu \mathrm{g} / \mathrm{ml}$ 4', 6-diamidino-2-phenylindole (DAPI) (Thermo Fisher Science). Images were acquired under the fluorescence microscope with a $20 \times$ objective (BZ-X700, Keyence, Osaka, Japan) or a $40 \times$ objective (Zeiss, Jena, Germany). The number of RANKL-expressing adipocytes (defined as perilipin-1-expressing cells) in the marrow space within $300 \mu \mathrm{m}$ from the proximal epiphyseal plate was counted using ImageJ.

\section{Immunohistochemistry}

Immunohistochemistry for 4-HNE was performed on deparaffinized sections of the L3 and L4 vertebrae from adult (4 months old) and middle-aged (13 months old) male mice. Endogenous peroxidase activity was inhibited by $3 \% \mathrm{H}_{2} \mathrm{O}_{2}$ treatment for $10 \mathrm{~min}$. Antigen retrieval was performed with Tris-EDTA buffer (10 $\mathrm{mM}$ Tris, $1 \mathrm{mM}$ EDTA, $0.05 \%$ Tween $20, \mathrm{pH} 9.0$ ) in a boiling water bath at $95^{\circ} \mathrm{C}$ for 12 min. Slides were cooled to room temperature and blocked with TNB blocking buffer for $30 \mathrm{~min}$ at room temperature and incubated with anit-4-HNE antibody (\#GTX40953, GeneTex, Irvine, CA, USA) in TNB blocking buffer overnight at $4^{\circ} \mathrm{C}$. Slides were washed and incubated with rabbit anti-goat IgG (\#305-065-003, Jackson ImmunoResearch Laboratories) for $30 \mathrm{~min}$ at room temperature. Subsequently, slides were washed and incubated for $30 \mathrm{~min}$ with streptavidin-conjugated horseradish peroxidase (\#43-8323, Zymed Laboratories) and tyramide following the manufacturer's protocol (TSA Biotin Kit, PerkinElmer). The signal was developed with a 3,3'-diaminobenzidine (DAB) substrate-chromogen system (Vector Laboratories). Cell nuclei were counterstained with hematoxylin. Bright field images were acquired under the microscope with a $40 \times$ objective (Nikon Eclipse E800, Nikon, Tokyo, Japan) or with a 20× objective (EVOS XL, Thermo Fisher Scientific). For quantitative analysis, using ImageJ, 4- 
HNE positive osteocytes were counted with a $20 \times$ objective in three-five adjacent fields per vertebra and normalized to the total number of osteocytes per field.

\section{Marrow adiposity analysis}

Bone marrow adiposity was quantitatively analyzed, using ImageJ, as the ratio of adipocyte area over the marrow area within 300 or $1,200 \mu \mathrm{m}$ from the proximal epiphyseal plate of the tibiae of middle-aged male (13 months old) or aging female (20 months old) animals, respectively. Briefly, bright-field images of H\&E-stained proximal tibiae were acquired under the microscope with a $4 x$ objective (Keyence). Using the segmented line tool (width $=300$ or $1,200 \mu \mathrm{m}$ ) on ImageJ, the marrow area of interest was defined by tracing the epiphyseal plate manually. The area of marrow adipocytes (represented as white patches with a round or oval shape) was manually traced by using the polygon selection tool.

\section{TUNEL assay}

TUNEL staining was performed on deparaffinized tibiae sections of Dmp1-PPR ${ }^{\mathrm{KO}}$ and control male (13 months old) and female (20 months old) mice following the manufacturer's protocol (DeadEnd colorimetric TUNEL, Promega, or TUNEL chromogenic apoptosis detection kit, GeneCopoeia, Rockville, MD, USA). For the TUNEL chromogenic kit (GeneCopoeia), modifications were made on the antigen retrieval and permeabilization step where the deparaffinized and rehydrated tibia sections were exposed to $10 \mathrm{mM}$ citrate buffer ( $\mathrm{pH}$ 6.0) for $5 \mathrm{~min}$ at $48^{\circ} \mathrm{C}$ and $0.05 \%$ pepsin (Roche, Basel, Switzerland) in $0.1 \mathrm{~N} \mathrm{HCl}$ (Fisher Scientific) for $4 \mathrm{~min}$ at $37^{\circ} \mathrm{C}$, respectively as reported previously [30]. Cell nuclei were counterstained with either hematoxylin or $0.5 \%$ methyl green (Sigma). Images were acquired under the microscope with a $40 \mathrm{X}$ objective (EVOS XL). The number of TUNEL-positive apoptotic osteocytes in the cortical and trabecular bone was counted using ImageJ either manually or unbiasedly. For the unbiased quantitative analysis, images were first color-deconvoluted into three singlecolored images (methyl green, $\mathrm{DAB}$, and background color) by manually selecting regions of interest that represent each color. The intensity of DAB signal on each osteocyte (identified as a methyl green positive cell within the bone matrix) was quantified and osteocytes with high and homogeneous DAB signal (threshold: mean $>100$, modal $>60$, standard deviation $>60$ per cell) were defined as TUNEL-positive.

\section{Serology}

Serum was isolated from the blood collected by retroorbital bleeding or cardiac puncture using pre- heparinized capillary tubes (Fisher Scientific) or insulin syringes (BD) heparinized with $1000 \mathrm{IU} / \mathrm{ml}$ of heparin (Alfa Aesar), respectively. Serum levels of P1NP (Rat/Mouse P1NP enzyme immunoassays (EIA)) and CTX (RatLaps EIA) were measured using ELISA (Immunodiagnostic Systems, Tyne and Wear, United Kingdom). Serum calcium was measured by calcium liquicolor arsenazo kit (Stanbio Laboratory, Boerne, TX, USA) and inorganic phosphate was quantified by phospho liquid-UV kit (Stanbio Laboratory) according to the manufacturer's instructions. Serum PTH was measured using mouse intact PTH ELISA kit (MicroVue Bone Mouse PTH 1-84, Quidel Corporation, San Diego, CA, USA) according to the manufacturer's protocol. Serum sclerostin was measured using mouse/rat SOST/Sclerostin Quantikine ELISA kit (\#MSST00, R\&D Systems, Minneapolis, MN, USA) according to the manufacturer's protocol. Serum cytokines included IL-6, -10, and -12p70, MCP-1, interferon $\gamma$, and TNF were measured using BD cytometric bead array mouse inflammation kit (BD) following the manufacturer's instructions.

\section{$\mu \mathrm{CT}$ analysis}

The left femora and the L5 vertebrae of adult (4 months old) and middle-aged (13-16 months old) male mice were isolated and cleaned of soft tissues. The femora were either fixed in $70 \%$ ethanol at $4^{\circ} \mathrm{C}$ or frozen at $20^{\circ} \mathrm{C}$ being wrapped by PBS-soaked gauze (8-ply, Covidien, Dublin, Ireland). The L5 vertebrae were fixed in 10\% phosphate-buffered formalin ( $\mathrm{pH}$ 6.9-7.2) for at least $48 \mathrm{hrs}$ and stored in $70 \%$ ethanol. Bone morphology and microarchitecture were analyzed in the distal femoral metaphysic, the femoral midshaft, and the vertebral body using a desktop high-resolution $\mu \mathrm{CT}$ ( $\mu \mathrm{CT} 40$, Scanco Medical, Wangen-Brüttisellen, Switzerland), as described previously [22]. Following parameters were assessed for the trabecular bone region: bone volume over total tissue volume, BV/TV (\%); trabecular number, Tb.N (/mm); trabecular thickness, Tb.Th (mm); trabecular separation, Tb.Sp (mm); and for the cortical bone region: cortical thickness, Cort.Th $(\mathrm{mm})$; cortical density, Cort.Dens (mmHA/ccm); cortical area, Cort.A $\left(\mathrm{mm}^{2}\right)$; medullary area, MA $\left(\mathrm{mm}^{2}\right)$; cortical porosity, Cort.Por (\%); cortical density, Cort.Den $(\mathrm{mgHA} / \mathrm{ccm})$; polar moment of inertia, pMOI $\left(\mathrm{mm}^{4}\right)$. See Supplementary Table 1 for the full list of analyzed parameters.

\section{Histomorphometric analysis}

Adult (4 months old) and middle-aged (13 months old) male mice were injected intraperitoneally with 20 $\mathrm{mg} / \mathrm{kg}$ calcein (Sigma) on days 9 and 2 before sacrifice. The left femora and the L5 vertebrae were isolated, 
cleaned of adherent tissues, and used for $\mu \mathrm{CT}$ analysis (described above) prior to histomorphometric analysis. Both the femora and vertebrae were dehydrated, infiltrated, and embedded in methyl methacrylate. Undecalcified 4- $\mu \mathrm{m}$-thick sections were cut using a microtome (Leica RM 2255, Heidelberg, Germany). Consecutive sections were stained by von Kossa with van Gieson counterstain and toluidine blue to determine structural and cellular parameters, respectively. Dynamic parameters were quantified using unstained and undecalcified sections of the femora. Undecalcified sections of the femora were also stained for TRAP. Histomorphometric parameters (i.e., formation and resorption) were measured using the Osteomeasure image analysis system (OsteoMetrics, Decatur, GA, USA) coupled to a microscope (BX 50 combined with a DP72 digital camera, Olympus, Hamburg, Germany). A sampling site of about $2 \mathrm{~mm}^{2}$ was established in the cancellous bone at $400 \mu \mathrm{m}$ below the growth plate. Analysis was done in a standardized fashion by an experienced scientist and results were expressed according to the updated standardized American Society for Bone and Mineral Research (ASBMR) nomenclature [4]. In detail, cancellous bone volume in the distal femora and the L5 vertebrae was assessed as BV/TV (\%). Tb.Th, Tb.N, and Tb.Sp were also calculated both in the distal femora and in the L5 vertebrae. Additional parameters included: mineralizing surface over bone surface, MS/BS (\%); mineral apposition rate, MAR $(\mu \mathrm{m} /$ day); bone formation rate (BFR) over bone surface, BFR/BS; over bone volume, $\mathrm{BFR} / \mathrm{BV}$ (\%/year); and over total volume, BFR/TV (\%/year); osteoid volume (OV) over bone volume, $\mathrm{OV} / \mathrm{BV}(\%)$; and osteoid surface (OS) over bone surface, OS/BS (\%). Formation parameters were expressed as osteoblast surface per bone surface, Ob.S/BS (\%); osteoblast number per bone perimeter, N.Ob/B.Pm $(/ \mathrm{mm})$; and osteoblast number per tissue area, N.Ob/T.Ar $\left(/ \mathrm{mm}^{2}\right)$. Resorption parameters were expressed as osteoclast surface per bone surface, Oc.S/BS (\%); osteoclast number per bone perimeter, N.Oc/B.Pm $(/ \mathrm{mm})$; and osteoclast number per tissue area, N.Oc/T.Ar $\left(/ \mathrm{mm}^{2}\right)$. We also quantified the number of osteocytes per bone volume, N.Ot/BV $\left(/ \mathrm{mm}^{2}\right)$, in the cancellous bone. Cortical bone parameters, such as Cort.Th $(\mathrm{mm})$; endocortical mineral apposition rate, End.Cort MAR $(\mu \mathrm{m} /$ day); and osteocyte density, Ot density $\left(/ \mathrm{mm}^{2}\right)$, were analyzed at the femoral midshaft. See Supplementary Table 1 for the full list of analyzed parameters.

\section{RNA isolation and purification}

The right femora and/or tibiae were dissected from adult male (4 months old) and middle-aged (13-16 months old) male or middle-aged and aging (13 and 20 months old) female mice. The bones were cut at both proximal and distal end, centrifuged briefly at 8.0-9.0 $\times \mathrm{g}$ for 7 sec (at start) to remove bone marrow, placed in $1 \mathrm{ml}$ of TRIzol reagent (Thermo Fisher Scientific, Waltham, MA, USA) with a grinding stainless steel bead (5-mm diameter, OPS Diagnostics, Lebanon, NJ, USA), snapfrozen in liquid nitrogen, and subsequently stored at $80^{\circ} \mathrm{C}$ for RNA isolation. The bone marrow removed from the femora and/or tibiae was lysed in $600 \mu \mathrm{l}$ of lysis buffer (RLT Plus (Qiagen) supplemented with 1\% $\beta$-mercaptoethanol (Sigma)) by pipetting and stored at $80^{\circ} \mathrm{C}$ for RNA isolation. Cells under in vitro culture were harvested in $350 \mu \mathrm{l}$ of lysis buffer and either frozen at $-80^{\circ} \mathrm{C}$ or directly processed for RNA isolation.

Prior to RNA isolation, the frozen bones were homogenized with TissueLyser II (Qiagen) at $30 \mathrm{~Hz}$ at room temperature for 8-12 min (including the time for thawing), refrozen in liquid nitrogen, and subsequently restored at $-80^{\circ} \mathrm{C}$. Bone marrow and in vitro cell samples were both homogenized with QIAshredder (Qiagen). The total RNA from long bones or bone marrow and in vitro cells was isolated using PureLink RNA mini kit (Invitrogen) or RNeasy Plus mini kit (Qiagen), respectively, as per manufacturer's instructions. Some of the bones from middle-aged male (13 months old) mice were subjected to sequential collagenase (Worthington Biochemical, Lakewood, NJ, USA) and EDTA digestions to remove endosteal and periosteal osteoblasts and bone marrow cells and snapfrozen in liquid nitrogen followed by homogenization and RNA isolation. The quality and quantity of the total RNA was measured by UV spectrophotometry (NanoDrop 2000c, Thermo Fisher Scientific).

\section{Quantitative real time PCR}

RNA was reverse transcribed into complementary DNA (cDNA) using PrimeScript RT reagent kit (Clontech, Takara Bio, Kusatsu, Shiga, Japan) with a genomic DNA elimination step or qScript cDNA SuperMix (QuantaBio, Beverly, MA, USA). Real time qPCR assay was subsequently performed with StepOne Plus (Applied Biosystems) using SYBR Green (Power SYBR, Thermo Fisher Scientific). The PCR conditions were as follows: one cycle of $95^{\circ} \mathrm{C}(10 \mathrm{~min}), 50$ cycles of $95^{\circ} \mathrm{C}, 58^{\circ} \mathrm{C}$, and $72^{\circ} \mathrm{C}(15 \mathrm{sec}, 15 \mathrm{sec}$, and $30 \mathrm{sec}$, respectively), and one cycle of $95^{\circ} \mathrm{C}(30 \mathrm{~s})$, followed by a melting curve step $\left(58^{\circ} \mathrm{C}\right.$ to $95^{\circ} \mathrm{C}$ with an increment of $+0.5^{\circ} \mathrm{C}, 1 \mathrm{~min}$ for each temperature). See Supplementary Table 2 for the primer sequences. Data analysis was based on the comparative cycle threshold $(\triangle \mathrm{CT})$ method and expression of each gene was normalized to $A c t b$ expression or the geometric mean of the three gene expression (Actb, B2m, and Gapdh), which were selected as the most stable housekeeping 
genes among the eight genes (Actb, B2m, Gapdh, Hprt, Ywhaz, Rlp13a, Sdha, and 18S) by geNorm (qbase+ software, Biogazelle, Gent, Belgium) [5].

\section{Treatment of BMSCs with OEBE conditioned medium or mouse serum}

BMSCs were isolated from control male mice (3-4 months of age) and incubated with either $50 \%(\mathrm{v} / \mathrm{v})$ of conditioned medium from OEBEs, as previously described [39], or 3\% (v/v) mouse serum (along with $7 \%(\mathrm{v} / \mathrm{v})$ FBS) of 13 months old control and Dmp1$\mathrm{PPR}^{\mathrm{KO}}$ mice for 6 or 4 days under osteogenic or adipogenic differentiation medium, respectively. For ALP activity assay, cells were lysed with $0.1 \%$ Triton $\mathrm{X}-100$ in Tris buffer (pH 7.6) and the cell extract $(25 \mu \mathrm{l})$ was incubated with $25 \mu \mathrm{lmix}$ of 2-aminomethyl propanol (0.5 M) (Sigma), $\mathrm{MgCl}_{2}(5.3 \mathrm{mM})$ (Sigma) and Na-p-nitrophenyl phosphate $(1.3 \mathrm{mM})$ (Sigma) for $10 \mathrm{~min}$ at $37^{\circ} \mathrm{C}$. The reaction was stopped by $\mathrm{NaOH}$ $(0.2 \mathrm{~N})$ (Fisher Scientific) and the absorbance was measured at $405 \mathrm{~nm}$ using a spectrophotometer (TECAN, Mannedorf, Switzerland). ALP activity was normalized by protein content measured by Bradford method using protein assay dye reagent concentrate (Bio-Rad, Hercules, CA, USA). Cell proliferation was measured using PrestoBlue cell viability reagent (Invitrogen) as per manufacturer's protocol. For adipogenic differentiation assay, BMSCs were cultured in differentiation medium ( $\alpha$ MEM containing $0.5 \mathrm{mM}$ 3-Isobutyl-1-methylxanthine (IBMX) (Acros Organics), $1 \mu \mathrm{M}$ dexamethasone (Sigma), $10 \mu \mathrm{g} / \mathrm{ml}$ insulin (Sigma), and $1 \mu \mathrm{M}$ rosiglitazone (Sigma)) for 2 days at $37^{\circ} \mathrm{C}+5 \% \mathrm{CO}_{2}$ in the presence of the mouse serum. Cells were then maintained in base medium ( $\alpha$ MEM containing $10 \mu \mathrm{g} / \mathrm{ml}$ insulin and $1 \mu \mathrm{M}$ rosiglitazone) for additional 2 days in the presence of the mouse serum. Cells were fixed with $10 \%$ phosphate-buffered formalin for $15 \mathrm{~min}$ followed by incubation with $0.3 \%$ oil-red $\mathrm{O}$ (Sigma) for $30 \mathrm{~min}$ at $37^{\circ} \mathrm{C}$. Bright field images were acquired under the microscope with a $10 \mathrm{X}$ objective (Keyence). Quantification of lipid was performed by elution of oil-red $\mathrm{O}$ stain and by measuring absorbance at $540 \mathrm{~nm}$ using a spectrophotometer (Berthold Technologies).

\section{TRAP staining and activity assay}

Histology sections of tibiae and/or femora were deparaffinized, rehydrated, and stained for TRAP as described previously [6]. Briefly, the sections were incubated in acetate buffer $(0.2 \mathrm{M}$ sodium acetate and $50 \mathrm{mM}$ sodium tartrate, $\mathrm{pH} 5.0$ ) for $20 \mathrm{~min}$ at room temperature followed by a $30 \mathrm{~min}$ incubation in the same buffer containing $0.5 \mathrm{mg} / \mathrm{ml}$ naphthol AS-MX phosphate and $1.1 \mathrm{mg} / \mathrm{ml}$ Fast Red Violet LB Salt
(\#F3381, Sigma) at $37^{\circ} \mathrm{C}$. For in vitro experiments, BMMCs were isolated from control mice (3-4 months of age) and purified by Ficoll-Paque (GE Healthcare, Chicago, IL, USA) purification as described previously [39]. BMMCs were cultured for 3 days with $25 \mathrm{ng} / \mathrm{ml}$ M-CSF (Shenandoah Biotechnology, Warwick, PA, USA) followed by 4 days of incubation with $3 \%(\mathrm{v} / \mathrm{v})$ mouse serum (along with 7\% (v/v) FBS) from control and Dmp1-PPR ${ }^{\mathrm{KO}}$ mice in the presence of $25 \mathrm{ng} / \mathrm{ml} \mathrm{M}$ $\mathrm{CSF}$ and $50 \mathrm{ng} / \mathrm{ml}$ RANKL (Shenandoah Biotechnology). Medium was replaced every 3 days. Cells were then fixed with $10 \%$ formalin and incubated in TRAP staining buffer (the acetate buffer containing $0.1 \mathrm{mg} / \mathrm{ml}$ naphthol AS-MX phosphate and $0.6 \mathrm{mg} / \mathrm{ml}$ Fast Red Violet LB Salt) for $10 \mathrm{~min}$ at $37^{\circ} \mathrm{C}$. Cell images were acquired by the microscope with a $4 \mathrm{X}$ objective (Keyence) and the number and size of TRAP+ multinuclear osteoclasts ( $>3$ nuclei) was quantified using ImageJ. For TRAP activity assay, conditioned medium $(30 \mu \mathrm{l})$ was incubated with TRAP staining buffer $(170 \mu \mathrm{l})$ for $2 \mathrm{hrs}$ at $37^{\circ} \mathrm{C}$ and absorbance was measured at $590 \mathrm{~nm}$ using a spectrophotometer (Berthold Technologies).

\section{Cyclic AMP assay}

Control and $12 \mathrm{H}-\mathrm{PPR}^{\mathrm{KO}}$ cells were plated on 96-well plate at a density of $5 \times 10^{3}$ cells/well. After 4-5 days of culture at $33^{\circ} \mathrm{C}$, the cells were treated with $10 \mathrm{nM}$ $\mathrm{hPTH}(1-34)$ or $10 \mu \mathrm{M}$ FSK for $30 \mathrm{~min}$ at room temperature under 3-Isobutyl-1-methylxanthine (IBMX) buffer $(0.5 \mathrm{mg} / \mathrm{ml}$ IBMX (Acros Organics), 10\% BSA, 1 M HEPES dissolved in Hank's balanced salt solution (Sigma)). Reaction was stopped by adding $\mathrm{HCl}$ (16.6 $\mathrm{mM}$ ) (Fisher Scientific) and the cells were frozen immediately at $-80^{\circ} \mathrm{C}$ for RIA analysis.

\section{REFERENCES}

1. Ran FA, Hsu PD, Wright J, Agarwala V, Scott DA, Zhang F. Genome engineering using the CRISPR-Cas9 system. Nat Protoc. 2013; 8:2281-308. https://doi.org/10.1038/nprot.2013.143 PMID:24157548

2. Sinha $P$, Aarnisalo $P$, Chubb $R$, Ono $N$, Fulzele $K$, Selig $M$, Saeed $H$, Chen M, Weinstein LS, Pajevic PD, Kronenberg HM, Wu JY. Loss of Gsa early in the osteoblast lineage favors adipogenic differentiation of mesenchymal progenitors and committed osteoblast precursors. J Bone Miner Res. 2014; 29:2414-26. https://doi.org/10.1002/jbmr.2270 PMID:24806274

3. Morimoto D, Kuroda S, Kizawa T, Nomura K, Higuchi C, Yoshikawa H, Tomita T. Equivalent osteoblastic differentiation function of human mesenchymal 
stem cells from rheumatoid arthritis in comparison with osteoarthritis. Rheumatology (Oxford). 2009; 48:643-9.

https://doi.org/10.1093/rheumatology/kep044

PMID:19398485

4. Dempster DW, Compston JE, Drezner MK, Glorieux $\mathrm{FH}$, Kanis JA, Malluche $\mathrm{H}$, Meunier PJ, Ott SM, Recker RR, Parfitt AM. Standardized nomenclature, symbols, and units for bone histomorphometry: a 2012 update of the report of the ASBMR Histomorphometry Nomenclature Committee. J Bone Miner Res. 2013; 28:2-17.

https://doi.org/10.1002/jbmr.1805

PMID:23197339
5. Vandesompele J, De Preter K, Pattyn F, Poppe B, Van Roy N, De Paepe A, Speleman F. Accurate normalization of real-time quantitative RT-PCR data by geometric averaging of multiple internal control genes. Genome Biol. 2002; 3:RESEARCH0034. https://doi.org/10.1186/gb-2002-3-7-research0034 PMID: 12184808

6. Erlebacher A, Derynck R. Increased expression of TGFbeta 2 in osteoblasts results in an osteoporosis-like phenotype. J Cell Biol. 1996; 132:195-210.

https://doi.org/10.1083/jcb.132.1.195

PMID:8567723 


\section{Supplementary Figures}

A

Control

Dmp1-PPR KO
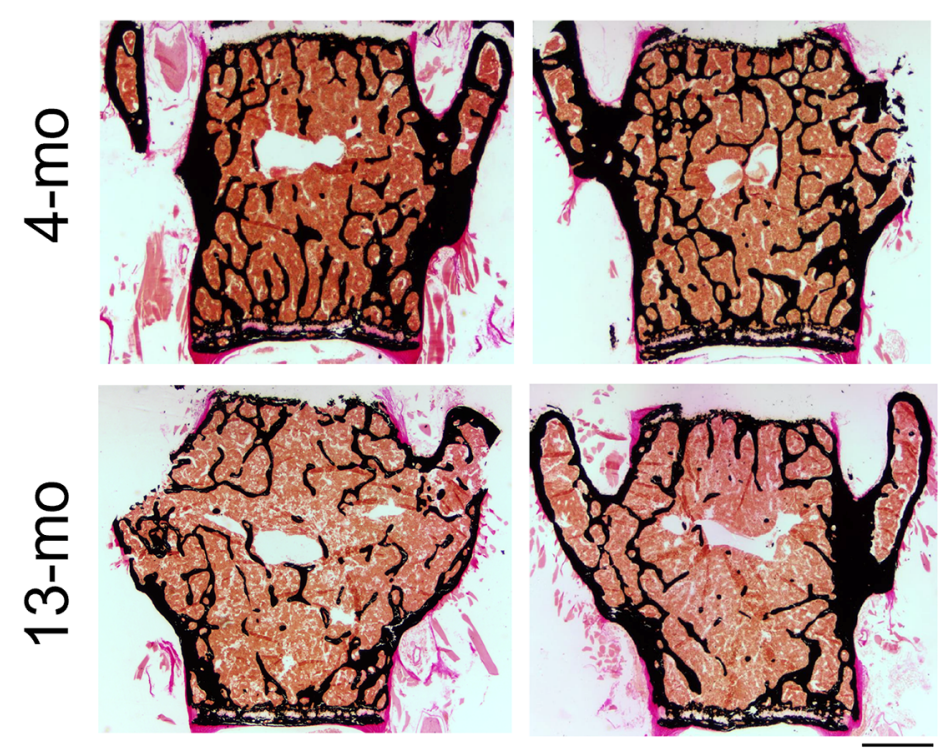

B
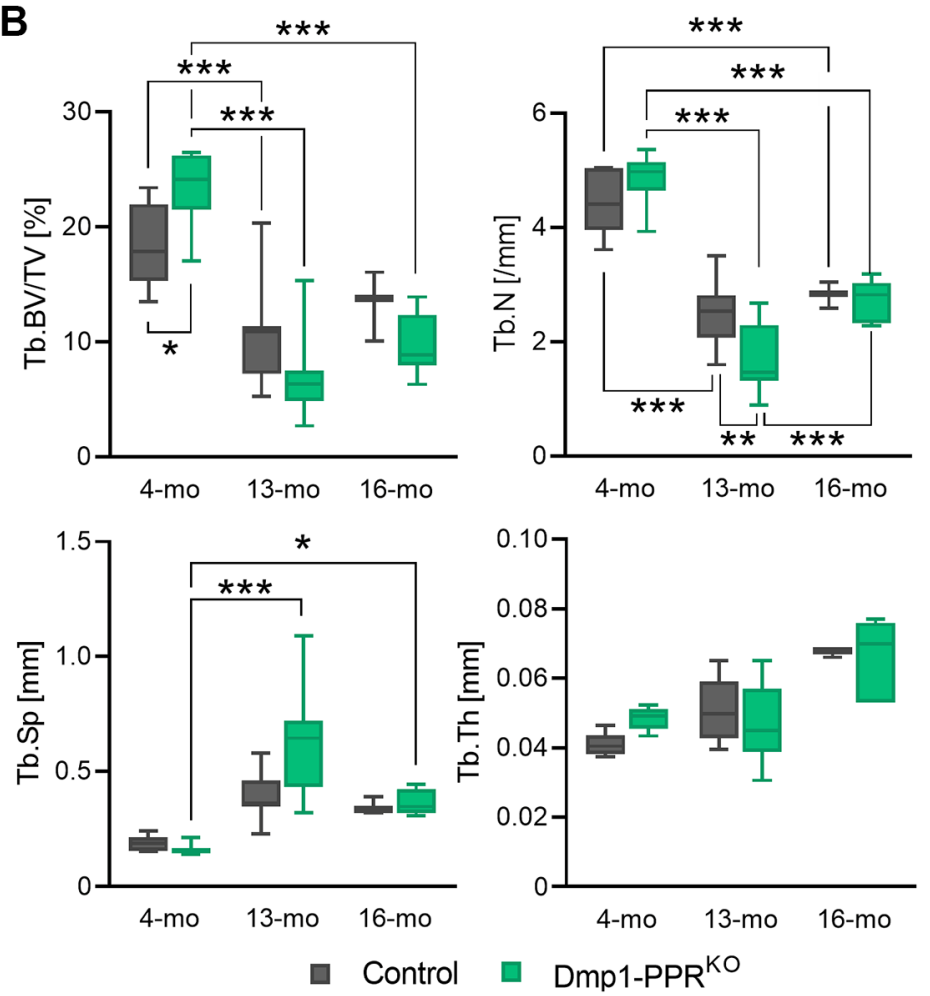

Supplementary Figure 1. Analysis of the skeletal phenotype of Dmp1-PPR ${ }^{\mathrm{KO}}$ mice. (A) Representative images of Von Kossa staining on the L5 vertebrae of 4- and 13-month-old male control and Dmp1-PPR ${ }^{K O}$ mice. (B) Skeletal parameters of the distal femora analyzed by $\mu \mathrm{CT}$ were compared among male control and Dmp1-PPR ${ }^{\mathrm{KO}}$ animals at different ages $(4,13$, or 16 months of age). Data is shown as box and whisker plot. $N=7-15$ per group. Two-way ANOVA with Tukey's post hoc test was performed. ${ }^{*} p<0.05,{ }^{* *} p<0.01,{ }^{* * *} p<0.001$. 
A

\section{Control}
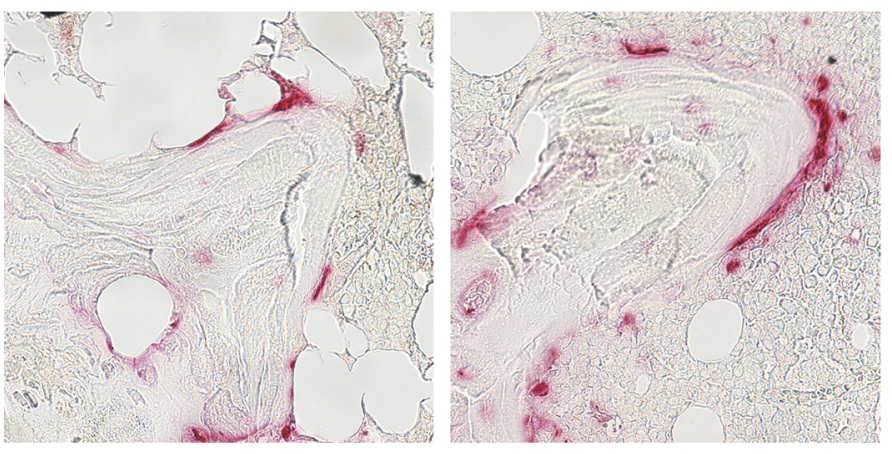

B

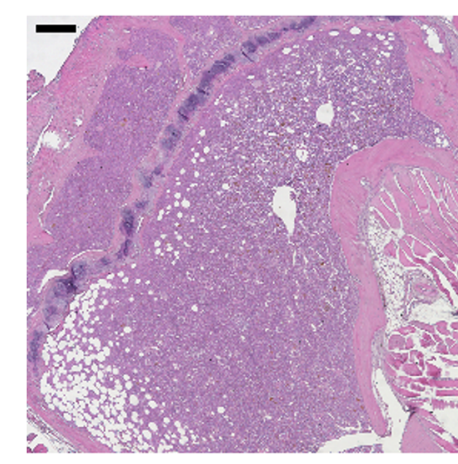

\section{Dmp1-PPR KO}
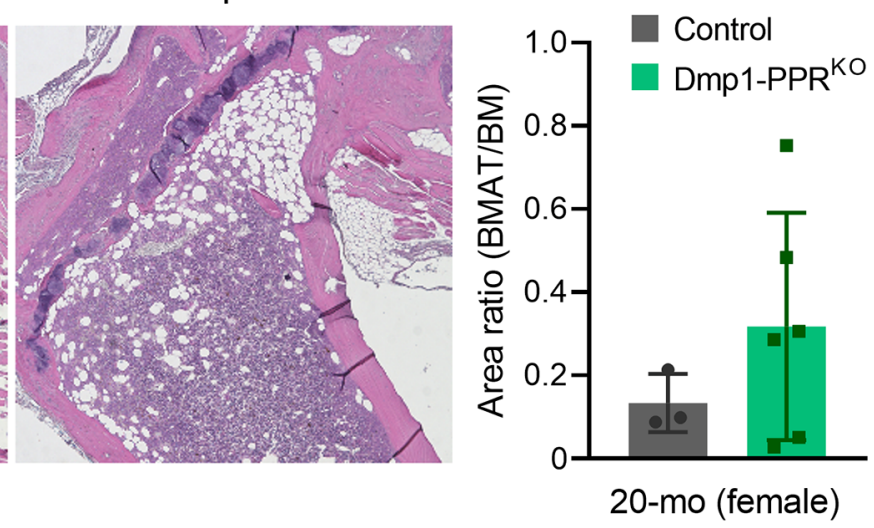

C

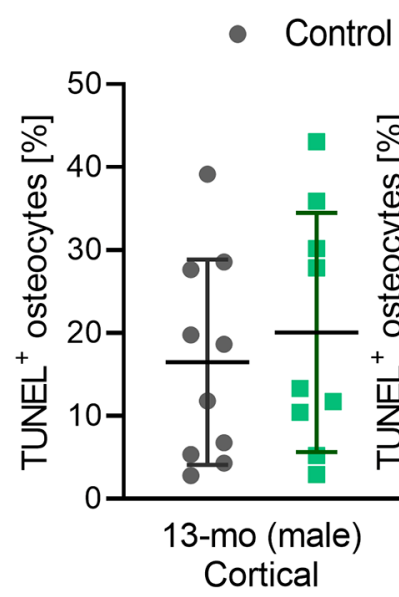

\section{Dmp1-PPR ${ }^{K O}$}

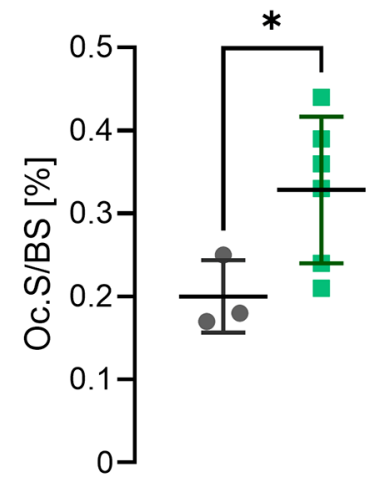

20-mo (female)
- Control

- Dmp1-PPR ${ }^{\mathrm{KO}}$

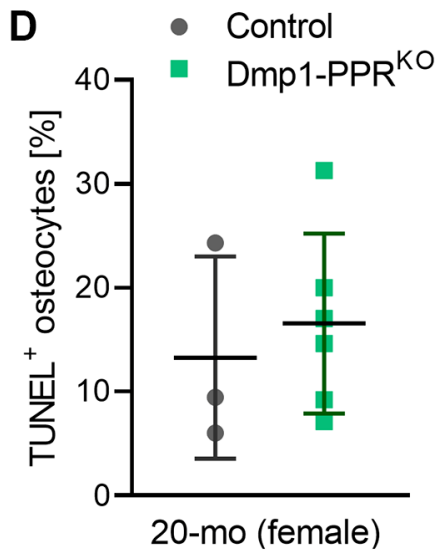

Supplementary Figure 2. (A) Representative images of TRAP staining and quantification of Oc.S/BS on the proximal tibiae (trabecular compartment) of female control and Dmp1-PPR ${ }^{\mathrm{KO}}$ mice at 20 months of age are shown. $N=3-6$ per group. (B) Representative images of H\&E staining and quantification of BMAT/BM ratio on the proximal tibiae of female control and Dmp1-PPR ${ }^{\mathrm{KO}}$ mice at 20 months old are shown. $N=3-6$ per group. (C, D) TUNEL analysis on the tibiae from aging control and Dmp1-PPR ${ }^{\mathrm{KO}}$ mice. (C) Quantification of TUNEL+ osteocytes in the tibiae of 13-month-old male control and Dmp1-PPR KO mice is shown. Analysis was performed on the cortical region (left, midshaft) and the trabecular region (right, proximal) of the tibiae. $N=4-10$ per group. (D) Quantification of TUNEL+ osteocytes in the tibiae (cortical region) of 20-month-old female control and Dmp1-PPR ${ }^{\mathrm{KO}}$ mice is shown. $N=3-6$ per group. Data are presented as mean \pm SD. Unpaired student's or Welch's $t$ test was performed. ${ }^{*} p<0.05$. 

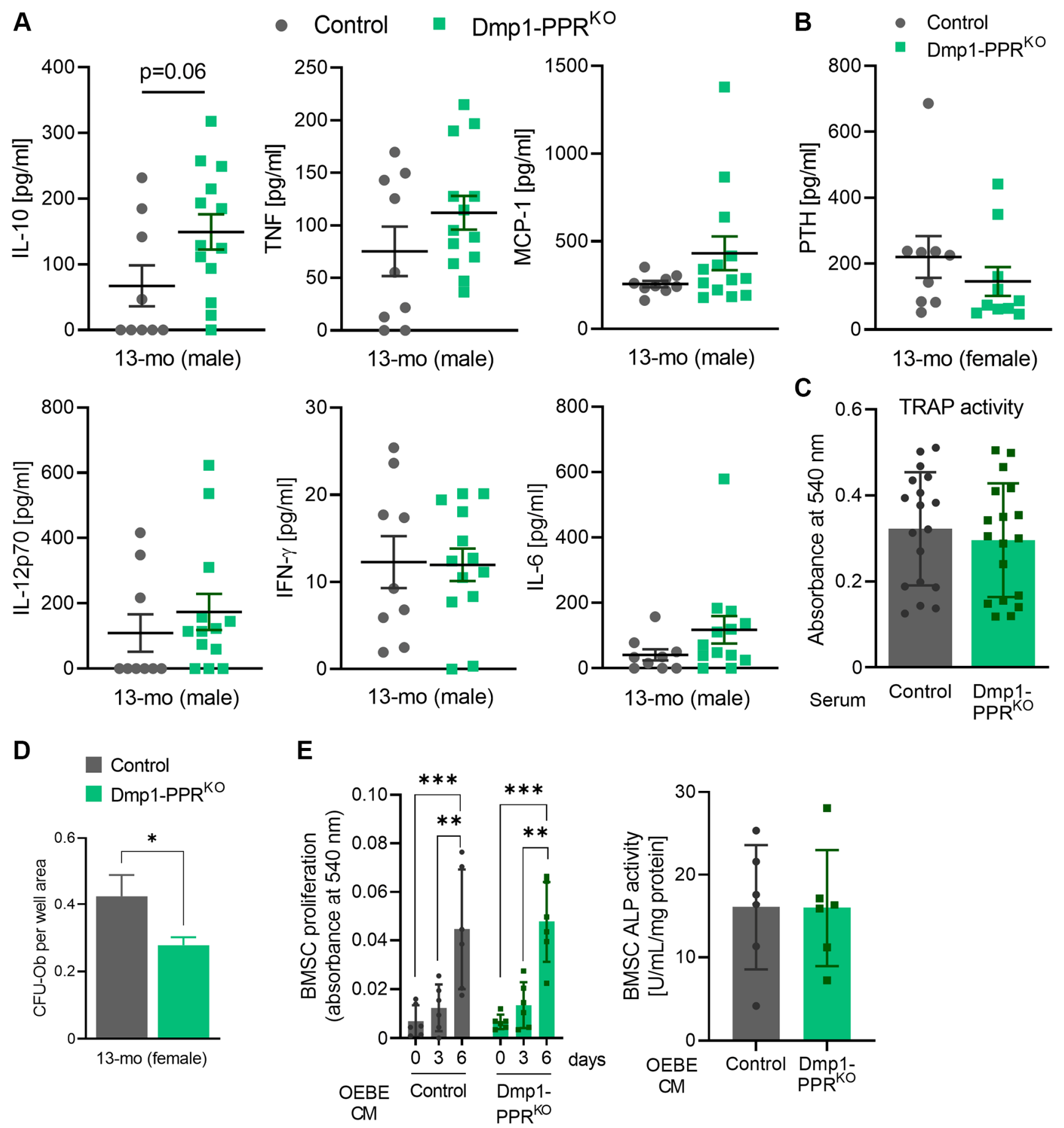

Supplementary Figure 3. (A) Serum cytokines in 13-month-old Dmp1-PPR ${ }^{\mathrm{KO}}$ mice were analyzed. Quantification of serum cytokines of 13month-old male control and Dmp1-PPR ${ }^{\mathrm{KO}}$ mice is shown. Data are expressed as mean \pm SEM. $N=7-13$ per group. (B) Serum PTH levels in 13month-old female mice were analyzed by ELISA. Means \pm SEM are shown. (C) TRAP activity was measured in the conditioned medium from BMMCs under osteoclastic differentiation in the presence of control or Dmp1-PPR ${ }^{\mathrm{KO}}$ serum. Means \pm SD are shown. (D) CFU-Ob assay was performed on BMSCs isolated from female control and Dmp1-PPR ${ }^{K O}$ mice at 13 months of old is shown. Means \pm SEM are shown. (E) Proliferation (left) and ALP activity measured on BMSCs under osteogenic differentiation in the presence of conditioned medium from control and Dmp1-PPR KO OEBEs culture. Means \pm SD are shown. Unpaired student's $t$ test was performed. ${ }^{*} p<0.05,{ }^{* *} p<0.01,{ }^{* * *} p<0.001$. 

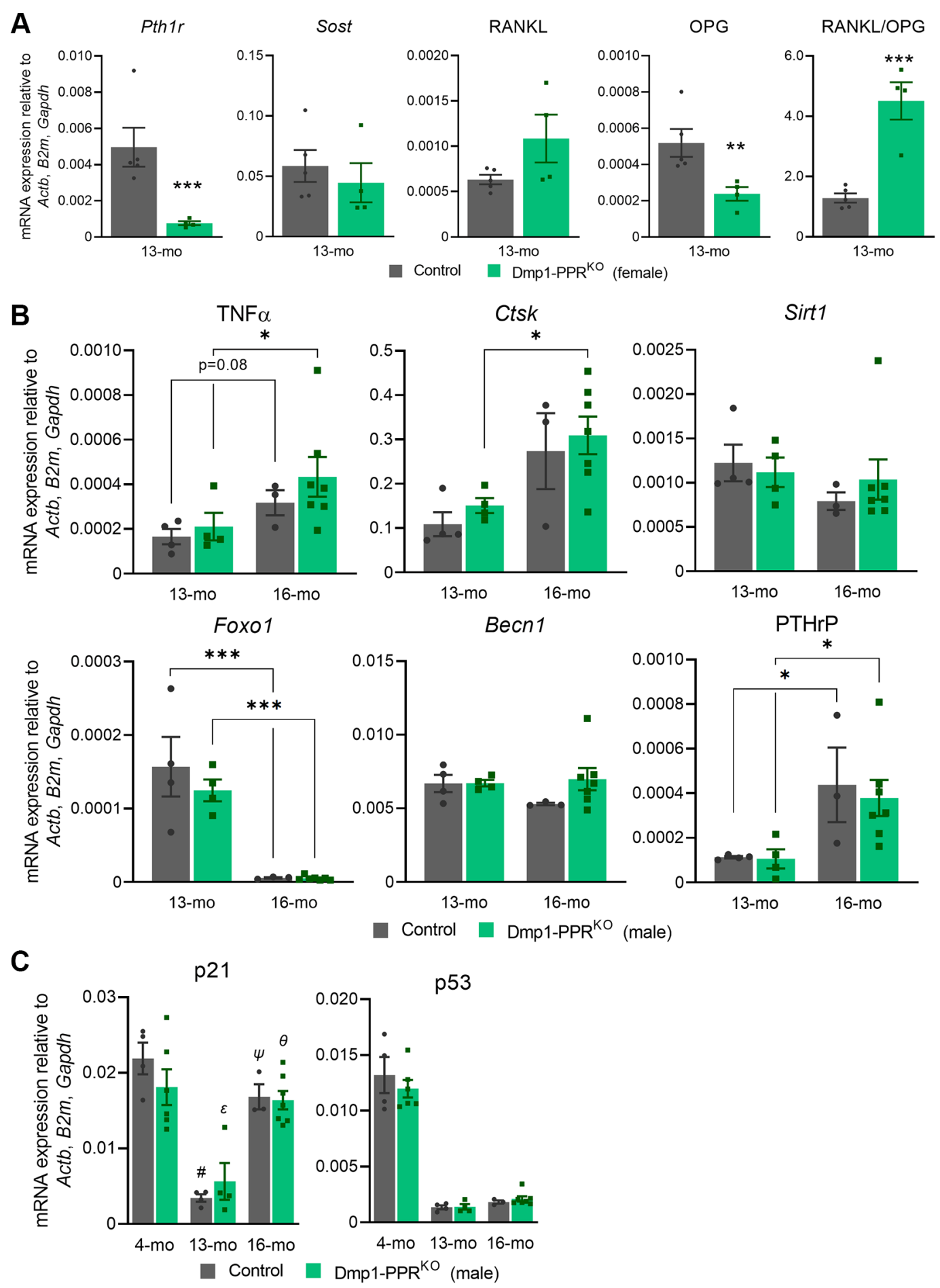

Supplementary Figure 4. (A) Gene expression in marrow-removed femora from 13-month-old female mice is shown. $N=4-5$ per group. (B, C) Gene expression in the tibiae and/or femora of control and Dmp1-PPR ${ }^{\mathrm{KO}}$ mice in male $(4,13$, and 16 months of age). Expression of genes involved in osteoclasts, autophagy and/or senescence was analyzed by qPCR. $N=4-11$ per group. Data are presented as mean \pm SEM. One-way ANOVA with Sidak's post hoc test, Two-way ANOVA with Tukey's post hoc test or unpaired student's $t$ test was performed. ${ }^{*} p<0.05,{ }^{* * *} p<0.001,{ }^{\#} p<0.001$ (vs. 4-mo Control), ${ }^{\varepsilon} p<0.001$ (vs. 4-mo Dmp1-PPR ${ }^{\mathrm{KO}}$ ), ${ }^{\psi} p<0.001$ (vs. $13-\mathrm{mo}$ Control), ${ }^{\theta} p<0.001$ (vs. $13-$ mo Dmp1-PPR ${ }^{\mathrm{KO}}$ ). 


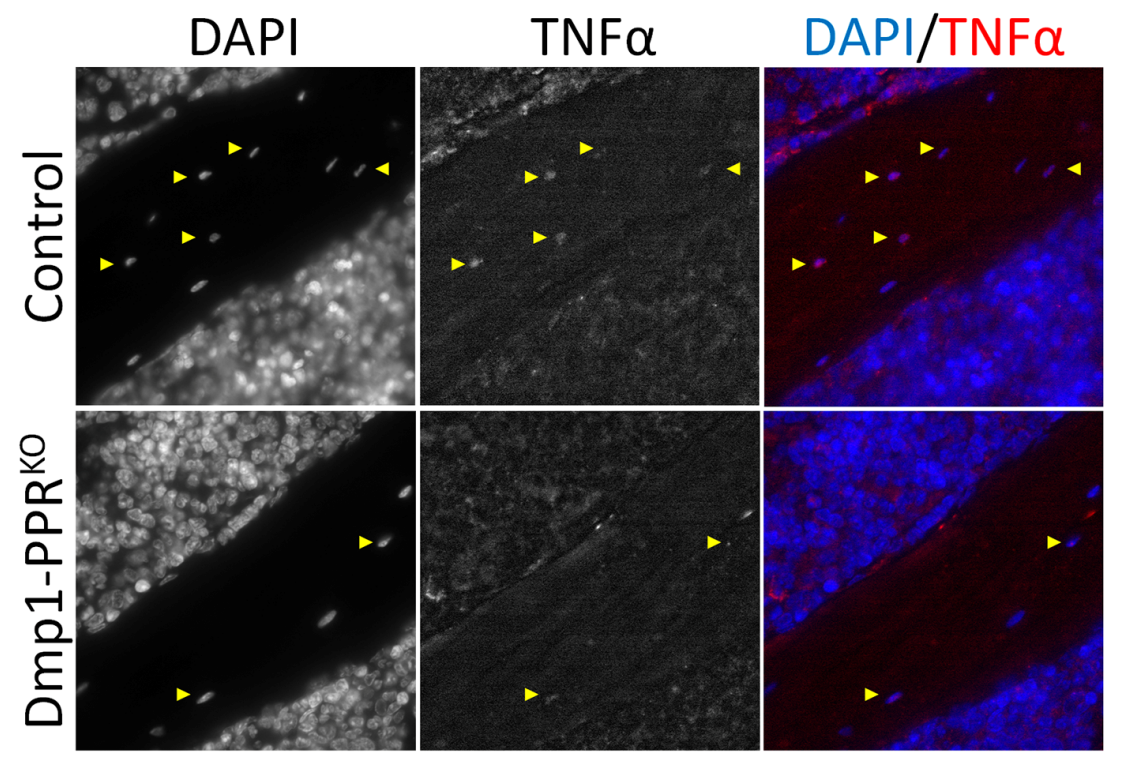

- Control ${ }^{-}$Dmp1-PPR ${ }^{\mathrm{KO}}$

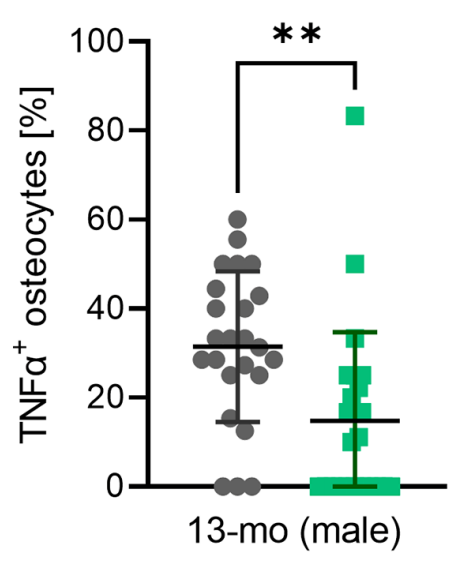

Supplementary Figure 5. Representative TNF $\alpha$ immunofluorescent images of the tibia of 13-month-old male mice. The frequency of $\mathrm{TNF}^{+}$(red) osteocytes (yellow arrowheads) per field was quantified over the total number of osteocytes (stained with DAPI, blue). $N=4$ per group. Data are presented as mean \pm SD. Unpaired Welch's $t$ test was performed. ${ }^{* *} p<0.01$. 

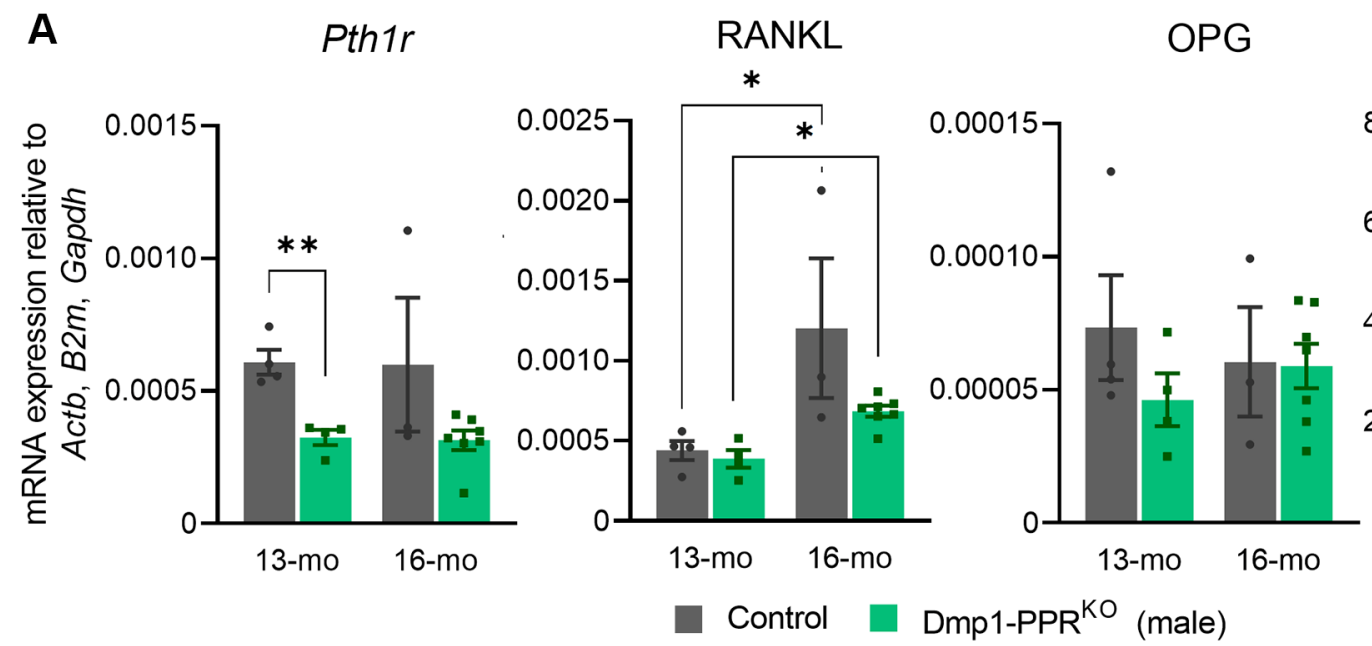

RANKL/OPG

B

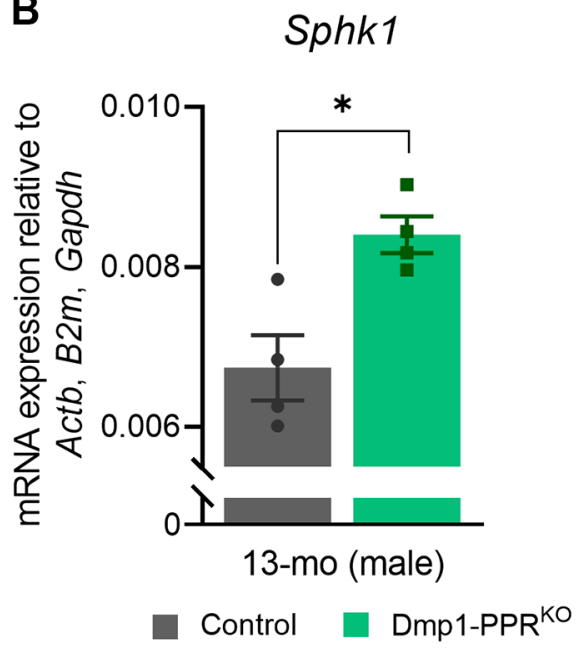

C

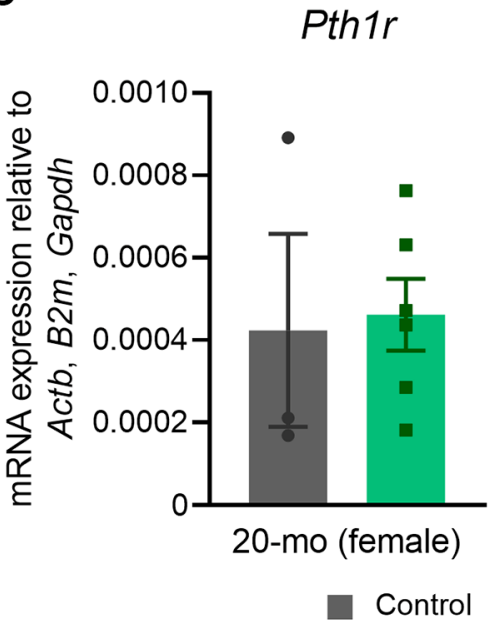

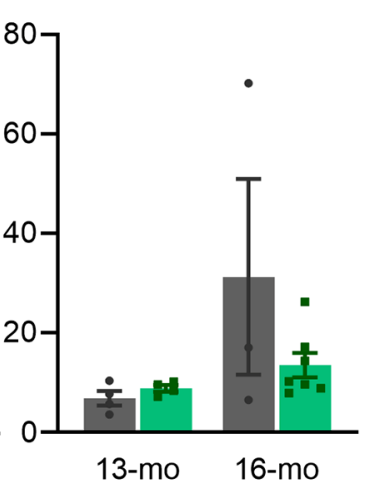

13-mo 16-mo

Dmp1-PPR (male) 

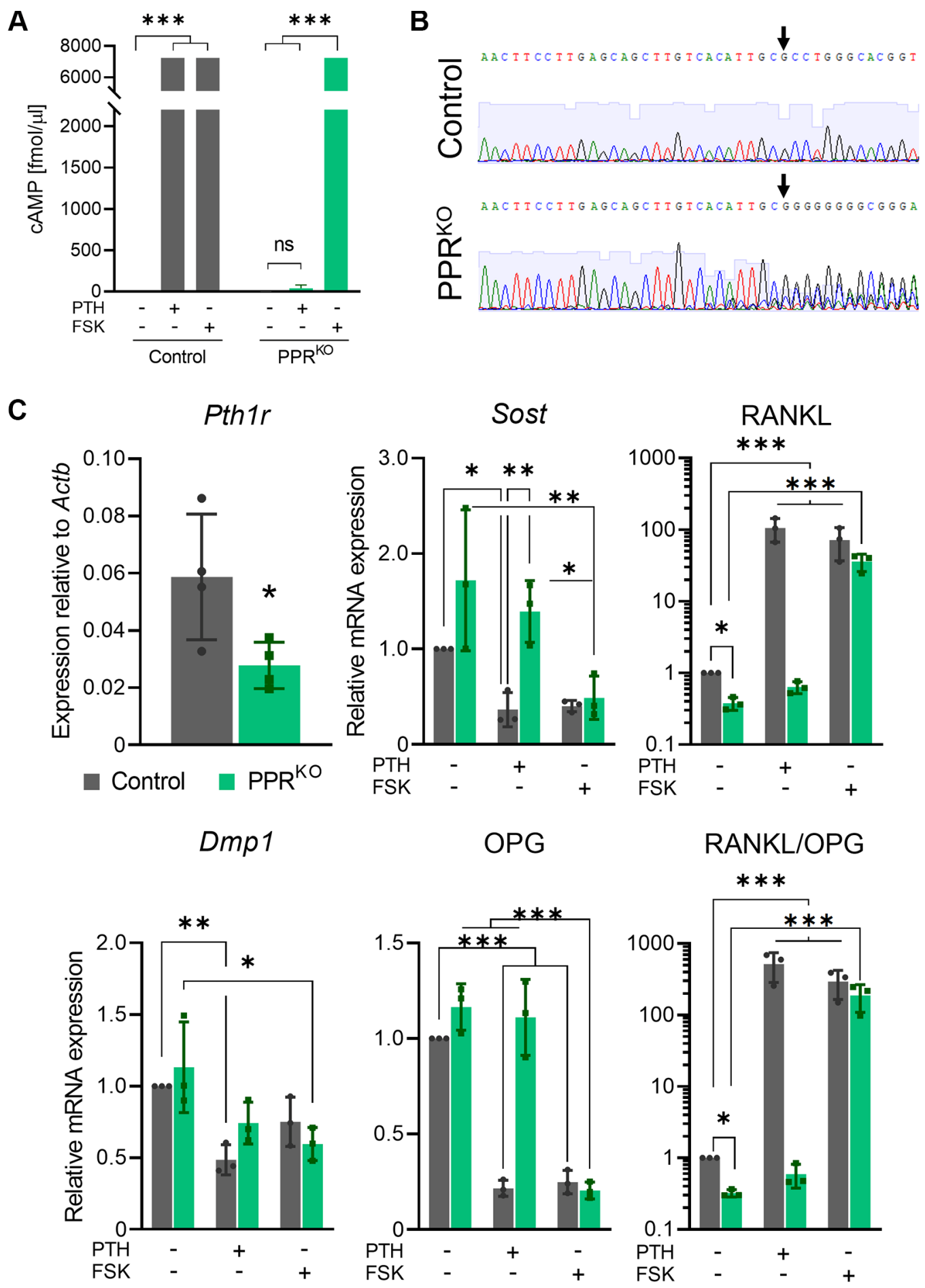

\section{RANKL/OPG}

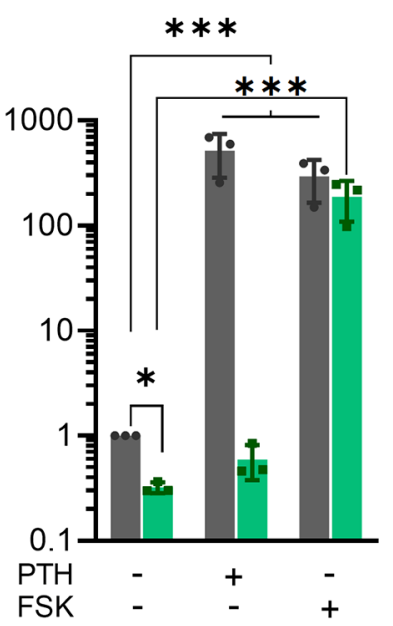

Supplementary Figure 7. Characterization of Ocy454-12H PPR ${ }^{\mathrm{KO}}$ cells. (A) CAMP accumulation assay in $10 \mathrm{nM}$ PTH- or $10 \mu \mathrm{M}$ forskolin-treated control and PPR ${ }^{\mathrm{KO}}$ cells. PPR ${ }^{\mathrm{KO}}$ cells showed no CAMP response to PTH but forskolin. (B) Sanger DNA sequencing results of the targeted Pth1r exon 3 sequence in control and PPR ${ }^{\mathrm{KO}}$ cells are shown. Black arrows indicate the cleavage site by Cas9 protein. Unlike control cells, the sequence of PPR ${ }^{\mathrm{KO}}$ after the cleavage site was unreadable due to random repair via nonhomologous end joining (NHEJ). (C) Expression of PPR and osteocytic genes in control and PPR ${ }^{\mathrm{KO}}$ cells treated with $10 \mathrm{nM}$ PTH or $10 \mu \mathrm{M}$ forskolin was analyzed by qPCR. $N=3$ per group. Data are presented as mean \pm SD. Two-way ANOVA with Tukey's post hoc test was performed. ${ }^{*} p<0.05,{ }^{* *} p<0.01,{ }^{* * *} p<0.001$. 


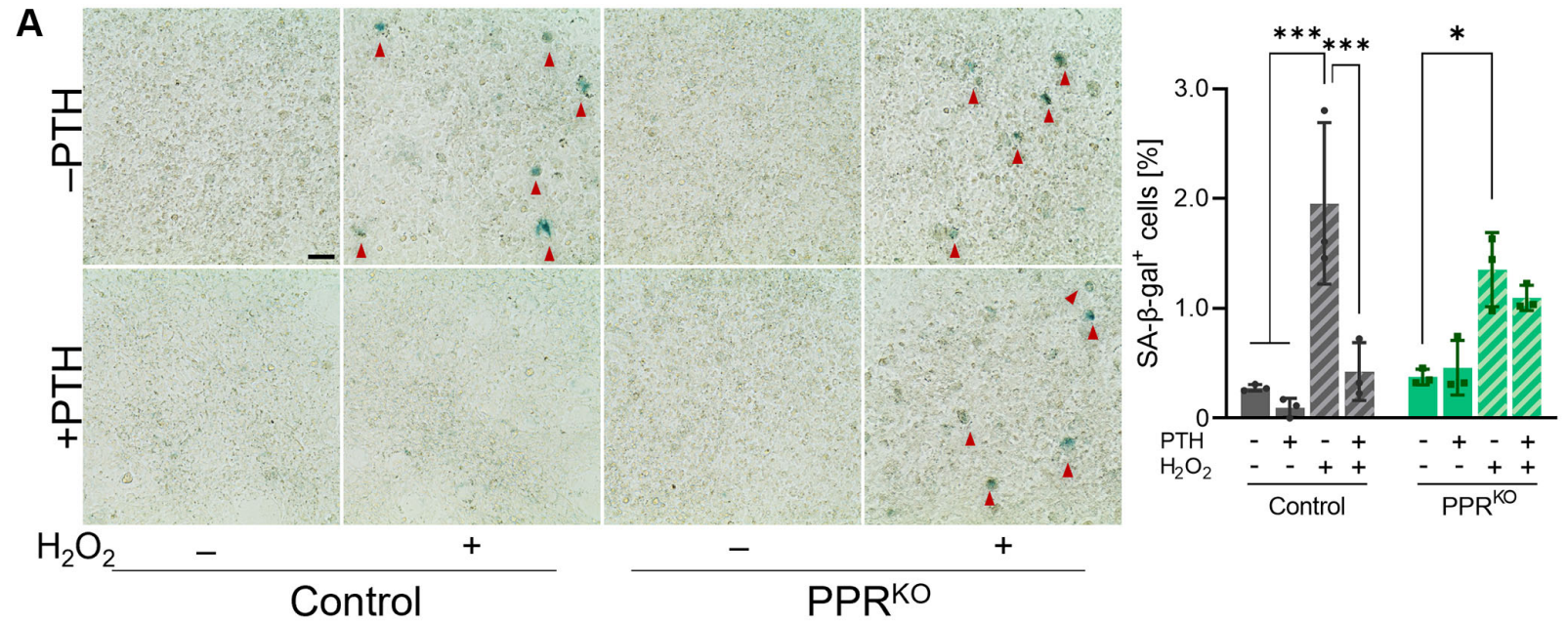

B
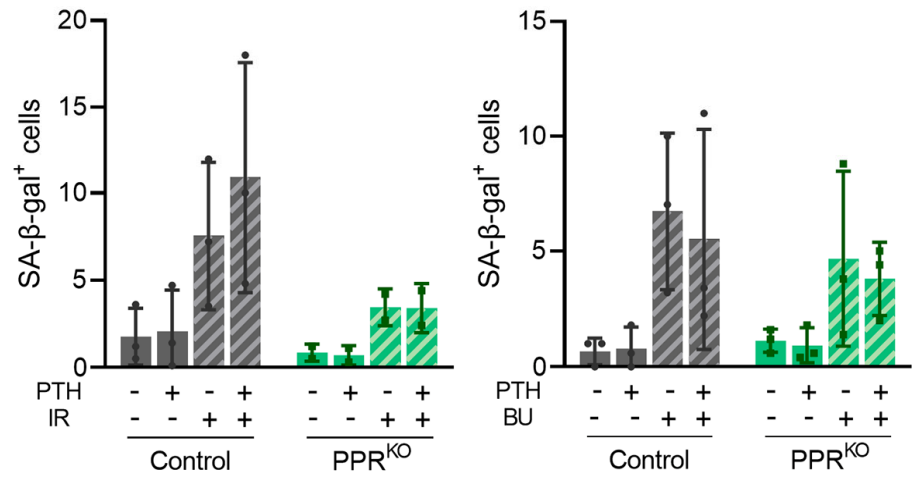

Supplementary Figure 8. (A) SA $\beta$-gal staining on Ocy454-12H PPR ${ }^{\mathrm{KO}}$ under oxidative stress. Cells were pretreated with $10 \mathrm{nM} \mathrm{hPTH}(1-$ 34) for 18-22 hrs and then exposed to $\mathrm{H}_{2} \mathrm{O}_{2}(150 \mu \mathrm{M}, 7$ days). (B) SA $\beta$-gal staining on irradiated (5 Gy) or busulfan (50 $\mu \mathrm{M})$-treated control and PPR ${ }^{\mathrm{KO}}$ cells. $N=3$ per group. Data are presented as mean \pm SD. Two-way ANOVA with Tukey's post hoc test was performed. ${ }^{*} p<0.05$, ${ }^{* * *} p<0.001$. 


\section{Supplementary Tables}

Supplementary Table 1. Abbreviations of bone parameters for histomorphometrical and $\mu \mathrm{CT}$ analysis.

\begin{tabular}{|c|c|c|c|c|}
\hline Type of index & Parameter & Abbreviation & Unit & Analyzed bone \\
\hline Structural & Bone volume/tissue volume & $\mathrm{BV} / \mathrm{TV}$ & $\%$ & Distal femur, L5 vertebra \\
\hline \multirow[t]{3}{*}{ (Trabecular) } & Number & Tb.N & $/ \mathrm{mm}$ & \\
\hline & Thickness & Tb.Th & $\mathrm{mm}$ & \\
\hline & Separation & $\mathrm{Tb} . \mathrm{Sp}$ & $\mathrm{mm}$ & \\
\hline Structural & Thickness & Cort.Th & $\mathrm{mm}$ & Midshaft femur \\
\hline \multirow[t]{5}{*}{ (Cortical) } & Density & Cort.Dens & $\mathrm{mmHA} / \mathrm{ccm}$ & \\
\hline & Area & Cort.A & $\mathrm{mm}^{2}$ & \\
\hline & Medullary area & MA & $\mathrm{mm}^{2}$ & \\
\hline & Porosity & Cort.Por & $\%$ & \\
\hline & Polar moment of inertia & pMOI & $\mathrm{mm}^{4}$ & \\
\hline \multirow[t]{4}{*}{ Dynamic } & Mineralizing surface/bone surface & MS/BS & $\%$ & Distal and midshaft femur \\
\hline & Mineral apposition rate & MAR & $\mu \mathrm{m} /$ day & \\
\hline & Bone formation rate/bone surface & $\mathrm{BFR} / \mathrm{BS}$ & & \\
\hline & Bone formation rate/bone volume & BFR/BV (\%/year) & $\% /$ year & \\
\hline \multirow[t]{5}{*}{ Formation } & Osteoid volume/bone volume & $\mathrm{OV} / \mathrm{BV}$ & $\%$ & Distal femur \\
\hline & Osteoid surface/bone surface & OS/BS & $\%$ & \\
\hline & Osteoblast surface/bone surface & Ob.S/BS & $\%$ & \\
\hline & Osteoblast number/tissue area & N.Ob/T.Ar & & \\
\hline & Osteoblast number/bone perimeter & N.Ob/B.Pm & $/ \mathrm{mm}$ & \\
\hline \multirow[t]{3}{*}{ Resorption } & Erosion surface/bone surface & $\mathrm{ES} / \mathrm{BS}$ & $\%$ & Distal femur \\
\hline & Osteoclast surface/bone surface & Oc.S/BS & $\%$ & \\
\hline & Osteoclast number/bone perimeter & N.Oc/B.Pm & $/ \mathrm{mm}$ & \\
\hline \multirow[t]{2}{*}{ Osteocyte } & Osteocyte number/bone volume & N.Ot/BV & $/ \mathrm{mm}^{2}$ & Distal and midshaft femur \\
\hline & & Ot density $\left(/ \mathrm{mm}^{2}\right)$ & $/ \mathrm{mm}^{2}$ & \\
\hline
\end{tabular}

Supplementary Table 2. Primer sequences for real time qPCR.

\begin{tabular}{|c|c|c|}
\hline Gene Symbol & Forward $\left(5^{\prime}-3^{\prime}\right)$ & Reverse $\left(5^{\prime}-3^{\prime}\right)$ \\
\hline $18 S$ & TCAAGAACGAAAGTCGGAGG & GGACATCTAAGGGCATCAC \\
\hline$A c t b(\beta$-actin) & GGCTGTATTCCCCTCCATCG & CCAGTTGGTAACAATGCCATGT \\
\hline$B 2 m$ & TTCACCCCCACTGAGACTGAT & GTCTTGGGCTCGGCCATA \\
\hline Becn1 & GAGGCTAACTCAGGAGAGGAGC & TGCCTCCCCGATCAGAGTGA \\
\hline Bglap (Osteocalcin) & CCGGGAGCAGTGTGAGCTTA & TAGATGCGTTTGTAGGCGGTC \\
\hline Cdkn1a (p21 $\left.1^{C i p l}\right)$ & CCTGGTGATGTCCGACCTG & CCATGAGCGCATCGCAATC \\
\hline$C d k n 2 a\left(p 16^{\operatorname{Ink} 4 a}\right)$ & GAACTCTTTCGGTCGTACCC & AGTTCGAATCTGCACCGTAGT \\
\hline$C s f 1(M-C S F)$ & GACCCTCGAGTCAACAGAGC & TGTCAGTCTCTGCCTGGATG \\
\hline Ctsk & GAAGAAGACTCACCAGAAGCAG & TCCAGGTTATGGGCAGAGATT \\
\hline Dmpl & AAGCTAGCCCAGAGGGACAGGCAA & TTATCGGCGCCGGTCCCCGTAC \\
\hline Foxol & CCCAGGCCGGAGTTTAACC & GTTGCTCATAAAGTCGGTGCT \\
\hline
\end{tabular}




\begin{tabular}{|c|c|c|}
\hline Gapdh & AGGTCGGTGTGAACGGATTTG & TGTAGACCATGTAGTTGAGGTCA \\
\hline Hprt & TCAGTCAACGGGGGACATAAA & GGGGCTGTACTGCTTAACCAG \\
\hline Pthlr (PPR) & CAGATTTTCCTGCTGCACCG & CTGCTGTGTGCAGAACTTCC \\
\hline Pthlh (PTHrP) & CAGTTAGAGGCGCTGATTCC & AGCTCTGATTTCGGCTGTGT \\
\hline Rlp13a & GGGCAGGTTCTGGTATTGGAT & GGCTCGGAAATGGTAGGGG \\
\hline Sdha & GGAACACTCCAAAAACAGACCT & CCACCACTGGGTATTGAGTAGAA \\
\hline Sirt1 & GCTGACGACTTCGACGACG & TCGGTCAACAGGAGGTTGTCT \\
\hline Sost (Sclerostin) & CTTCAGGAATGATGCCACAGAGGT & ATCTTTGGCGTCATAGGGATGGTG \\
\hline Sphk1 & GAACCATAACTCTGTGCCTTTGTCT & AGCAATGGGGAGTGTCTTCTATATG \\
\hline $\operatorname{Tnf}(T N F \alpha)$ & AGACCCTCACACTCAGATCATCTTC & CCACTTGGTGGTTTGCTACGA \\
\hline Tnfsf11 (RANKL) & CACAGCGCTTCTCAGGAGCTC & GAGATCTTGGCCCAGCCTCGA \\
\hline Tnfrsfl1b $(O P G)$ & ACCCAGAAACTGGTCATCAGC & CTGCAATACACACACTCATCACT \\
\hline $\operatorname{Trp} 53(p 53)$ & СТCTCCCCCGCAAAAGAAAAA & CGGAACATCTCGAAGCGTTTA \\
\hline Ywhaz & GAAAAGTTCTTGATCCCCAATGC & TGTGACTGGTCCACAATTCCTT \\
\hline
\end{tabular}

